\author{
UNIVERSIDADE DE SÃO PAULO \\ ESCOLA DE ENFERMAGEM DE RIBEIRÃO PRETO
}

CAMILA APARECIDA PINHEIRO LANDIM

A competência de pessoas com diabetes mellitus

para o autocuidado em um programa

educativo multiprofissional

Ribeirão Preto

2009 


\title{
A competência de pessoas com diabetes mellitus para o autocuidado em um programa educativo multiprofissional
}

\author{
Dissertação apresentada à Escola de \\ Enfermagem de Ribeirão Preto da \\ Universidade de São Paulo para obtenção do \\ título de Mestre em Ciências, Programa de \\ Pós-Graduação em Enfermagem.
}

Área de Concentração: Enfermagem Fundamental.

Linha de Pesquisa: Processo de cuidar do adulto com doenças agudas e crônicodegenerativas.

Orientadora: Profa. Dra. Carla Regina de Souza Teixeira

Ribeirão Preto 
AUTORIZO A REPRODUÇÃO E DIVULGAÇÃO TOTAL OU PARCIAL DESTE TRABALHO POR QUALQUER MEIO CONVENCIONAL OU ELETRÔNICO PARA FINS DE ESTUDO E PESQUISA, DESDE QUE SEJA CITADA A FONTE.

\section{Catalogação-na-publicação}

Escola de Enfermagem de Ribeirão Preto

\section{FICHA CATALOGRÁFICA}

Landim, Camila Aparecida Pinheiro

A competência de pessoas com diabetes mellitus para o autocuidado em um programa educativo multiprofissional. Ribeirão Preto, 2009.

153 p. : il. ; $30 \mathrm{~cm}$

Dissertação de Mestrado, apresentada à Escola de Enfermagem de Ribeirão Preto da Universidade de São Paulo. Área de Concentração: Enfermagem Fundamental.

Orientadora: Teixeira, Carla Regina de Souza

1. Diabetes Mellitus

2. Autocuidado

3. Enfermagem

4. Educação em Saúde 


\section{FOLHA DE APROVAÇÃO}

LANDIM, Camila Aparecida Pinheiro

A competência de pessoas com diabetes mellitus para o autocuidado em um programa educativo multiprofissional

Dissertação apresentada à Escola de Enfermagem de Ribeirão Preto da Universidade de São Paulo para obtenção do título de Mestre em Ciências, Programa de Pós-Graduação em Enfermagem

Área de Concentração: Enfermagem Fundamental.

Aprovado em 1 I

COMISSÃO JULGADORA

Prof. Dr.:

Instituição: Assinatura:

Prof. Dr.:

Instituição: Assinatura:

Prof. Dr.: 


\section{DEDICATÓRIA}

Ao meu papai Antânia Carlas e à minha mamãe Lúcia, que durante todos os dias de suas vidas dedicaram-se por inteiros, renunciando aos seus próprios sonhos em busca de realizar os meus. Meus queridos pais, por natureza, destino e amor, diante do caráter humano de vocês; as palavras são infinitamente menosprezíveis, as expressões tornam-se insuficientes e os gestos absolutamente dispensáveis. Juntos, as palavras, as expressões e os gestos silenciam em uma emoção ímpar impossível de ser traduzida. O exemplo de vida dado por vocês torna público ao mundo e declara o quanto sou abençoada por chamá-los de papai e mamãe. Amo muito vocês.

Aos meus irmãos $\mathcal{N i l a}$ e $\mathcal{N i c a ́ r c i a , ~}$ que me transmitiram forças para crescer e ser melhor a cada dia. A pureza do amor de vocês me transformou no melhor que pude ser. Durante a minha ausência no tempo de execução dessa dissertação, aprendi algo maior que amar vocês com os olhos: amar com o coração.

"Sá, enquanta eu respirar... uau me lembrar de 'uacês'" Fernando Anitelli 
À minha querida orientadora Prafa. Dra. Carla Regina de Sawa Jeixeira, que acreditou no meu desejo e amor pela pesquisa em educação em diabetes, concedendo-me oportunidade de ingressar como sua aluna de mestrado no processo seletivo da pós-graduação, somente por prévios contatos virtuais. Durante todo o longo período de elaboração desse trabalho, muito obrigada por ter sido tão paciente e perfeccionista, intercalando momentos de supervisão, participação e críticas com momentos de amizade e suporte. Você me fez perceber que há um detalhe especial muito melhor do que finalizar um trabalho de mestrado: ser orientada por você. Parabéns. "Êita" 


\section{AGRADECIMENTOS}

À Deus, pelo dom da existência e possibilidade de realização desse sonho.

À minha mamãe Lúcia, ao meu papai Antânia Carlas e aos meus irmãos $\mathcal{N}$ ila e Nicárcia, vocês são as mais brilhantes estrelinhas da minha vida. Muito obrigada pelo apoio e o amor inconstante de vocês. "Sou feliz, por isso estou aqui. Também quero viajar nesse balão! Super fantástico! No Balão Mágico!"

Ao maior presente da minha vida, meu amor Thiaga, que compartilhou comigo todos os momentos dessa trajetória, com admiração e respeito, acreditando e fazendo parte da minha capacidade. Muito obrigada por fazer dos nossos dias os mais felizes da minha vida. "Busquei quem sou, você pra mim mostrou que eu não sou 'sozinha' nesse mundo". Te amo muito, muito!

À minha querida orientadora Prafa. Dra. Carla Regina de Sawza Teixeira, pela dedicação inconstante ao longo dessa caminhada. Obrigada pela sabedoria, apoio, carinho, confiança e credibilidade.

À Profa. Dra. Maria Lúcia Zanetti, pelo carinho, força e paciência nas sugestões fundamentais para o aperfeiçoamento desse trabalho.

À todos da equipe mutiprofissional da Casa 5, Prof. Dr. Manael, Anelise, Camilinha, Délearah, Ellen, Flávia, Jeffersan, Karina, Nunila, Rasana, Thais, Valmir, Vúuian, Yara, pelo apoio, carinho e auxílio na coleta dos dados.

À minha queridíssima tia Zélia, meu querido tio $\mathcal{P e i x a t a , ~ m e u s ~ p r i m o s ~ e ~ i r m a ̃ o s ~}$ Daniel e Caral, obrigada pelo amparo, força, amor e carinho. Vocês são simplesmente o máximo! Amo vocês! 
Aos meus primos irmãos que eu amo, Cadu, J́tala, Jaeffsan, Juan e Marlin, pela torcida, confiança, amor e carinho. A distância e a saudade me provaram o que eu já desconfiava: eu jamais conseguiria viver sem a alegria de vocês.

Às minhas célebres amigas, Luciana e Tayana, que eu aprendi a amar de uma forma muito especial, obrigada pela disposição, apoio, força e confiança para a conclusão desse trabalho. $\mathcal{L} \boldsymbol{u}^{\prime}$, por ter me feito rir até perder o fôlego tantas vezes, mesmo em muitos momentos difíceis pelos quais passamos juntas. Tatá, obrigada pelo seu amor e pelo seu cuidado traduzido em conselhos e conversas.

As mais lindas amigas $\mathcal{T}$ hithiça e $\mathcal{N}$ aná, pelo amor e força incansáveis!

À minha grande amiga $\mathcal{T} \mathbf{a i}$, meu anjinho da guarda, me concedendo apoio em todas as minhas decisões, estando de braços abertos para me acolher, independente de quantos dos quilômetros distantes tenham nos separado. Amo muito você!

Aos meus eternos amigos, Gigi, Tallyne, Livinha, Pitty, Rulens e Samanthinha. Nada é mais valioso do que a amizade e o carinho de vocês. Obrigada pela torcida. Vocês moram no meu coração. Amo vocês!

Aos presentinhos especiais proporcionados pela pós-graduação: o entusiasmo da Caral, a doçura da Alêzinha, a energia contagiante da Gallilì e a virtude da Danny tornaram esses dois anos muito mais agradáveis. Muito obrigada!

Ao meu amigo Derlan, pelas ajudas e pela prontidão nos momentos de apuros. Peço desculpas quanto ao meu perfeccionismo, mas você me inspira confiança. Muito obrigada pela disposição e simpatia!

Ao amigo Dauglas, pelos árduos e oportunos ensinamentos estatisticamente significantes para o término desse trabalho. 
Ao amigo Juliana, pela imensa paciência com os meus relatórios científicos, além de ter demonstrado sempre cuidado e dedicação com os trabalhos. À você, o meu eterno muito obrigada!

Às pessaas cam dialetes mellitus do Centro de Pesquisa e Extensão Universitária que participaram desse estudo. Muito obrigada!

À FAPESP, pelo auxílio financeiro concedido durante 15 meses da dissertação.

À tadas as professares e funcianárias da Escola de Enfermagem de Ribeirão Preto da Universidade de São Paulo pela contribuição ao meu crescimento profissional.

À tadas as meus amigas e familiares, que de alguma forma contribuíram para a realização desse trabalho e que por ventura não tenha sido mencionado, muito obrigada! 
Parta... Parta...

A paesia prevalece! A paesia prevalece!

O primeiro senso é a fuga

Bom, na verdade é o medo

Daí então a fuga

Evoca-se na sombra uma inquietude

Uma alteridade disfarçada

Inquilina de todos nossos riscos

A juventude plena e sem planos... se esvai

O parto ocorre!

Parta-me... Parta-me... Parta-me... Parta-me...

Aborto certas convicções

Abordo demônios e manias

Flagelo-me

Exponho cicatrizes

$\mathrm{E}$ acordo os meus, com muito mais cuidado

Muito mais atenção

E a tensão que parecia nunca não passar

O ser vil que passou para servir

Para discernir

Harmonizar o tom

Movimento, som

Toda terra que devo doar

Todo voto que devo parir

Não dever ao devir

Nunca deixar de ouvir...

\section{Cam autras alhas!}

Fernando Anitelli

(O Teatro Mágico: Amadurecência, O $2^{\circ}$ Ato) 


\section{RESUMO}

\section{LANDIM, C. A. P. A competência de pessoas com diabetes mellitus}

para o autocuidado em um programa educativo multiprofissional. 2009. 152 f. Dissertação (Mestrado) - Escola de Enfermagem de Ribeirão Preto, Universidade de São Paulo, Ribeirão Preto, 2009.

Trata-se de um estudo descritivo, prospectivo e comparativo, do tipo antes e depois, abordagem quantitativa. Objetivo geral: comparar a competência de pessoas com diabetes mellitus (DM) para o autocuidado antes e após a participação em um programa educativo multiprofissional. 0 estudo foi realizado no Centro de Pesquisa e Extensão Universitária do interior paulista com 43 pessoas com DM. A coleta de dados ocorreu em março 2009, Tempo 1 (T1), a junho 2009, Tempo 2 (T2), através de entrevista semi-estruturada, norteada por dois instrumentos de coleta de dados, incluindo a "Escala para Identificação da Competência do portador de DM para o Autocuidado". Na análise dos dados utilizou-se o programa SPSS 15.0 onde foi proposto o modelo de efeitos mistos, com distribuição normal, média 0 e variância s2. O nível de significância estatístico adotado foi de $5 \%(\mathrm{p}<0.05)$. Das $43(100 \%)$ pessoas entrevistadas, $67.4 \%$ foram do sexo feminino, $86.0 \%$ procedente de Ribeirão Preto, $83.7 \%$ brancas, $65.2 \%$ casadas, $46.5 \%$ aposentadas, $60.5 \%$ católicas, $41.9 \%$ viviam com até 2 pessoas, $25.6 \%$ tinham até o primeiro grau incompleto, $44.1 \%$ possuíam renda familiar entre 3 à 4 salários mínimos, e 32.6\% encontravam-se na faixa etária entre 60 à 69 anos. Em relação aos parâmetros clínicos: $97.7 \%$ tinham o DM tipo 2, 46.5\% com tempo de diagnóstico $\leq 5$ anos, $79.0 \%$ declararam que não fumam, $88.3 \%$ que não ingerem bebida alcoólica; $51.2 \%$ que não seguem dieta; $72.0 \%$ que não realizam atividade física, $76.7 \%$ utilizam somente antidiabético oral, $76.8 \%$ tinham hipertensão arterial e $23.3 \%$ retinopatia. Com relação à Pressão arterial sistólica (PAS) e Pressão arterial diastólica (PAD), a média foi de $130 \mathrm{mmHg} \pm 13.58$ e $81 \mathrm{mmHg} \pm 10.47$ no T1, e $123 \mathrm{mmHg} \pm 14.26$ e $76 \mathrm{mmHg} \pm 8.90$ no T2. Na glicemia capilar pósprandial, a média foi de $181 \mathrm{mg} / \mathrm{dL} \pm 81.74$ no T1 e $157 \mathrm{mg} / \mathrm{dL} \pm 64.54$ no T2. Para o peso e IMC, a média foi $77.7 \mathrm{~kg} \pm 16.70$ e $30.2 \mathrm{~kg} / \mathrm{m} 2 \pm 5.57$ no T1, e, $76.1 \mathrm{~kg} \pm 17.29$ e $29.4 \mathrm{~kg} / \mathrm{m} 2 \pm 5.66$ no T2. Quanto a competência física para o autocuidado, no T1 a média foi de $15.07 \pm 1.01$ e no T2 foi $18.10 \pm 1.43$. Na competência cognitiva para o autocuidado, no T1 a média foi de $21.35 \pm 4.28$ e no T2 foi de $33.26 \pm 3.68$. Na competência emocional e motivacional para o autocuidado, a média foi de $34.51 \pm 4.50$ no T1 e $37.98 \pm 3.80$ no T2. Na análise estatística, as diferenças entre as médias do T1 em comparação ao T2 foram estatisticamente significantes na PAS $(p=0.03)$, PAD $(p=0.01)$, competência cognitiva $(p<0.01)$ e competência emocional e motivacional $(p<0.01)$. Conclui-se que a participação de pessoas com DM em um programa educativo multidisciplinar favorece a melhora da competência para o autocuidado, mesmo em curto período obteve-se mudanças significativas podendo ser uma ferramenta valiosa para o alcance dos benefícios esperados.

Palavras-chave: Enfermagem. Diabetes Mellitus. Autocuidado. Educação em Saúde. 


\begin{abstract}
LANDIM, C. A. P. The competence of patients with diabetes mellitus for self care in a multiprofissional educational program. 2009. 152 p. Thesis (Master Degree) - Ribeirao Preto College of Nursing, University of Sao Paulo, Ribeirao Preto, 2009.
\end{abstract}

This descriptive, prospective, quantitative and comparative study, with before and after design. Main objective: compare the competence of patients with diabetes mellitus (DM) for self care before and after their participation in a multiprofissional educational program. The study was carried out in the Research and Community Service Center in the interior of the state of São Paulo, with 43 patients with DM. The data collection was carried out between March 2009, Period 1 (T1), and June 2009, Period 2 (T2), through semi-structured interview, guided by two instruments, including the "Scale to identify DM patients' competence for Self Care". The SPSS 15.0 was used for data analysis, with mixed effects model, normal distribution, average 0 and variance s2. The statistical level of significance adopted was 5\% $(p<0.05)$. Of the $43(100 \%)$ patients interviewed, $67.4 \%$ were female, $86.0 \%$ from the city of Ribeirão Preto, $83.7 \%$ white, $65.2 \%$ married, $46.5 \%$ retired, $60.5 \%$ catholic, $41.9 \%$ lived with up to 2 people, $25.6 \%$ had con completed secondary education, $44.1 \%$ had monthly family income between 3 and 4 minimum wages, and $32.6 \%$ were aged between 60 and 69 years. With regard to the clinical parameters: $97.7 \%$ had type 2 DM, 46.5\% had been diagnosed for $\leq 5$ years, 79.0\% declared not to smoke, $88.3 \%$ reported not drinking alcoholic drinks; $51.2 \%$ not following any diet; $72.0 \%$ not performing any physical activity, $76.7 \%$ use only oral antidiabetic medications, $76.8 \%$ has high blood pressure and $23.3 \%$ retinopathy. Regarding the Systolic blood pressure (SBP) and Diastolic blood pressure (DBP), the average was $130 \mathrm{mmHg} \pm 13.58$ and $81 \mathrm{mmHg} \pm 10.47$ at $\mathrm{T} 1$, and 123 $\mathrm{mmHg} \pm 14.26$ and $76 \mathrm{mmHg} \pm 8.90$ at T2. For postprandial capillary glucose, the average was $181 \mathrm{mg} / \mathrm{dL} \pm 81.74$ at $\mathrm{T} 1$ and $157 \mathrm{mg} / \mathrm{dL} \pm 64.54$ at $\mathrm{T} 2$. For weight and BMI (body mass index), the average was $77.7 \mathrm{~kg} \pm 16.70$ and 30.2 $\mathrm{kg} / \mathrm{m} 2 \pm 5.57$ at $\mathrm{T} 1$, and, $76.1 \mathrm{~kg} \pm 17.29$ and $29.4 \mathrm{~kg} / \mathrm{m} 2 \pm 5.66$ at T2. Regarding the physical competence for self care, at T1 the average was $15.07 \pm$ 1.01 , and at T2 it was $18.10 \pm 1.43$. In the cognitive competence for self care, at T1 the average was $21.35 \pm 4.28$, and at T2, it was $33.26 \pm 3.68$. In the emotional and motivational competence for self care, the average was $34.51 \pm$ 4.50 at $\mathrm{T} 137.98 \pm 3.80$ at $\mathrm{T} 2$. In the statistical analysis the differences between the averages at T1 in comparison to T2 were statistically significant for SBP $(p=0.03), \operatorname{DBP}(p=0.01)$, cognitive competence $(p<0.01)$ and emotional and motivational competence $(p<0.01)$. It was concluded that the participation of patients with DM in a multiprofissional educational program favors the improvement of the competence for self care, since even in a short period of time significant changes were observed, it can be an important tool to reach the expected benefits.

Key words: Nursing. Diabetes Mellitus. Self Care. Health education. 


\section{RESUMEN}

LANDIM, C. A. P. La competencia de las personas con diabetes
mellitus para el autocuidado en un programa educativo
multiprofesional. 2009 . 152 h. Disertación (Maestría) - Escuela de multiprofesional. 2009. 152 h. Disertación (Maestria) - Escuela de 2009.

Este estudio descriptivo, prospectivo y comparativo, con aproximación cuantitativa, del tipo antes y después. Objetivo general: comparar la competencia de las personas con diabetes mellitus (DM) para el autocuidado antes y después de la participación en un programa educativo multiprofesional. El estudio fue realizado en el Centro de Investigación y Extensión Universitaria del interior del estado de São Paulo, con 43 personas con DM. La recolecta de datos ocurrió entre marzo 2009, Tiempo 1 (T1), y junio 2009, Tempo 2 (T2), a través de entrevista semi-estructurada, guiada por dos instrumentos, incluyendo la "Escala para Identificación de la Competencia del portador de DM para el Autocuidado". El programa SPSS 15.0 fue utilizado para el análisis de los datos, con el modelo de efectos mistos, con distribución normal, promedio 0 y variancia s2. El nivel de significancia estadístico adoptado fue del $5 \%(p<0.05)$. De las 43 (100\%) personas entrevistadas, el $67,4 \%$ fue del sexo femenino, el $86,0 \%$ procedente de Ribeirão Preto, el $83,7 \%$ de blancos, el $65.2 \%$ personas casadas, el $46.5 \%$ jubilado, el $60,5 \%$ católico, el $41,9 \%$ vivía con hasta 2 personas, el $25,6 \%$ tenía hasta la educación primaria incompleta, el $44,1 \%$ tenía renta familiar entre 3 y 4 sueldos mínimos, y el $32,6 \%$ se encontraba en la franja etaria entre 60 y 69 años. En relación a los parámetros clínicos: el 97,7\% tenía el DM tipo 2, el 46,5\% con tiempo de diagnóstico $\leq 5$ años, el 79,0\% declaró que no fumaba, el $88,3 \%$ que no ingería bebida alcohólica; el $51,2 \%$ que no sigue dieta; el $72,0 \%$ que no realiza actividad física, el 76,7\% utiliza solamente antidiabético oral, el 76,8\% tenía hipertensión arterial y el 23,3\% retinopatía. Con relación a la Presión arterial sistólica (PAS) y Presión arterial diastólica (PAD), el promedio fue de $130 \mathrm{mmHg} \pm 13,58$ y $81 \mathrm{mmHg} \pm 10,47$ en el $\mathrm{T} 1$, y $123 \mathrm{mmHg} \pm 14,26$ y $76 \mathrm{mmHg} \pm 8.90$ en el T2. En la glucemia capilar postprandial, el promedio fue de $181 \mathrm{mg} / \mathrm{dL} \pm 81,74$ en el T1 y $157 \mathrm{mg} / \mathrm{dL} \pm$ 64.54 en el T2. Para el peso e IMC (Índice de Masa Corporal), el promedio fue $77,7 \mathrm{~kg} \pm 16,70$ y $30,2 \mathrm{~kg} / \mathrm{m} 2 \pm 5,57$ en el $\mathrm{T} 1, y, 76.1 \mathrm{~kg} \pm 17.29$ y $29,4 \mathrm{~kg} / \mathrm{m} 2$ $\pm 5,66$ en el T2. Cuanto a la competencia física para el autocuidado, en el T1 el promedio fue de $15,07 \pm 1.01$, y en el T2 fue 18,10 $\pm 1,43$. En la competencia cognitiva para el autocuidado, en el T1 el promedio fue de $21.35 \pm 4,28$ y en el T2 de 33,26 $\pm 3,68$. En la competencia emocional y motivacional para el autocuidado, el promedio fue de 34,51 \pm 4,50 en el T1 y 37,98 $\pm 3,80$ em el T2. En el análisis estadístico, las diferencias entre los promedios del T1 en comparación al T2 fueron estadísticamente significantes en la PAS $(p=0.03)$, PAD $(p=0.01)$, competencia cognitiva $(p<0.01)$ y competencia emocional y motivacional $(p<0.01)$. Se concluye que la participación de las personas com DM en un programa educativo multiprofesional favorece el incremento de la competencia para el autocuidado, mismo en curto período de tiempo se obtuvo cambios significativos pudiendo ser una herramienta valiosa para el alcance de los beneficios esperados.

Palabras clave: Enfermería. Diabetes Mellitus. Autocuidado. Educación en Salud. 


\section{LISTA DE FIGURAS}

Figura 1 - Centro Educativo de Enfermagem para Adultos e Idosos da Escola de Enfermagem de Ribeirão Preto da Universidade de São Paulo - EERP/USP. Ribeirão Preto, 2009

Figura 2 - Média \pm desvio padrão, valor $p$, IC e diferença entre a comparação das médias no T1 e no T2 da PAS e PAD da população do estudo ( $n=43$ ). Ribeirão Preto, 2009

Figura 3 - Média \pm desvio padrão, valor $p$, IC e diferença entre a comparação das médias no T1 e no T2 da glicemia capilar pós-prandial da população do estudo $(n=43)$. Ribeirão Preto, 2009

Figura 4 - Média \pm desvio padrão, valor $p$, IC e diferença entre a comparação das médias no $\mathrm{T} 1$ e no $\mathrm{T} 2$ da CA da população do estudo ( $n=43)$. Ribeirão Preto, 2009

Figura 5 - Média \pm desvio padrão, valor $p$, IC e diferença entre a comparação das médias no $\mathrm{T} 1$ e no $\mathrm{T} 2$ do peso da população do estudo ( $n=43)$. Ribeirão Preto, 2009

Figura 6 - Média \pm desvio padrão, valor $p$, IC e diferença entre a comparação das médias no T1 e no T2 do IMC da população do estudo $(n=43)$. Ribeirão Preto, 2009 


\section{LISTA DE TABELAS}

Tabela 1 - Distribuição numérica da população do estudo segundo motivos de exclusão. Ribeirão Preto, 2009 .....................

Tabela 2 - Distribuição dos materiais necessários para a coleta dos dados referentes aos cinco itens da subescala I da "ECDAC". Ribeirão Preto, 2009

Tabela 3 - Distribuição numérica ( $\mathrm{n}$ ) e percentual (\%) das variáveis sociodemográficas qualitativas nominais da população do estudo ( $n=43)$. Ribeirão Preto, 2009

Tabela 4 - Distribuição numérica ( $\mathrm{n}$ ) e percentual (\%) das variáveis sociodemográficas qualitativas ordinais da população do estudo $(n=43)$. Ribeirão Preto, 2009

Tabela 5 - Distribuição numérica $(n)$, percentual $(\%)$, média $\pm d p *$, valores mínimo, máximo e mediana da idade da população do estudo $(n=43)$. Ribeirão Preto, 2009

Tabela 6 - Distribuição numérica $(n)$, percentual (\%), média $\pm d p *$, valores mínimo, máximo e mediana da idade da população do estudo ( $n=43)$. Ribeirão Preto, 2009

Tabela 7 - Distribuição numérica $(n)$, percentual (\%), média $\pm d p *$, valores mínimo, máximo e mediana da população do estudo segundo o tempo de diagnóstico do diabetes mellitus $(\mathrm{n}=43)$. Ribeirão Preto, 2009

Tabela 8 - Média \pm desvio padrão, Coeficiente de Variação (CV), valores mínimo e máximo dos escores obtidos da competência física no T1 e no T2 da população do estudo $(n=43)$. Ribeirão Preto, 2009

Tabela 9 - Diferença entre as médias, valor $\mathrm{p}$ e Intervalo de Confiança (IC) $95 \%$ da comparação entre o T1 e o T2 dos itens da subescala I. Ribeirão Preto, 2009

Tabela 10 - Média \pm desvio padrão $(\mathrm{dp})$ dos escores obtidos no T1 e no T2 da população do estudo $(n=43)$ dos cinco itens da subescala I. Ribeirão Preto, 2009 
Tabela 11 - Média \pm desvio padrão, Coeficiente de Variação (CV), valores mínimo e máximo dos escores obtidos da competência cognitiva no $\mathrm{T} 1$ e no T2 da população do estudo ( $n=43)$. Ribeirão Preto, 2009

Tabela 12 - Diferença entre as médias, valor $\mathrm{p}$ e Intervalo de Confiança (IC) 95\% da comparação entre o T1 e o T2 dos itens da subescala II. Ribeirão Preto, 2009

Tabela 13 - Distribuição numérica (n) e percentual (\%) dos escores obtidos no T1 e no T2 da população do estudo $(n=43)$ dos itens da subescala II. Ribeirão Preto, 2009

Tabela 14 - Média \pm desvio padrão dos escores obtidos no T1 e no T2 da população do estudo $(n=43)$ dos itens da subescala II. Ribeirão Preto, 2009

Tabela 15 - Média \pm desvio padrão (dp), Coeficiente de Variação (CV), valores mínimo e máximo dos escores obtidos no T1 e no T2 da população do estudo $(n=43)$ da competência emocional e motivacional. Ribeirão Preto, 2009

Tabela 16 - Diferença entre as médias, valor $\mathrm{p}$ e Intervalo de Confiança (IC) 95\% da comparação entre o T1 e o T2 dos itens da subescala III. Ribeirão Preto, 2009

Tabela 17 - Distribuição numérica $(n)$ e percentual (\%) dos escores obtidos no T1 e no T2 da população do estudo $(n=43)$ dos itens da subescala III. Ribeirão Preto, SP, Brasil, 2009

Tabela 18 - Média \pm desvio padrão (dp) dos escores obtidos no T1 e no T2 da população do estudo $(n=43)$ no Programa de Educação em Diabetes dos itens da subescala III. Ribeirão Preto, SP, Brasil, 2009 


\section{LISTA DE SIGLAS}

AADE American Association of Diabetes Educators

ABNT Associação Brasileira de Normas Técnicas

ADA American Diabetes Association

CA Circunferência Abdominal

CE Ceará

CEP Comitê de Ética em Pesquisa

CIHD Centro Integrado de Hipertensão e Diabetes

CNPq Conselho Nacional de Desenvolvimento Científico e Tecnológico

CNS Conselho Nacional de Saúde

CV Coeficiente de Variação

DCCT Diabetes Control and Complications Trial

DEGE Departamento de Enfermagem Geral e Especializada

DM Diabetes mellitus

DM1 Diabetes mellitus tipo 1

DM2 Diabetes mellitus tipo 2

DP Desvio Padrão

ECDAC Escala para identificação da Competência do portador de diabetes mellitus para o Autocuidado

EERP Escola de Enfermagem de Ribeirão Preto

FAPESP Fundação de Amparo à Pesquisa do Estado de São Paulo

FFCLRP Faculdade de Filosofia, Ciências e Letras de Ribeirão Preto

HAS Hipertensão Arterial Sistêmica

HbA1c Hemoglobina Glicosilada

HOT Hypertension Optimal Treatment

HUWC Hospital Universitário Walter Cantídio

IC Intervalo de Confiança

IDC International Diabetes Center

IDF International Diabetes Federation

IMC Índice de Massa Corporal

ITG Intolerância à Glicose 
JAMA Journal of the American Medical Association

MG Minas Gerais

NPD Núcleo de Processamento de Dados

$\mathrm{NPH} \quad$ Neutral Protamine Hagedorn, Insulin

NUMED Núcleo Multidisciplinar para Educação em Diabetes

OMS Organização Mundial de Saúde

OPAS Organização Pan-Americana de Saúde

PAD Pressão Arterial Diastólica

PAE Programa de Aperfeiçoamento de Ensino

PAS Pressão Arterial Diastólica

R Regular, Insulin

RS Rio Grande do Sul

SBD Sociedade Brasileira de Diabetes

SBH Sociedade Brasileira de Hipertensão

SC Santa Catarina

SPSS Statistical Package for the Social Science

SUS Sistema Único de Saúde

T1 Tempo 1

T2 Tempo 2

TCLE Termo de Consentimento Livre e Esclarecido

UERJ Universidade do Estado do Rio de Janeiro

UFC Universidade Federal do Ceará

UFSC Universidade Federal de Santa Catarina

UKPDS United Kingdom Prospective Diabetes Study

UNIFOR Universidade de Fortaleza

USP Universidade de São Paulo

WHO World Health Organization 


\section{SUMÁRIO}

APRESENTAÇÃO

1 INTRODUÇÃo

1.1 panorama das doenças crônicas: 0 diabetes mellitus

1.2 A educação em saúde e a competência de pessoas com diabetes mellitus para o autocuidado

1.3 Justificativa e relevância

2 OBJETIVOS

2.1 Objetivo geral

2.2 Objetivos específicos

3 METODOLOGIA

44

3.1 Tipo do estudo 44

3.2 Período do estudo 45

3.3 Local do estudo 45

3.4 População-base do estudo (Universo) ...................... 50

3.4.1 Critérios de inclusão 50

3.4.2 População do estudo 51

3.5 Variáveis do estudo 52

3.5.1 Variáveis sociodemográficas

3.5.2 Variáveis clínicas e relacionadas ao tratamento 55

3.5.3 Variáveis relacionadas aos valores de pressão arterial, glicemia capilar pós-prandial, circunferência abdominal, peso e Índice de Massa Corporal

3.5.4 Variáveis relacionadas à competência de pessoas com diabetes mellitus para o autocuidado 
3.6 Instrumento de coleta de dados .............................. 58

3.7 Período da coleta de dados ...................................... 62

3.8 Procedimentos da coleta de dados .......................... 62

3.9 Organização e análise dos dados ............................. 65

3.10 Aspectos éticos .................................................... 66

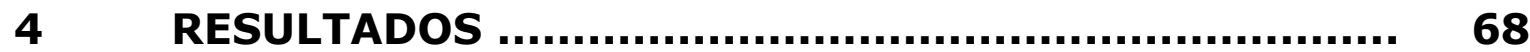

4.1 Caracterização da população do estudo segundo as variáveis sociodemográficas

4.2 Caracterização da população do estudo segundo as variáveis clínicas e relacionadas ao tratamento do diabetes mellitus

4.3 Comparação dos valores obtidos em relação às variáveis pressão arterial, glicemia capilar pósprandial, circunferência abdominal, peso e IMC antes e após 0 oferecimento das atividades educativas

4.4 Comparação da competência de pessoas com diabetes mellitus para o autocuidado antes e após o oferecimento das atividades educativas

4.4.1 Competência física da população do estudo antes e após a participação no Programa de Educação em Diabetes do referido Centro

4.4.2 Competência cognitiva da população do estudo antes e após a participação no Programa de Educação em Diabetes do referido Centro

4.4.3 Competência emocional e motivacional da população do estudo antes e após a participação no Programa de Educação em Diabetes do referido Centro 
variáveis sociodemográficas

5.2 Caracterização da população do estudo segundo as variáveis clínicas e relacionadas ao tratamento do diabetes mellitus

5.3 Comparação dos valores obtidos em relação às variáveis pressão arterial, glicemia capilar pósprandial, circunferência abdominal, peso e IMC antes e após $o$ oferecimento das atividades educativas

5.4 Comparação da competência de pessoas com diabetes mellitus para o autocuidado antes e após o oferecimento das atividades educativas

5.4.1 Competência física da população do estudo antes e após a participação no Programa de Educação em Diabetes do referido Centro

5.4.2 Competência cognitiva da população do estudo antes e após a participação no Programa de Educação em Diabetes do referido Centro

5.4.3 Competência emocional e motivacional da população do estudo antes e após a participação no Programa de Educação em Diabetes do referido Centro

6 CONCLUSÕES

6.1 Caracterização da população do estudo segundo as variáveis sociodemográficas

6.2 Caracterização da população do estudo segundo as variáveis clínicas e relacionadas ao tratamento do diabetes mellitus

6.3 Comparação dos valores obtidos em relação às variáveis pressão arterial, glicemia capilar pósprandial, circunferência abdominal, peso e IMC antes e após $o$ oferecimento das atividades 
educativas

6.4 Comparação da competência de pessoas com diabetes mellitus para o autocuidado antes e após o oferecimento das atividades educativas

6.4.1 Competência física da população do estudo antes e após a participação no Programa de Educação em Diabetes do referido Centro

6.4.2 Competência cognitiva da população do estudo antes e após a participação no Programa de Educação em Diabetes do referido Centro

6.4.3 Competência emocional e motivacional da população do estudo antes e após a participação no Programa de Educação em Diabetes do referido Centro

7 CONSIDERAÇÕES FINAIS 
"Sem haras e sem dares... Sintaxe à coutade"

Fernanda Anitelli 


\section{APRESENTAÇÃO}

Em 2003, ingressei na Universidade de Fortaleza (UNIFOR) como aluna de graduação do curso de Bacharelado em Enfermagem do Centro de Ciências da Saúde, com conclusão em junho de 2007. Durante a graduação, tive oportunidade de atuar como monitora voluntária (2004) e bolsista (2005-2006) da Fundação Edson Queiroz, na disciplina de Histologia e Embriologia Humanas, ampliando o meu desenvolvimento técnico-científico e despertando o meu interesse pelas questões relacionadas ao diabetes mellitus.

Destaco que em abril de 2005, participei da fundação do grupo de pesquisa vinculado à UNIFOR: Núcleo Multidisciplinar para Educação em Diabetes (NUMED), onde o meu crescimento científico se ampliou com a participação em projetos de pesquisas, "Projeto Sala de Espera em um ambulatório de Diabetes" e "Abordagem da depressão e do diabetes mellitus no curso de odontologia da Universidade de Fortaleza e da Universidade Federal do Ceará", reuniões semanal clínicas e educativas, estágios em ambulatórios de endocrinologia, Hospital Universitário Walter Cantídio da Universidade Federal do Ceará (HUWC/UFC) e Centro Integrado de Hipertensão e Diabetes do Estado do Ceará (CIHD/CE), e organização de cursos e eventos relacionados.

Em novembro de 2005, realizou-se a "Campanha para rastreamento de fatores de risco para diabetes mellitus, hipertensão arterial e doença cardiovascular", promovido pelo grupo de pesquisa NUMED/UNIFOR. A minha participação como organizadora do evento resultou no periódico intitulado "Levantamento dos Fatores de Risco para doenças crônicas em universitários", publicado na Revista Brasileira de Promoção da Saúde, RBPS, Fortaleza (CE), v. 20, n. 3, 2007, com aprovação em 20/08/2007.

Em 29 de junho de 2007, obtive conclusão no curso de graduação em Enfermagem, com o trabalho intitulado "Clientes com diabetes mellitus gestacional - déficits de autocuidado" que objetivou identificar déficits de 
autocuidado em mulheres com diabetes mellitus gestacional, à luz do Modelo Conceitual de Enfermagem de Orem. Atualmente, tal estudo intitulado "Déficits de Autocuidado em clientes com diabetes mellitus gestacional: uma contribuição para a enfermagem" foi publicado na Revista Gaúcha de Enfermagem, Porto Alegre, v. 29, n. 3, 2008, com aprovação em 18/06/2008.

Em janeiro de 2008, como aluna do Programa de Pós-Graduação (Mestrado) Enfermagem Fundamental da Escola de Enfermagem de Ribeirão Preto da Universidade de São Paulo (EERP/USP), investigou-se comparar a competência de pessoas com diabetes mellitus para o autocuidado em um programa educativo multidisciplinar, na busca de evidências científicas para a fundamentação da minha prática profissional.

Durante o ano letivo de 2008, os créditos mínimos exigidos foram rigorosamente cumpridos, perfazendo 42 créditos. Em paralelo, participei como aluna bolsista do Estágio Supervisionado em Docência do Programa de Aperfeiçoamento de Ensino (PAE) da disciplina "Cuidado de Enfermagem a Pessoa Portadora de Diabetes Mellitus", sobre a supervisão da Profa. Dra. Carla Regina de Souza Teixeira. A troca de experiências com a professora supervisora (orientadora), as demais professoras da disciplina, os professores convidados e os alunos de graduação foi muito relevante para o meu crescimento científico e profissional.

Em setembro de 2008, fui beneficiada pela Fundação de Amparo à Pesquisa do Estado de São Paulo (FAPESP) com a aprovação do projeto de pesquisa (nível mestrado) intitulado "A competência do diabético para o autocuidado em um processo educativo interdisciplinar", sob o $\mathrm{n}^{\circ}$. 2008/52681-3. Tal processo traz como responsável a Profa. Dra. Carla Regina de Souza Teixeira e vínculo institucional a EERP/USP.

Em abril de 2009, após a aprovação no meu Exame de Qualificação, a originalidade e a exequibilidade do projeto de pesquisa foram evidenciadas pela Banca Examinadora, definindo assim a contribuição efetiva na linha de pesquisa inserida "Processo de cuidar do adulto com doenças agudas e crônico-degenerativas". 
Como membro do Grupo de Pesquisas em Enfermagem e Diabetes Mellitus, cadastrado no diretório do CNPq e vinculado ao Departamento de Enfermagem Geral e Especializada da EERP/USP, proporcionou uma grande aproximação com as dificuldades vivenciadas por pessoas com diabetes mellitus no Programa de Educação em Diabetes do Centro Educativo de Enfermagem para Adultos e Idosos.

Tal Centro abrange alguns objetivos primordiais: reconhecer 0 diabetes mellitus como prioridade de saúde pública; produzir conhecimentos na área do DM, em equipe multiprofissional; promover articulação entre ensino, pesquisa e extensão à comunidade em DM; promover integração entre os alunos de graduação e pós-graduação da USP com as atividades da equipe multiprofissional.

Dessa forma, a construção e o desenvolvimento do projeto de pesquisa foram realizados por meio de referências teóricas, em vista do reconhecimento na complexidade de ser uma pessoa com diabetes mellitus, tornando-a competente para o desenvolvimento seguro de comportamentos de autocuidado, com adequação a um novo estilo de vida saudável e uma melhor qualidade de vida.

A possibilidade teórica de refletir sobre a temática apresentada consistiu no ponto de partida para enfrentar a árdua e prazerosa elaboração da dissertação de mestrado, ora apresentada. 


\section{Intraduçãa}

"Tempa de dar cala, tempa de decalar $\mathcal{O}$ que há é a que é; e a que será Nascerá... será?"

Fernanda Anitelli 


\section{INTRODUÇÃO}

\subsection{O panorama das doenças crônicas: o diabetes mellitus}

A evolução do comportamento de algumas doenças, ao longo do tempo, afeta e também é afetada pelo processo de desenvolvimento das diversas sociedades. Desse modo, fatores epidemiológicos, demográficos e mudanças nutricionais associados interferem no padrão de morbimortalidade, devendo-se, portanto, serem estudados em conjunto às formas de desenvolvimento econômico e social dos diferentes países (SANTOS, 2008).

Ao final do século $X X$, observou-se uma significativa transformação nas condições de saúde da população humana. Esse processo atingiu quase todos os continentes, alterando a estrutura demográfica e os padrões de morbimortalidade. Em síntese, as modificações da estrutura demográfica caracterizaram-se pela acentuada queda da mortalidade, diminuição da fecundidade, aumento da expectativa de vida e, por decorrência, pelo envelhecimento da população (TEIXEIRA, 2004).

Essas grandes mudanças no padrão epidemiológico ocorreram predominantemente das doenças infecciosas associadas com carências primárias (nutrição, abastecimento de água e condições de vida) às doenças crônicas não transmissíveis e causas externas relacionadas a fatores secundários (segurança pessoal ou ambiental) (CARMO; BARRETO; SILVA JUNIOR, 2003)

De fato, a maioria dos países da América Latina, experimenta na atualidade uma profunda mudança onde a diminuição dos índices das doenças infecciosas e parasitárias têm sido rápida, porém ainda insuficiente, sendo também acompanhada pelo incremento rápido das doenças crônicas (TEIXEIRA, 2004). 
No Brasil, nas últimas décadas, o declínio nas taxas de fertilidade e a constante queda das taxas de natalidades mais acentuadas que as taxas de mortalidades implicaram profundamente sobre a pirâmide de tendência demográfica. Paralelamente, a diminuição nas taxas de crescimento populacional verifica-se um aumento da expectativa de vida ao nascer, com crescimento no número da população idosa e na proporção de indivíduos com idade superior a 60 anos, podendo-se afirmar que o envelhecimento da população brasileira é um fenômeno relativamente recente e irreversível (BRASIL, 2005a).

O envelhecimento populacional é atualmente, um fenômeno universal, característico tanto dos países desenvolvidos, como dos países em desenvolvimento. Embora haja diferença entre os mecanismos que levam a tal envelhecimento, assim como as formas de enfrentamento de suas conseqüências. As repercussões para a sociedade, de populações progressivamente mais idosas são consideráveis, particularmente no que diz respeito à saúde (MARQUES; ARRUDA; ESPIRITO SANTO, 2005). Assim, a predominância de óbitos relacionados às doenças crônicas não transmissíveis é bastante evidente em indivíduos maiores de 60 anos (SCHRAMM; OLIVEIRA; LEITE, 2004).

As doenças crônicas representam a principal causa de mortalidade e incapacidade mundial e são consideradas um reflexo das grandes mudanças que vêm ocorrendo no estilo de vida das pessoas, especialmente em relação aos hábitos alimentares, aos níveis de atividade física e à prática do tabagismo. Tais mudanças decorrem dos processos de industrialização, urbanização, desenvolvimento econômico e crescente globalização do mercado de alimentos (ORGANIZAÇÃO PAN-AMERICANA DA SAÚDE (OPAS), 2003).

Esse grupo de doenças é muito abrangente, incluindo as doenças cardiovasculares, o diabetes mellitus, o câncer, as doenças renais e reumáticas, além dos agravos decorrentes das causas externas (acidentes, violências e envenenamentos) e os transtornos de natureza mental que são reconhecidos como as mais prevalentes, contribuindo 
sobremaneira na carga global de doenças do país (ORGANIZAÇÃO MUNDIAL DE SAÚDE (OMS), 2003).

Em 2001, no Brasil, as doenças crônicas não transmissíveis foram responsáveis por $62 \%$ de todas as mortes e $39 \%$ de todas as hospitalizações registradas no Sistema Único de Saúde (SUS) (SCHRAMM; OLIVEIRA; LEITE, 2004). Em inquérito populacional realizado pelo IBGE em 2003 com o objetivo de gerar informações sobre acesso e utilização de serviços de saúde, aproximadamente, $29,9 \%$ da população brasileira reportou ser portadora de pelo menos uma doença crônica, verificando-se que esta proporção aumentava com a idade (SANTOS, 2008).

É reconhecido atualmente que as doenças crônicas, sejam transmissíveis ou não transmissíveis, assim como as incapacidades estruturais e os transtornos mentais apresentam características semelhantes entre si, passando então, a constituir uma categoria denominada "condições crônicas de saúde". As condições crônicas apresentam um ponto em comum: estão aumentando de forma exponencial, persistem por longos períodos de tempo e requerem gerenciamento contínuo por vários anos ou décadas. A inclusão dos distúrbios mentais e deficiências físicas alargam os conceitos tradicionais de condição crônica (OMS, 2003).

Dentre as condições crônicas, destaca-se o diabetes mellitus (DM), que é considerado uma das principais síndromes de evolução crônica que acometem o homem em qualquer idade, condição social e localização geográfica. É caracterizado por hiperglicemia e ocasionado por uma deficiência absoluta e/ou relativa de insulina, influenciando o metabolismo dos glicídios, proteínas, lipídios, água, vitaminas e, durante a sua evolução, na dependência do controle metabólico, podem advir complicações agudas e crônicas (OLIVEIRA; MILECH, 2004).

As duas formas mais frequentes de DM são o diabetes mellitus tipo 1 (DM1), e o diabetes mellitus tipo 2 (DM2), que correspondem a $5-10 \%$ e $85-90 \%$, respectivamente, dos casos de DM conhecidos. A primeira forma é caracterizada por uma deficiência severa de insulina e acomete 
predominantemente a criança e o adolescente. O DM2 está relacionado a anormalidades na ação da insulina associada à deficiência absoluta e/ou relativa de secreção desse hormônio. São considerados indivíduos de alto risco para desenvolvimento de DM2 aqueles com idade superior a 45 anos, obesos, sedentários, com histórico obstétrico de perimortalidade ou abortamentos de repetição, presença de doença vascular aterosclerótica anterior aos 50 anos ou doença vascular ou doença coronariana, dislipidêmicos, usuários de medicações hiperglicemiantes (corticosteróides, betabloqueadores, tiazídicos) e portadores de hipertensão arterial sistêmica (HAS) (GROSS et al., 2002).

O DM tem sido considerado como um importante problema de saúde na atualidade, tanto em prevalência e incidência, mortalidade prematura, como pelos custos envolvidos no seu controle e no tratamento de suas complicações. A prevalência mundial do DM tem aumentado nas últimas décadas, tornando-se uma das condições crônicas mais prevalentes em todo o mundo. Estudos epidemiológicos indicam que o DM deverá acometer mais de 300 milhões de pessoas em todo o mundo até o ano de 2025, dobrando os seus valores com predomínio em países da Ásia, África e América do Sul (INTERNATIONAL DIABETES FEDERATION (IDF), 2002). Dentre os fatores que explicariam esses dados, destaca-se 0 aumento das faixas populacionais mais idosas como conseqüência da maior expectativa de vida da população, além de mudanças nos padrões alimentares e no estilo de vida (MARLEBI; FRANCO, 1992).

As projeções para 2025, no Brasil, são de que possam existir cerca de 11 milhões de pessoas com diabetes, o que representa um aumento de $100 \%$ em relação aos atuais 5 milhões de pessoas com diabetes (IDF, 2002). Esse índice vem crescendo em decorrência de vários fatores, tais como o processo de modernização, maior taxa de urbanização, industrialização, hábitos alimentares inadequados, inatividade física, obesidade, estresse, aumento da expectativa de vida e maior sobrevida da pessoa com DM (OMS, 2003). 
De acordo com dados obtidos pelo Estudo Brasileiro de Prevalência do DM, realizado em 1990, em cinco capitais brasileiras, evidenciou-se que o DM apresenta prevalência de $7,6 \%$ para a população com idade entre 30-69 anos (MARLEBI; FRANCO, 1992). Um estudo semelhante, o Estudo de Prevalência de DM, Hipertensão Arterial e Hipercolesterolemia, realizado em Ribeirão Preto, no período de 1996/1997, comprovou o aumento do DM para $12,1 \%$ da população de 30-69 anos (TORQUATO et al., 2003).

A mortalidade por DM, em pessoas com mais de 40 anos, cresceu, entre 1996 e 2003, no Brasil. Nesse mesmo período, em Pernambuco a taxa passou de 78/100 mil habitantes para $113 / 100$ mil habitantes (BRASIL, 2005b, 2005c; LESSA, 2004). No ano de 2003, registraram-se $1.002,340$ óbitos por ocorrência no Brasil. Destes, $57 \%$ corresponderam à população de 60 anos ou mais. O grupo de doenças crônicas não transmissíveis representado por doenças do aparelho circulatório, neoplasias e doenças endócrinas, nutricionais e metabólicas colaboraram com 35,7\%, 14,8\% e 6,5\%, respectivamente (BRASIL, 2005a).

Estudos realizados pelo Diabetes Control and Complications Trial (DCCT, 1993) e United Kingdom Prospective Diabetes Study Group (UKPDS, 1998) encontraram que as mudanças no estilo de vida pela educação permanente das pessoas com diabetes resultam em redução de peso, melhor controle glicêmico, da pressão arterial e de lipídios, redução dos riscos cardiovasculares. Dessa forma, o controle metabólico é obtido por meio da educação em diabetes, do monitoramento glicêmico, da terapia nutricional, da atividade física regular, dos esquemas terapêuticos farmacológicos, das informações sobre a prevenção e tratamento das complicações crônicas e agudas, e do reforço dos objetivos do tratamento (AMERICAN DIABETES ASSOCIATION (ADA), 2001).

O tratamento das diversas formas do DM visa alcançar níveis normais de glicose sanguínea, evitando hipoglicemias e buscando uma adequação satisfatória ao estilo de vida. Baseia-se em cinco aspectos fundamentais: o tratamento nutricional, a atividade física, a terapia 
farmacológica, o monitoramento e a educação (GROSS et al., 2002). A educação para o tratamento da pessoa com diabetes é um dos objetivos primordiais para retardar as complicações crônicas provenientes da doença e aliviar os sintomas clássicos, modificando o estilo de vida (SOCIEDADE BRASILEIRA DE DIABETES (SBD), 2009).

Medidas de prevenção, de detecção precoce e de tratamento adequado nos vários níveis de atenção à saúde são muito importantes, pois podem contribuir para a redução da mortalidade, das diversas complicações observadas no DM e das morbidades associadas à condição (MONTENEGRO JÚNIOR, 2003).

A eficácia do controle metabólico da pessoa com diabetes depende de inúmeros fatores, alguns inerentes à própria doença, outros relacionados ao paciente, ao contexto social, em que ambiente o cuidado se desenvolve, à disponibilidade e acesso aos serviços de saúde, ao nível de educação e informação da população e até mesmo suas crenças e sua religiosidade (MONTENEGRO JÚNIOR et al., 2004).

Um estudo desenvolvido em Porto Alegre (RS), em 2005, revelou que o bom controle metabólico do DM está relacionado com o estado emocional dos pacientes, uma vez que a cronicidade do diabetes exige um controle intenso para evitar complicações, sendo, portanto, fundamental o apoio familiar para atuar junto da pessoa com diabetes (MARCELINO; CARVALHO, 2005).

Neste sentido, viver com o DM pode representar um desafio para a pessoa com diabetes e para seus familiares, pois a cronicidade da condição afeta sua vida em geral, alterando o seu próprio cotidiano e familiar (SILVA; SOUZA; MEIRELLES, 2004).

Uma pesquisa desenvolvida na cidade de Florianópolis (SC), em 2000, a partir da prática assistencial enfatizou que indivíduos com doenças, nas quais práticas de autocuidado se fazem necessárias, precisam de informações suficientes e adequadas para que possam conviver com a doença e superar as complicações por elas causadas 
através de uma adesão consciente ao regime terapêutico (RABELO; PADILHA, 2000).

Dessa forma, as práticas de autocuidado de pessoas com DM devem ser encorajadas por todos os profissionais de saúde, principalmente enfermeiros, que lidam frente ao acompanhamento do controle metabólico da doença. Assim, torna-se fundamental a adesão ao tratamento por meio de atividades educativas em saúde para o seu autocuidado, como um alicerce da prevenção de complicações em diabetes mellitus.

\subsection{A educação em saúde e a competência de pessoas com diabetes mellitus para o autocuidado}

A necessidade de educar pessoas para mudanças de comportamento a fim de prevenir as complicações das doenças levou a comunicação articular-se às práticas de educação em saúde, fornecendo um instrumental mais "adequado" para alcançar as desejadas mudanças de comportamento de pessoas (TEIXEIRA, 1996).

Dessa forma, a educação em saúde deve ser considerada como a comunicação enquanto práticas de relações entre os profissionais e as pessoas, com o objetivo de promover mudanças positivas de conhecimentos, para que sejam refletidas nos comportamentos de saúde de pessoas, grupos e comunidades (CYRINO, 2005).

O processo educativo tem a finalidade de transmitir informações para a população, objetivando a conscientização a respeito dos agravos à saúde. No entanto, isto só será possível acontecer se a pessoa que receber a informação ver isto como importante para si (RUIZ; LIMA; MACHADO, 2004).

Para o mesmo autor, os processos educativos envolvem uma comunicação bilateral ou seguem uma comunicação que envolve o 
educador e o educando, um processo dialógico, para o qual ambos contribuem cada qual à sua maneira para a construção do conhecimento. Tais processos ocorrem com base no contexto de vida das pessoas, dos seus cotidianos, das suas experiências e devem ter como propósito libertar as pessoas para que estas possam ser sujeitos sociais capazes de fazer opções construtivas para suas vidas e para a sociedade.

A educação, portanto, implica em busca realizada por um sujeito que é o homem, e este deve ser o sujeito de sua própria educação, não pode ser o objeto dela, assim, ninguém educa ninguém. Ensinar não é transferir conhecimentos; é sim criar possibilidades para sua construção e produção (FREIRE, 2003).

A educação em diabetes deve voltar-se para a construção de conhecimentos que favoreçam o autocuidado e a autonomia das pessoas, na perspectiva de uma vida mais saudável (COELHO; SILVA, 2006).

O trabalho iniciado na Clínica Joslin de Boston pelo Dr. Elliot P. Joslin, em 1897, é um marco histórico na educação em diabetes, quando ele passou a exercer uma medicina preventiva junto às pessoas com DM (STEINER; LAWRENCE, 1992). Do ponto de vista histórico, a educação das pessoas com diabetes incluía seções de atendimento hospitalar, com um profissional de enfermagem ou nutricionista orientando-os sobre a importância da automonitorização no controle do DM. Posteriormente, os programas hospitalares evoluíram para experiências mais custo-efetivas ambulatoriais em grupo, incluindo a instrução através de uma equipe multiprofissional de especialistas em diabetes (BROWN et al., 2002).

Essa estratégia educacional tem um impacto impressionante sobre o comportamento e a evolução de saúde das pessoas com diabetes, assim como nos custos de atendimento à saúde, uma vez que, estudos mostraram que as mudanças no estilo de vida através da educação continuada das pessoas com diabetes resultam em redução de peso, melhor controle glicêmico, da pressão arterial e lipídios, e conseqüentemente, reduzem os riscos cardiovasculares (DCCT, 1993; UKPDS, 1998). 
A frequência apropriada de automonitorização glicêmica, a terapia nutricional, a atividade física regular, os esquemas terapêuticos farmacológicos, as instruções sobre a prevenção e tratamento das complicações crônicas e agudas, a educação contínua, o reforço e a avaliação periódica dos objetivos do tratamento são estratégias da educação em diabetes para o bom controle glicêmico e metabólico (ADA, 2001).

Portanto, torna-se fundamental que pessoas com diabetes adquiram o conhecimento sobre as atividades de autocuidado para tomar decisões diárias no seu cotidiano (IDF, 2002). Uma vez que, um problema importante detectado na maioria das intervenções de profissionais para o esclarecimento das atividades de autocuidado é a falta de conhecimento das pessoas com diabetes para compreender as conseqüências e complicações da não-aderência ao tratamento (GARY et al., 2003; STEED; COOKE; NEWMAN, 2003).

As orientações para o autocuidado são necessárias tanto para fornecer informações suficientes às pessoas com DM acerca da doença quanto para perdurar a realização dessas orientações, adequando-as a um novo estilo de vida saudável (THOOLEN et al., 2008).

Neste contexto, quando há sucesso nas intervenções educativas, com aderência ao tratamento, atitudes e comportamentos de autocuidado adequados, com resultados satisfatórios de exames de rotina, as melhoras obtidas são geralmente por pouco tempo, desaparecendo gradualmente uma vez que é cessado o contato da pessoa com diabetes com os profissionais (NORRIS et al., 2002; STEED, COOKE, NEWMAN, 2003).

Além da manutenção do seguimento pela equipe multiprofissional, as intervenções parecem ser bem sucedidas na maioria das pessoas com DM que apresentam maior motivação para iniciar o autocuidado, mas podem apresentar dificuldades para a manutenção do tratamento. Dessa forma, a continuidade das atividades para o autocuidado deve ser o principal objetivo do tratamento para um controle metabólico contínuo e eficaz do DM (ROTHMAN, 2000). 
Diversos autores publicaram suas experiências na assistência e na educação para pessoas com diabetes. Alguns desses autores experimentaram desenvolver modelos teóricos para assistência de enfermagem, específicos para a pessoa com diabetes. Dentre os modelos, alguns contribuíram significativamente para o estudo das variáveis que influenciam o autocuidado de uma pessoa com diabetes mellitus (ALLISON, 1963; ARMSTRONG, 1987; BACKSHEIDER, 1974; HAENSGEN, 1986; LUCE et al., 1990; MAZZUCA et al., 1986; MILLER, 1982; PAIVA et al., 1986; PELCZYNSKI; REILLY, 1981; ROCHA, 1984; RUBIN; PEYROT; SAUDEK, 1989).

Haensgen (1986) destaca que o desenvolvimento de programas educativos é um fator que influi positivamente no seguimento do controle metabólico e do tratamento. O aumento de conhecimentos sobre o estado de saúde constitui o início para a aplicação de um modelo de atenção à saúde com ênfase na educação para o autocuidado.

Armstrong (1987) desenvolveu um modelo de intervenção em enfermagem baseado nas respostas psicológicas de pessoas com diabetes mellitus frente aos processos de adaptação para a adesão aos comportamentos de autocuidado. Essas respostas estão relacionadas com algumas características do DM, tais como a duração da doença, a incerteza de quando e quantas complicações ocorrerão e as ambiguidades do conhecimento e das circunstâncias negativas e positivas do DM.

Dessa forma, tais incertezas formam a base para determinar necessidades de natureza imediata ou em longo prazo, categorizadas em: psicossociais, que envolvem alterações do estilo de vida, considerando o impacto social do DM na família, amigos e trabalho; autocuidado, que envolvem comportamentos relacionados à manutenção de bons níveis glicêmicos e prevenção de complicações; conhecimentos e habilidades, que envolvem a solução de problemas e a tomada de importantes decisões relacionadas ao cuidado do DM (ARMSTRONG, 1987).

Rubin, Peyrot e Saudek et al. (1989) estudaram os efeitos da educação no autocuidado, controle metabólico e bem-estar emocional de 
pessoas com DM. As pessoas que entraram no programa educativo com altos níveis de bem-estar emocional ou com bom padrão de autocuidado ou controle glicêmico mostraram pouca mudança nas medidas subsequentes. Por outro lado, aquelas que entraram no programa com baixos níveis de bem-estar emocional ou padrões insatisfatórios de autocuidado ou controle glicêmico mostraram melhoras significativas nestas medidas (RUBIN; PEYROT; SAUDEK, 1989).

Ao analisar o preparo de pessoas com diabetes e suas famílias para o autocuidado em unidades de internação, através da pesquisa-ação, visitas domiciliares e orientação de cuidados, encontrou-se que variáveis relacionadas à internação hospitalar e à convivência com a família interferem no preparo da pessoa com diabetes para o autocuidado (LUCE et al., 1990).

A educação realizada de forma individual (por consultas com nutricionistas, enfermeiras ou outros educadores) quando comparada à educação em grupo, utilizando-se a mesma metodologia, foi equivalente na melhora do controle metabólico, visto que o aprendizado em grupo apresentou melhor relação custo-benefício (RICKHEIM et al., 2002).

A utilização de metodologias de educação em grupo nas intervenções em DM tem apresentado uma forma eficaz para adesão de pessoas ao autocuidado, já que proporciona troca de experiências entre os participantes, assim como apoio emocional, idéias e sugestões para a modificação do estilo de vida (TORRES; HORTALE; SCHALL, 2007).

Considerando a cronicidade do diabetes e a importância do controle glicêmico como prevenção de complicações e seqüelas, o conhecimento do DM por meio de educação constitui aspecto relevante no tratamento. Para o sucesso da educação para pessoas com diabetes, é imprescindível considerar a participação da família e o estabelecimento de vínculos efetivos com a equipe multiprofissional (PONTE et al., 2006).

Além da participação da família, valoriza-se a forma que a equipe conduz os programas educativos em saúde. Sabemos que nas experiências caracterizadas por ações integradas em saúde, são utilizadas 
terminologias distintas (multiprofissional, multidisciplinar, interdisciplinar, grupos de apoio e outras) para ações similares, indicando que não existe um consenso na prática sobre estes conceitos. Diversos autores, entretanto, reforçam a importância de que a perspectiva de ações integradas, independente da denominação que recebam multi, inter ou transdisciplinares, têm-se constituído em indicativos para a organização da assistência em saúde (ALMEIDA, MISHIMA, 2001; CAMPOS, DOMITTI, 2007; PEDUZZI, 2002).

Para esse estudo, adotou-se o conceito de trabalho em equipe multiprofissional, que consiste em uma modalidade de trabalho coletivo configurada na relação recíproca entre as intervenções técnicas e a interação dos agentes de diferentes áreas profissionais (PEDUZZI, 2001).

$\mathrm{Na}$ Enfermagem, há o modelo conceitual desenvolvido por Orem (1995) que conceitua autocuidado como a prática de atividades iniciadas e executadas pelos indivíduos em seu próprio benefício para a manutenção da vida e do bem-estar. A demanda terapêutica para o autocuidado é a soma das ações de autocuidado solicitadas pelos indivíduos para atender as suas necessidades específicas em relação a suas condições e circunstâncias.

A competência do indivíduo para o autocuidado é a capacidade desenvolvida em distinguir fatores que devem ser controlados ou administrados para regular seu próprio funcionamento e desenvolvimento, a fim de decidir o que pode e deve ser feito, reconhecer os componentes das suas demandas terapêuticas de autocuidado e desenvolver as medidas de cuidado para atender aos seus requisitos de autocuidado ao longo do tempo (OREM, 1995). Enquanto que, a competência da enfermagem é a propriedade do enfermeiro para conhecer e ajudar os outros ao reconhecimento das suas demandas terapêuticas de autocuidado, atendendo a estas demandas e organizando o exercício ou desenvolvimento de sua competência para o autocuidado ou competência para o cuidado dependente. 
O Modelo Conceitual de Enfermagem de Orem tem sido amplamente utilizado na pesquisa e na prática profissional, porém, percebe-se a necessidade da utilização de um instrumento válido e confiável para mensurar os conceitos pressupostos daquela época. Segundo McBride (1987), existem poucos instrumentos objetivos disponíveis para medir a competência para o autocuidado.

Apesar de Orem não ter proposto um instrumento de avaliação para identificar a competência da pessoa para o autocuidado, alguns autores procuraram aprofundar essa questão. Porém, há alguns estudos revisados que contribuem para o desenvolvimento de instrumentos que permitem medir variáveis relacionadas com o autocuidado da pessoa com diabetes (DENYES, 1980; HAMDI; HUTELMEYER, 1970; IRVINE et al., 1990; KEARNEY; FLEISCHER, 1979; MCBRIDE， 1987; NEVES， 1987; NUNES, 1982).

Além da identificação da competência para o autocuidado em diabetes, Nunes (1982) aponta a necessidade de estudos que investiguem a influência de uma educação estruturada com base nos déficits de competência para o autocuidado, onde o instrumento de avaliação utilizado no pré e pós teste pode guiar atividades educativas.

Desta maneira, surge a necessidade de comparar a competência de pessoas com diabetes mellitus para o autocuidado antes e após a participação em um programa educativo multiprofissional.

\subsection{Justificativa e relevância}

As condições crônicas constituem condições de saúde que persistem em longo prazo, requerendo, portanto, acompanhamento contínuo e permanente. Atualmente, o diabetes mellitus é considerado como uma das principais condições crônicas que afetam o homem moderno, em decorrência da sua alta prevalência e incidência mundial. 
O tratamento da pessoa com DM visa alcançar níveis normais de glicemia, baseando-se em cinco aspectos fundamentais: o tratamento nutricional, a atividade física, a terapia farmacológica, o monitoramento glicêmico e a educação (GROSS et al., 2002; SBD, 2009).

A educação como suporte para o tratamento de pessoas com diabetes mellitus é um dos objetivos primordiais a fim de aliviar os sintomas clássicos e retardar as complicações crônicas provenientes da doença (SBD, 2009). Portanto, torna-se fundamental que pessoas com DM adquiram conhecimento acerca das atividades de autocuidado em diabetes para as decisões diárias no seu cotidiano.

A educação realizada de maneira individual quando comparada à educação em grupo tem se mostrado equivalente na melhora do controle glicêmico e metabólico. No entanto, as atividades desenvolvidas em grupo permitem maior troca de experiências entre as pessoas, melhor relação custo-benefício e têm apresentado maior adesão as ações de autocuidado para o tratamento.

Desse modo, o autocuidado deve ser encorajado por todos os profissionais de saúde que atuam em diabetes mellitus. A fim de contribuir para a fundamentação do trabalho do enfermeiro em programas educativos, torna-se fundamental comparar a competência de pessoas com diabetes mellitus para o autocuidado antes e após a participação em um programa educativo multiprofissional. Para a comunidade científica, o estudo torna-se extremamente relevante e poderá ser utilizado como subsídios para embasar pesquisas futuras da mesma temática. 
"Tanta faz nãa satisfaz a que precisa Além da mais quem lusca nunca é indecisa"

Fernanda Anitelli 


\section{OBJETIVOS}

\subsection{Objetivo geral}

- Comparar a competência de pessoas com diabetes mellitus para o autocuidado antes e após a participação em um programa educativo multiprofissional.

\subsection{Objetivos específicos}

- Caracterizar as pessoas com diabetes mellitus atendidas em um Programa de Educação em Diabetes oferecido por equipe multiprofissional, segundo variáveis sociodemográficas, clínicas e relacionadas ao tratamento;

- Comparar a Pressão Arterial Sistólica (PAS), a Pressão Arterial Diastólica (PAD), a glicemia capilar pós-prandial, a circunferência abdominal (CA), o peso e o Índice de Massa Corporal (IMC) antes e após a participação nas atividades educativas oferecidas pela equipe multiprofissional;

- Comparar as competências física, cognitiva, emocional e motivacional de pessoas com diabetes mellitus antes e após a participação nas atividades educativas oferecidas pela equipe multiprofissional. 
"Flar parece a gente

Pais samas sementes da que ainda virá"

Fernanda Anitelli 


\section{METODOLOGIA}

\subsection{Tipo do estudo}

Trata-se de um estudo não-experimental, descritivo, prospectivo e comparativo, do tipo antes e depois, com abordagem quantitativa.

Os desenhos de pesquisa não-experimentais são utilizados em estudos em que o pesquisador deseja construir o quadro de um fenômeno ou explorar acontecimentos, pessoas ou situações na medida em que eles ocorrem naturalmente (LOBIONDO-WOOD; HABER, 2001).

Nos desenhos não-experimentais uma categoria muito utilizada é o estudo descritivo, utilizado para coletar descrições detalhadas de variáveis existentes, valendo-se dos dados para justificar e avaliar condições e práticas correntes ou para a elaboração de planos a fim de melhorar as práticas de atenção à saúde. O pesquisador se apóia na fundamentação teórico/prática que demanda uma revisão aprofundada de literatura sobre o objeto do estudo. Tem como finalidade observar, descrever, explorar e documentar aspectos de uma situação (POLIT; BECK, 2006).

Um estudo descritivo bem construído poderá fornecer uma riqueza de dados sobre um fenômeno específico de interesse, sem estabelecimento de relações entre as variáveis (LOBIONDO-WOOD; HABER, 2001; POLIT; BECK, 2006).

Os estudos prospectivos exploram e avançam no tempo, iniciando no presente com o exame de uma causa presumida e prosseguindo no futuro até o efeito presumido (LOBIONDO-WOOD; HABER, 2001; POLIT; BECK, 2006). São considerados estudos significativamente fortes, pois não há ambiguidade quanto à sequência temporal do fenômeno. Além disso, as amostras têm maiores possibilidades de serem representativas e os pesquisadores podem estar em uma posição de impor controles para 
descartar as explicações concorrentes para os efeitos observados (POLIT; BECK, 2006).

Os estudos prospectivos permitem a observação, o registro e a investigação dos fatos e fenômenos do mundo físico e humano sem a interferência do pesquisador, procurando descobrir com precisão a frequência do acontecimento do fenômeno, sua relação com os outros e as suas características (RAMPAZZO, 2002). A comparação estatística entre os resultados de dois grupos permite alcançar conclusões significativas para o objeto de estudo (MASSAD et al., 2004).

Portanto, o tipo de estudo eleito possibilitará comparar a competência de pessoas diabetes mellitus para o autocuidado antes e após a participação em um programa educativo multiprofissional.

\subsection{Período do estudo}

O estudo foi realizado no período de março de 2008 a novembro de 2009.

\subsection{Local do estudo}

O estudo foi realizado no Centro Educativo de Enfermagem para Adultos e Idosos inaugurado em 1999 e localizado no Campus Universitário da Universidade de São Paulo, no município de Ribeirão Preto-SP, e, vinculado à Escola de Enfermagem de Ribeirão Preto da Universidade de São Paulo (EERP-USP) (Figura 1). 


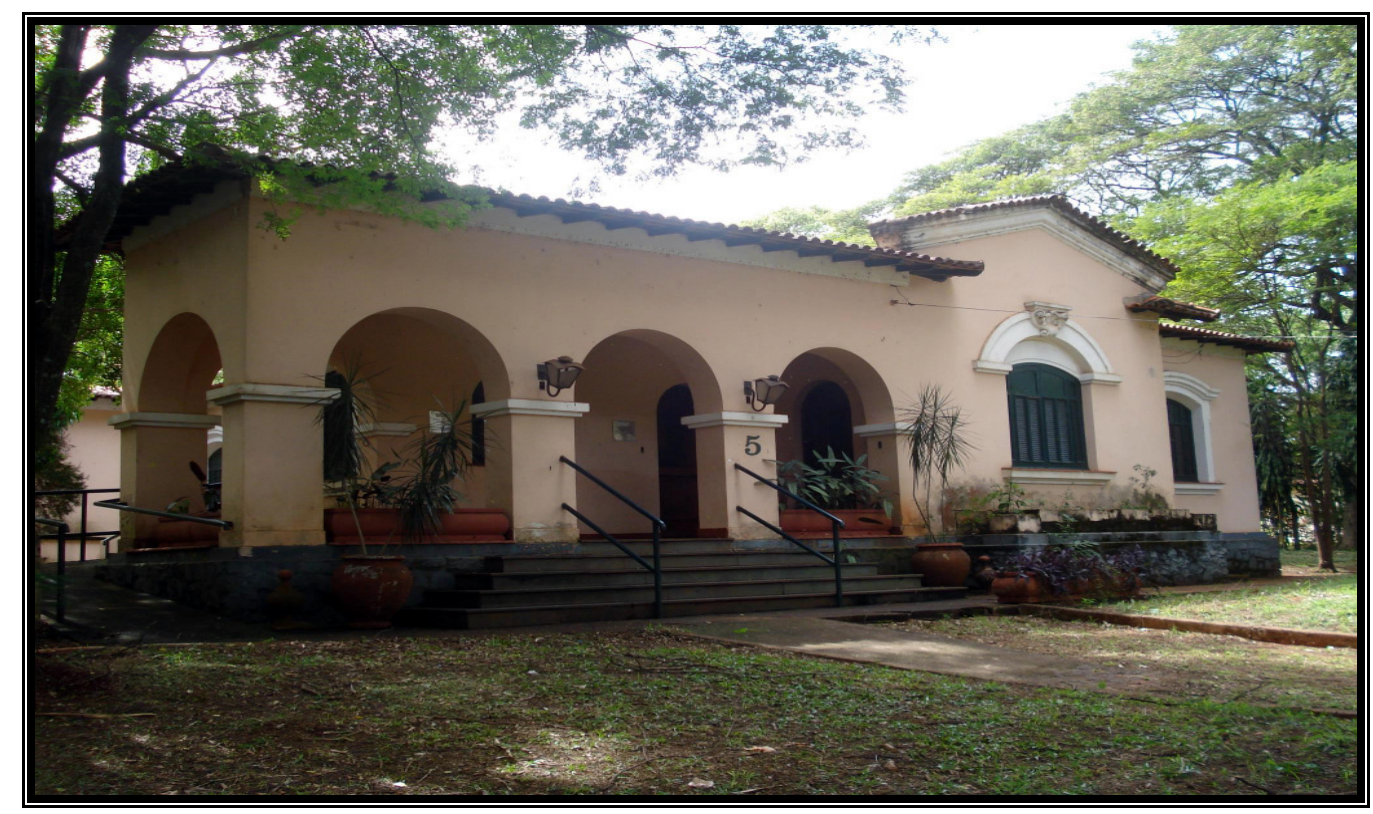

Figura 1 - Centro Educativo de Enfermagem para Adultos e Idosos da Escola de Enfermagem de Ribeirão Preto da Universidade de São Paulo EERP/USP. Ribeirão Preto, 2009

A estrutura física do Centro assemelha-se a uma casa, contendo uma sala para a recepção, uma sala para reuniões e almoxarifado, quatro salas de aulas com capacidade média de 15 pessoas, além de uma varanda, dois banheiros, uma cozinha e uma ampla área externa para atividades sociais.

Atualmente, nesse Centro, são desenvolvidas atividades de ensino, pesquisa e extensão dos seguintes núcleos vinculados ao Departamento de Enfermagem Geral e Especializada da Escola de Enfermagem de Ribeirão Preto da Universidade de São Paulo (DEGE-EERP/USP): Grupo de Pesquisas em Enfermagem e Diabetes Mellitus e Núcleo de Pesquisa em Geriatria e Gerontologia.

O estudo está vinculado ao Grupo de Pesquisas em Enfermagem e Diabetes Mellitus. Esse grupo iniciou suas atividades formais no Centro Educativo de Enfermagem para Adultos e Idosos em setembro de 2000, com os seguintes objetivos primordiais: reconhecer o diabetes mellitus como prioridade de saúde pública; produzir conhecimentos na área do DM, em equipe multiprofissional, a partir de problemas detectados no 
Centro; promover articulação entre ensino, pesquisa e extensão à comunidade, na área de DM (OTERO, 2005).

Como também, promover integração extracurricular dos alunos de graduação e pós-graduação em Enfermagem e outras disciplinas com as atividades da equipe multiprofissional; capacitar profissionais da área da saúde para atuar em programa de DM; e, assegurar o desenvolvimento de estratégias, a fim de tornar as pessoas com diabetes mellitus capacitadas para o desenvolvimento de atividades de autocuidado, melhorando a sua qualidade de vida (OTERO, 2005).

A equipe multiprofissional desse Centro, coordenada por duas enfermeiras docentes do Curso de Graduação em Enfermagem da Escola de Enfermagem de Ribeirão Preto da Universidade de São Paulo (EERP/USP) e um psicólogo docente da Faculdade de Filosofia, Ciências e Letras de Ribeirão Preto da Universidade de São Paulo (FFCLRP/USP), tem realizado um acompanhamento contínuo às pessoas com DM atendidas.

Para o desenvolvimento deste estudo a equipe multiprofissional foi composta por: duas enfermeiras docentes da EERP-USP; um psicólogo docente da FFCLRP/USP; uma enfermeira assistencial de apoio aos núcleos de pesquisa da EERP-USP; dois psicólogos mestrandos da EERP/USP; quatro enfermeiras mestrandas da EERP-USP; três nutricionistas, sendo duas mestrandas da EERP/USP e uma nutricionista clínica; quatro educadores físicos, sendo um mestrando da EERP/USP e três professores de educação física voluntários; duas alunas de iniciação científica da EERP/USP; duas alunas voluntárias do Curso de Graduação em Enfermagem da EERP/USP e da FFCLRP/USP.

Essa equipe realizou atendimento à pessoa com DM através de atividades educativas em grupo do Programa de Educação em Diabetes, com o objetivo de proporcionar ferramentas para a execução das atividades de autocuidado, promovendo uma melhor qualidade de vida.

Durante o período do estudo, o Programa de Educação em Diabetes estava conformado em quatro grupos: 
- três grupos de pessoas com DM que iriam iniciar as atividades educativas. Para este grupo são realizados encontros semanais, formado por pessoas com diabetes mellitus tipo 1 ou tipo 2, que, no momento do seu cadastramento no referido Centro, referiram nunca ter recebido algum tipo de orientação formal de atividades educativas em grupos;

- um grupo de pessoas com DM para reforço das atividades educativas. Para este grupo foram realizados encontros mensais, formado por pessoas com diabetes mellitus tipo 1 ou tipo 2, que, já tenham recebido algum tipo de orientação formal em atividades educativas em grupo no Centro de Enfermagem para Adultos e Idosos em anos anteriores ou em alguma outra Instituição.

Portanto, as atividades educativas aos quatro grupos foram realizadas em encontros semanais e mensais, às terças-feiras, das 14 às 17 horas, com duração de quatro meses. $O$ atendimento das pessoas com DM mediante o oferecimento de atividades educativas para cada um dos grupos foi realizado através do rodízio em escala da equipe dos profissionais de saúde: psicologia, nutrição, educação física e enfermagem.

Para o desenvolvimento das atividades educativas, a equipe multiprofissional selecionou um tema mensal, no qual constituiu o eixo de trabalho para os profissionais da enfermagem, nutrição, psicologia e educação física. Esses temas foram sistematizados por meio de estratégias pedagógicas de educação em grupo, constituído por um conjunto de intervenções abordadas na seguinte sequencia: conhecendo o diabetes mellitus, promovendo hábitos alimentares saudáveis, praticando o exercício físico e aderindo a terapia medicamentosa em DM.

Frente às diferentes estratégias para sistematização de atividades educativas em DM padronizadas, a equipe de profissionais do International Diabetes Center (IDC) (2001), assim como Harris et al. (2000) propõem estratégias semelhantes de educação básica, individuais ou em grupo, distribuídas em quatro sessões, a seguir: 
- Primeira sessão: a pessoa aprende o DM como doença, seus tipos, noções de fisiopatologia e os sintomas da doença; o papel da insulina e as consequências de sua falta; noções fundamentais de terapia insulínica, incluindo os tipos de insulina disponíveis, o tempo de ação, técnica de administração e armazenamento; conceitos de automonitorização, significado e interpretação da HbA1c; ênfase nos aspectos emocionais e na importância do envolvimento de familiares; alguns aspectos sobre a importância do plano alimentar;

- Segunda sessão: enfatizam aspectos nutricionais, como controle de peso, pirâmide alimentar e leitura de rótulos, além de noções de contagem de carboidratos para o planejamento individual da alimentação; relação entre o uso de insulina e alimentação, álcool e DM, o efeito do exercício físico na glicemia; a conscientização e a prevenção da hipoglicemia;

- Terceira sessão: avaliação dos resultados dos testes de glicemia; identificação, resolução de problemas e treinamento nas habilidades básicas para o auto-ajuste da insulina; maior aprofundamento sobre prevenção da hipoglicemia e atividade física; habilidades de manejo durante quadros infecciosos ou doenças intercorrentes;

- Quarta sessão: relação entre automonitorização e HbA1c; cuidado com os pés, prevenção e vigilância das complicações; adaptação de alimentos e planos de insulina; conhecimentos nutricionais adicionais e meios para a continuação da educação em DM.

Destaca-se ainda que, no referido Centro, os encontros em grupo foram realizados sempre com a mesma equipe multiprofissional procurando modificar as metodologias de ensino e aprendizagem.

Ao final de cada encontro, foram verificados e registrados os valores da pressão arterial $(\mathrm{mmHg})$, glicemia capilar pós-prandial $(\mathrm{mg} / \mathrm{dL})$, circunferência abdominal $(\mathrm{cm})$, peso $(\mathrm{kg})$, altura $(\mathrm{m})$ e Índice de Massa Corporal (IMC) $\left(\mathrm{kg} / \mathrm{m}^{2}\right)$.

Destaca-se que também foram realizadas reuniões clínicas semanais entre os profissionais da equipe multiprofissional, a fim de 
elaborar e discutir o fluxo de atendimento, capacitação e treinamento dos profissionais do Centro, assim como a avaliação dos casos clínicos. Os profissionais buscavam uma linguagem compreensível e simples, adequada à realidade, como ponto fundamental o indivíduo, buscando conhecer seus conhecimentos prévios e suas necessidades em relação à doença.

Essas reuniões ocorreram semanalmente, com duração de uma hora, às terças-feiras, das 13 às 14 horas, antes do início das atividades educativas com os grupos. Tais reuniões constituíram-se em importantes momentos de reflexão entre os profissionais da equipe multiprofissional para a implantação da proposta e para a discussão dos conflitos que emergiram durante o desenvolvimento das atividades no Centro.

\subsection{População-base do estudo (Universo)}

A população-base do estudo foi constituída por todas as pessoas com diabetes mellitus tipo 1 e tipo 2 atendidas no Centro Educativo de Enfermagem para Adultos e Idosos, no mês de março de 2009, perfazendo um total de 68 pessoas.

\subsubsection{Critérios de inclusão}

Os seguintes critérios de inclusão foram considerados para a realização do estudo:

- Ser uma pessoa com diagnóstico de diabetes mellitus tipo 1 ou diabetes mellitus tipo 2, ambos os sexos e idade maior que 18 anos;

- Ser uma pessoa que nunca tenha recebido orientação formal em atividades educativas em grupos; 
- Apresentar frequência maior ou igual a $75 \%$ nas atividades educativas programadas.

\subsubsection{População do estudo}

A população do estudo foi constituída por 43 pessoas com diabetes mellitus tipo 1 e diabetes mellitus tipo 2, que atenderam aos critérios de inclusão estabelecidos para o presente estudo.

Das 68 pessoas com DM atendidas no Centro, no mês de março de 2009, 25 foram excluídas. Destas, 18 pessoas pertenciam ao grupo para reforço (encontros mensais) e 7 pessoas do grupo de iniciantes (encontros semanais). A exclusão dessas pessoas ocorreu pelos motivos descritos a seguir: 4 apresentaram frequência menor que 75\% nas atividades educativas programadas; 2 desistiram de participar por dificuldades com horários e questões socioeconômicas relacionadas ao transporte; e, 1 por motivo de complicações crônicas relacionadas ao DM (Tabela 1).

Tabela 1 - Distribuição numérica da população do estudo segundo motivos de exclusão. Ribeirão Preto, 2009

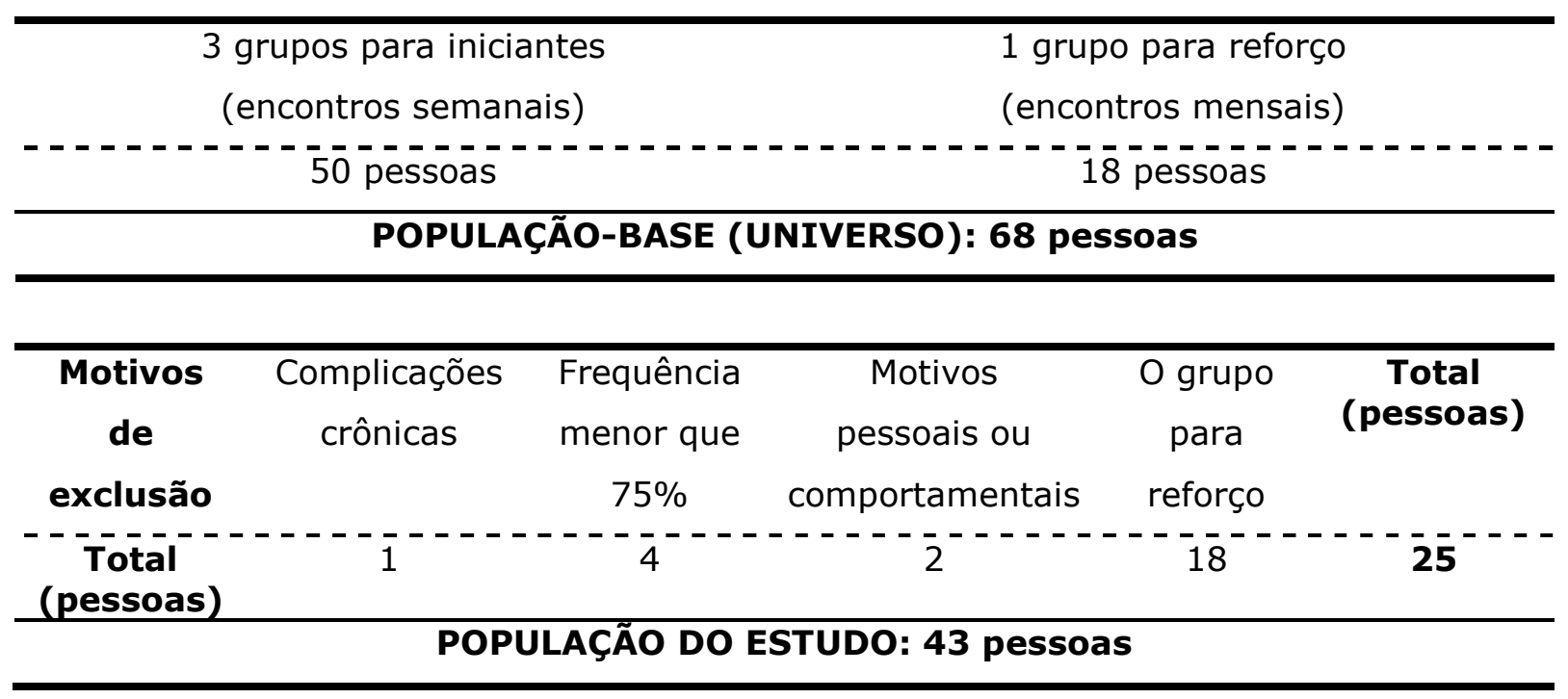




\subsection{Variáveis do estudo}

Uma variável é definida como toda e qualquer característica que, observada em uma unidade experimental, pode variar de uma pessoa para outra. É importante identificar o tipo de variável de um estudo para que sejam adotados os procedimentos estatísticos específicos. Há dois tipos principais de variáveis: qualitativas e quantitativas (CALLEGARIJACQUES, 2008).

As variáveis qualitativas fornecem dados de natureza nãonumérica, onde os dados podem ser categorizados numericamente, porém sem valor quantitativo. Há dois níveis de mensuração para as categorias dessas variáveis: nível nominal (as categorias diferenciam-se uma das outras somente por meio das suas denominações) ou nível ordinal (as categorias são diferenciadas uma das outras com graus de intensidade, possibilitando uma ordenação das várias categorias). As variáveis quantitativas fornecem dados numéricos que expressam quantidades e podem ser classificadas em: discretas (os dados são categorizados em números inteiros) ou contínuas (os dados são categorizados em determinados valores dentro de um intervalo de variação possível) (CALLEGARI-JACQUES, 2008).

O presente estudo foi contemplado com variáveis sociodemográficas (sexo, idade, procedência, cor/raça, estado civil, número de pessoas no domicílio, nível de escolaridade, renda familiar, ocupação e religião); variáveis clínicas (tipo de DM, tempo do diagnóstico (anos) de DM, hábito de fumar, ingestão de bebida alcoólica, acompanhamento médico, complicações crônicas (DM) e co-morbidades); variáveis relacionadas ao tratamento (plano alimentar; atividade física e tratamento medicamentoso); variáveis relacionadas aos valores de pressão arterial $[\mathrm{mmHg}]$, glicemia capilar pós-prandial $[\mathrm{mg} / \mathrm{dL}]$, circunferência abdominal $[\mathrm{cm}]$, peso $[\mathrm{kg}]$, altura $[\mathrm{m}]$ e Índice de Massa 
Corporal (IMC) $\left[\mathrm{kg} / \mathrm{m}^{2}\right]$ ); e as variáveis relacionadas à competência da pessoa com diabetes mellitus para o autocuidado.

\subsubsection{Variáveis sociodemográficas}

As variáveis sociodemográficas desse estudo foram classificadas em: qualitativas (nominais e ordinais) e quantitativas (discretas) (CALLEGARI-JACQUES, 2008).

As variáveis sociodemográficas qualitativas nominais foram: sexo, procedência, cor/raça, estado civil, ocupação e religião. As variáveis sociodemográficas qualitativas ordinais foram: número de pessoas no domicílio, nível de escolaridade e renda familiar. A idade foi contemplada como uma variável sociodemográfica quantitativa discreta (CALLEGARIJACQUES, 2008). A seguir, serão descritas essas variáveis sociodemográficas:

- Sexo: foi categorizado em: feminino; masculino.

- Idade: autodeclarada a partir da data de nascimento (dia/mês/ano), sendo expressa em anos completos e categorizada em intervalos dentro das seguintes faixas etárias: 18 a 19 anos; 20 a 29 anos; 30 a 39 anos; 40 a 49 anos; 50 a 59 anos; 60 a 69 anos; 70 a 79 anos; $\geq 80$ anos.

- Procedência: autodeclarada e categorizada em: Ribeirão Preto - São Paulo; outras cidades do estado de São Paulo.

- Cor/Raça: autodeclarada e categorizada em: branca; preta; amarela/oriental; parda/mulato; indígena.

- Estado civil: autodeclarado e considerando a situação especial de cada pessoa em relação aos seus direitos e às suas obrigações civis, categorizado em: solteiro; casado; viúvo; separado/divorciado; união consensual. 
- Número de pessoas no domicílio: autodeclarado e considerando o número total do número de pessoas que moram no domicílio junto com a pessoa entrevistada, categorizado em: $\leq 2$ pessoas; 3 à 5 pessoas; 6 à 8 pessoas; $\geq 9$ pessoas.

- Nível de escolaridade: autodeclarado e considerando o nível educacional. Foi categorizado em: pós-graduação; terceiro grau completo; terceiro grau incompleto; segundo grau completo; segundo grau incompleto; primeiro grau completo; primeiro grau incompleto; sem escolaridade - alfabetizada (a pessoa sabe ler, mas sabe escrever somente o nome completo); sem escolaridade - analfabetizada (a pessoa não sabe ler e escrever nem o próprio nome).

- Renda familiar: autodeclarada e considerando o total de salários mínimos dos membros que moram no domicílio com a pessoa entrevistada. Foi categorizada em faixas salariais: < 1 salário mínimo; 1 a 2 salários mínimos; 3 a 4 salários mínimos; 5 a 6 salários mínimos; 7 a 8 salários mínimos; > 8 salários mínimos. 0 valor de um salário mínimo foi igual a $\mathrm{R} \$ 465,00$, referente à vigência da época de realização do trabalho, segundo a Lei no 11.944, de 28 de maio de 2009, que dispõe sobre o salário mínimo a partir de $1^{0}$ de fevereiro de 2009 (BRASIL, 2009).

- Ocupação: autodeclarada e considerando a ocupação da pessoa entrevistada, categorizada em: funcionário público; trabalhador com carteira assinada; autônomo; estudante; do lar; aposentado; desempregado; voluntário; outra.

- Religião: autodeclarada e considerando a religião da pessoa entrevistada, categorizada em: católica; evangélica; espírita; outra; sem religião. 


\subsubsection{Variáveis clínicas e relacionadas ao tratamento}

As variáveis clínicas e relacionadas ao tratamento desse estudo foram classificadas em: qualitativas (nominais) e quantitativas (discretas) (CALLEGARI-JACQUES, 2008).

As variáveis clínicas e relacionadas ao tratamento do diabetes mellitus qualitativas nominais foram: tipo de DM, hábito de fumar, ingestão de bebida alcoólica, acompanhamento médico, seguimento do plano alimentar, realização de atividade física, tratamento medicamentoso (DM), complicações crônicas (DM) e co-morbidades. O tempo do diagnóstico (anos) de DM foi uma variável contemplada como quantitativa discreta (CALLEGARI-JACQUES, 2008). A seguir, serão descritas essas variáveis:

- Tipo de DM: autodeclarado segundo o tipo de diagnóstico de DM, categorizado em: diabetes mellitus tipo 1 (DM1); diabetes mellitus tipo 2 (DM2).

- Tempo do diagnóstico (anos) de DM: autodeclarado a partir do momento do diagnóstico até o momento do dia da entrevista, expresso em anos completos, categorizado em: $\leq 5$ anos; 6 à 10 anos; 11 à 20 anos; $\geq 30$ anos.

- Hábito de fumar: autodeclarado e categorizado em: não; sim (número de cigarros em 24 horas, expresso em unidades, e o tempo de tabagismo em anos completos); parou de fumar (número de cigarros consumidos em 24 horas, expresso em unidades, e o tempo no qual correspondeu ao período em que a pessoa fumou, expresso em anos completos).

- Ingestão de bebida alcoólica: autodeclarada e categorizada em: não; sim (frequência da ingestão da bebida alcoólica, expresso em número de dias por semana - sete dias).

- Acompanhamento médico: autodeclarado e categorizado em: rede pública; particular; conveniado. 
- Seguimento do plano alimentar: autodeclarado e categorizado em: não; sim.

- Realização de atividade física: autodeclarada e categorizada em: não; sim, regularmente.

- Tratamento medicamentoso: autodeclarado e considerado o tratamento atual medicamentoso utilizado para o DM, mediante confirmação da receita médica categorizado em: não utiliza; antidiabético oral (biguanidas); antidiabético oral (sulfoniluréias); antidiabético oral (biguanidas + sulfoniluréias); antidiabético oral (biguanidas + sulfoniluréias + arcabose); antidiabético oral (biguanidas) + insulina $(\mathrm{NPH})$; antidiabético oral (biguanidas) + insulina $(\mathrm{NPH}+\mathrm{R})$; insulina $(\mathrm{NPH})$; insulina (NPH + R).

- Complicações crônicas (DM): autodeclaradas e considerada a presença de complicação crônica decorrente do DM, categorizadas em: olhos (retinopatia); nervos (neuropatia); rins (nefropatia); problemas relacionados aos pés; coração (cardiopatia).

- Co-morbidades: autodeclaradas e considerada a presença de outras doenças, além do DM, categorizadas em: pressão alta; obesidade; colesterol alto; doença renal; cardiopatia; circulação; e outras doenças.

\subsubsection{Variáveis relacionadas aos valores de pressão arterial, glicemia capilar pós-prandial, circunferência abdominal, peso e Índice de Massa Corporal.}

As variáveis relacionadas aos parâmetros de pressão arterial, glicemia capilar pós-prandial, circunferência abdominal, peso e Índice de Massa Corporal do estudo foram classificadas em quantitativas (contínuas) (CALLEGARI-JACQUES, 2008).

As variáveis quantitativas contínuas foram: pressão arterial $(\mathrm{mmHg})$, glicemia capilar pós-prandial $(\mathrm{mg} / \mathrm{dL})$, circunferência abdominal 
$(\mathrm{cm})$, peso $(\mathrm{kg})$ e Índice de Massa Corporal (IMC) $\left(\mathrm{kg} / \mathrm{m}^{2}\right)$ (CALLEGARIJACQUES, 2008), conforme descritas a seguir:

- Pressão arterial: foi considerada a média dos dois valores da pressão arterial sistólica e diastólica registradas no prontuário, sendo a primeira medida realizada no mês de março de 2009 e a segunda medida no mês de junho de 2009. O valor da média foi registrado em $\mathrm{mmHg}$ (milímetros de mercúrio) no prontuário. O valor da Pressão Arterial Sistólica (PAS) considerado normal foi $<130 \mathrm{mmHg}$ e alterada $\geq 130$ $\mathrm{mmHg}$ e o da Pressão Arterial Diastólica (PAD) normal foi $<80 \mathrm{mmHg}$ e alterada $\geq 80 \mathrm{mmHg}$ (SBD, 2009).

- Glicemia capilar pós-prandial: foi considerado o valor da glicemia capilar pós-prandial registrada em março de 2009 e junho de 2009. Os valores foram registrados no prontuário em $\mathrm{mg} / \mathrm{dL}$ (miligramas por decililitro). Utilizaram-se como parâmetros glicêmicos de normalidade para a glicemia capilar pós-prandial (duas horas após o consumo do último alimento): valores < $140 \mathrm{mg} \backslash \mathrm{dL}$ (SBD, 2009).

- Circunferência abdominal: foram considerados os valores da circunferência abdominal, em março de 2009 e junho de 2009, ambas realizadas por um educador físico, inserido na equipe multiprofissional. Os valores foram registrados no prontuário em $\mathrm{cm}$ (centímetros). O ponto de corte estabelecido para a circunferência abdominal em adultos foi $94 \mathrm{~cm}$ para homens e $80 \mathrm{~cm}$ para mulheres (IDF, 2006).

- Peso: foram considerados os valores de massa corporal registrados em março de 2009 e junho de 2009. Os valores foram registrados em quilogramas $(\mathrm{kg})$ no prontuário.

- Índice de Massa Corporal (IMC): foi considerado o valor de IMC, obtido a partir da divisão entre a massa corporal (quilogramas) dividido pela altura (centímetros), registrados em março de 2009 e junho de 2009 [IMC = massa corporal $(\mathrm{kg}) /$ altura $\left.^{2}\left(\mathrm{~m}^{2}\right)\right]$. Os valores foram registrados em quilogramas por metro ao quadrado $\left(\mathrm{kg} / \mathrm{m}^{2}\right)$. Considerouse sobrepeso quando o valor do IMC apresentou-se entre 25 e $30 \mathrm{~kg} / \mathrm{m}^{2}$, 
e, obesidade quando o valor do IMC apresentou-se maior que $30 \mathrm{~kg} / \mathrm{m}^{2}$ (SOCIEDADE BRASILEIRA DE HIPERTENSÃO (SBH), 2006).

\subsubsection{Variáveis relacionadas à competência de pessoas com diabetes mellitus para o autocuidado}

Na avaliação da competência, utilizou-se a Escala para Identificação da Competência do portador de Diabetes mellitus para o Autocuidado (ECDAC) (ANEXO A) desenvolvida e validada por Nunes (1982).

\subsection{Instrumentos de coleta de dados}

Para obtenção dos dados referentes às variáveis eleitas e definidas para o presente estudo, foram utilizados dois instrumentos de coleta de dados. O primeiro refere-se a um Questionário (APÊNDICE A) referente às variáveis sociodemográficas, clínicas e relacionadas ao tratamento de pessoas com diabetes mellitus. Este questionário foi construído e fundamentado na literatura e na experiência profissional do pesquisador. É composto por 21 itens objetivos, distribuídos em duas partes: I - Dados Sociodemográficos (sexo; data de nascimento; idade; procedência; cor/raça; estado civil; número de pessoas no domicílio; nível de escolaridade; renda familiar; ocupação e religião); II - Dados clínicos e relacionados ao tratamento do diabetes mellitus (tipo de DM, tempo do diagnóstico de DM; hábito de fumar; ingestão de bebida alcoólica; acompanhamento médico; plano alimentar; realização de atividade física; tratamento medicamentoso utilizado para o DM; complicações crônicas decorrentes do DM; e co-morbidades). 
O Questionário (APÊNDICE A) foi avaliado por dois especialistas em diabetes mellitus para a apreciação do conteúdo com o propósito de aprimorá-lo em relação à clareza dos itens, facilidade de leitura, compreensão e forma de apresentação dos itens.

Realizaram-se algumas modificações decorrentes da apreciação do conteúdo do questionário: foram acrescentados e categorizados os itens 'procedência' e 'número de pessoas no domicílio'; no item 'estado civil', acrescentou-se a categoria união consensual. Em relação à segunda parte do questionário referente aos dados clínicos e relacionados ao tratamento do DM, foi realizada a reorganização da ordem dos itens e, uma distribuição mais adequada do item 'tratamento medicamentoso (DM)'.

O segundo instrumento contempla as variáveis relacionadas à competência para o autocuidado denominado Escala para Identificação da Competência do portador de Diabetes mellitus para o Autocuidado (ECDAC) (ANEXO A). É uma escala para pessoas adultas com DM, e permite investigar a estrutura cognitiva relacionada à saúde de pessoas com diabetes mellitus e os comportamentos adequados para o autocuidado (NUNES, 1982).

O instrumento em questão foi desenvolvido em 1982 por Ana Maria Pereira Nunes, conferindo-a o título de Mestre em Ciências da Enfermagem (saúde do adulto) pela Universidade Federal de Santa Catarina (UFSC), com o estudo metodológico intitulado "Desenvolvimento de um instrumento para identificação da competência do diabético para o autocuidado", onde um grupo de seis peritos (uma psicóloga, um médico e quatro enfermeiras) com experiência na orientação de pessoas com diabetes mellitus e/ou autocuidado, determinou a validade (fidedignidade) aparente e de conteúdo do instrumento, demonstrando, segundo o parecer dos validadores, objetividade e abrangência de conteúdo; ou seja, os itens do instrumento apresentaram-se adequados para medir as competências de pessoas adultas com diabetes mellitus para o autocuidado (NUNES, 1982). 
Esta escala é composta por 27 itens distribuídos em três subescalas (I, II e III). Os escores obtidos são calculados pela somatória dos escores de cada item e dão uma idéia clara do nível de desenvolvimento das competências física, cognitiva, emocional e motivacional para o autocuidado. A amplitude da somatória dos escores possíveis para a ECDAC varia entre 108 pontos (máximo) e 27 pontos (mínimo). A seguir, apresentam-se as três subescalas da ECDAC proposta por Nunes (1982):

A subescala I se refere à identificação das competências físicas (itens de 1 a 5). Os itens 1, 2, 3, 4 e 5 permitem identificar a acuidade visual para perto, a percepção das cores, a capacidade térmica, a capacidade sensitiva para objetos pontiagudos na planta dos pés e a destreza manual, respectivamente. Os escores atribuídos aos itens 1, 2, 3, 4 e 5 variam em escores de 1 a 4, com quatro alternativas de resposta. A amplitude da somatória dos escores possíveis para a subescala I da ECDAC varia entre 20 (máximo) e 5 (mínimo).

A subescala II possibilita a identificação das competências cognitivas (itens de 6 a 16), em relação à leitura, ao conhecimento do diabetes mellitus (sinais e sintomas da doença, exames, tratamento, hiperglicemias e hipoglicemias), e, a capacidade de atenção e memória. Para cada item desta subescala são oferecidas quatro alternativas de resposta, com escores que variam de 1 a 4 . A amplitude da somatória dos escores possíveis para a subescala II da ECDAC varia entre 44 (máximo) e 11 (mínimo).

A subescala III comporta os itens 17 ao 27 . Os onze itens contemplados permitem identificar as competências motivacionais e emocionais das pessoas com diabetes mellitus para o autocuidado, que incluem auto-estima (itens 17 e 19), auto-valorização (itens 18 e 20), controle emocional para fazer julgamentos e executar o autocuidado (itens $21,22,23,24$ e 25) e aceitação da situação de ser uma pessoa com DM (itens 24, 25, 26 e 27). Para cada item desta subescala são oferecidas quatro alternativas de resposta, com escores que variam entre 
1 e 4. Existe apenas uma alternativa de resposta, de acordo com uma escala de variação do tipo Likert: Sempre, Muitas Vezes, Poucas Vezes e Nunca. A amplitude da somatória dos escores possíveis para a subescala III da ECDAC varia, da mesma forma da subescala II, entre 44 (máximo) e 11 (mínimo).

A escala Likert é composta por vários enunciados declarativos (por vezes, chamados de itens), que expressam um ponto de vista sobre um tópico. Para a resposta solicita-se aos respondentes que indiquem em que grau concorda com a opinião expressa pelo enunciado, ou dela discordam (POLIT; BECK, 2006).

Para determinar a confiabilidade do instrumento, Nunes (1982) aplicou a ECDAC (ANEXO A) (27 itens) em uma população amostral de 81 pessoas adultas com diabetes mellitus, conforme as instruções descritas no Guia para Administração (ANEXO B) da ECDAC, elaborado também pela própria autora.

A análise de confiabilidade (precisão/reprodutividade) foi verificada pelo método da consistência interna dos itens da ECDAC, calculada pelo coeficiente alfa de Cronbach, e dos coeficientes de correlação itemsubescala e item-total, no Programa Testat, do Núcleo de Processamento de Dados (NPD) da UFSC (NUNES, 1982).

O coeficiente alfa de Cronbach obtido para a escala ECDAC em sua forma final com 27 itens foi de 0,92. Os coeficientes alfas de Cronbach obtidos para as subescalas I (5 itens), II (11 itens) e III (11 itens), foi de 0,75, 0,93 e 0,92, respectivamente (NUNES, 1982). Dessa forma, instrumentos que tem por objetivo a identificação de características individuais, podendo servir como subsídios para posteriores investigações, como é o caso da ECDAC, devem apresentar valores de coeficientes de confiabilidade mínima em torno de 8,0 (FOX, 1972).

Os coeficientes de correlação item-subescala obtidos para as subescalas I ( 5 itens), II ( 11 itens) e III (11 itens), apresentou-se entre 0,82 a $0,77,0,60$ a 0,74 e 0,75 a 0,79, respectivamente. 0 coeficiente de correlação item-total obtido para os 27 itens da ECDAC apresentou-se 
entre 0,35 e 0,80 (NUNES, 1982). Dessa forma, não houve itens com coeficientes de correlação, seja item-subescala ou item-total, inferior a 0,30 . Fox (1972) considera o ponto de corte 0,30 como o coeficiente mínimo de correlação aceitável para itens incluídos na construção de um instrumento, e, a partir de 0,50, como coeficientes de correlação apropriados.

Para a obtenção dos dados relacionados à pressão arterial, glicemia capilar pós-prandial, circunferência abdominal e Índice de Massa Corporal das pessoas com DM foram utilizados planilhas de registros das medidas aferidas pela equipe multiprofissional do referido Centro.

\subsection{Período da coleta de dados}

A coleta de dados foi realizada durante o período de quatro meses, março a junho de 2009, às terças-feiras, das 13 às 17 horas, no Centro Educativo de Enfermagem para Adultos e Idosos da EERP/USP, em dois tempos. Os dados foram coletados no mês de março de 2009, no início do Programa de Educação em Diabetes, caracterizado como Tempo 1 (T1), e, posteriormente, no mês de junho de 2009, após o término do Programa, caracterizado como Tempo 2 (T2).

\subsection{Procedimentos da coleta de dados}

A primeira etapa de coleta de dados ocorreu antes do início do Programa de Educação em Diabetes, em março de 2009 (T1), onde foram aplicados o Questionário (APÊNDICE A) e a "Escala para Identificação da Competência do portador de Diabetes mellitus para o Autocuidado (ECDAC)" (ANEXO A). 
Os dados do Questionário (APÊNDICE A) foram obtidos mediante entrevista dirigida e registrados manualmente pela própria pesquisadora no instrumento, durante o cadastro das pessoas com DM para a organização das atividades educativas realizado pelos profissionais da equipe multiprofissional do local do estudo.

Durante o cadastramento das pessoas com DM no Centro, a pesquisadora realizou a seleção das pessoas que atenderam aos critérios de inclusão adotados para o presente estudo. Foi solicitada a participação da pessoa a ser entrevistada, explicando-a o tipo e os objetivos do estudo. Após o consentimento da pessoa em participar do estudo e a assinatura do Termo de Consentimento Livre e Esclarecido (APÊNDICE B), as pessoas selecionadas foram entrevistadas numa sala individual, em ambiente previamente preparado, sendo uma pessoa entrevistada por vez pela pesquisadora. Cada entrevista durou aproximadamente 10 minutos. Após essa entrevista, foi aplicada a "ECDAC" (subescala I, II e III) (AENXO A), conforme as instruções descritas no Guia para Administração da ECDAC (ANEXO B).

Para a obtenção dos dados da subescala I (competência física), foi preparada uma bancada, em uma sala reservada, com os materiais necessários para a coleta dos cinco itens distribuídos em cinco estações, conforme Tabela 2. 
Tabela 2 - Distribuição dos materiais necessários para a coleta dos dados referentes aos cinco itens da subescala I da "ECDAC". Ribeirão Preto, 2009

\begin{tabular}{ll}
\hline ITEM & MATERIAIS \\
\hline ITEM 1 (visão) & - cartão de Jaeger \\
& - régua (30 centímetros) de plástico transparente \\
& - cartão para interrupção da visão do olho não examinado \\
\hline ITEM 2 (cores) & -18 novelos de lã coloridas: \\
& 1 verde claro +3 novelos com outros tons de verde \\
& 1 rosa claro +3 novelos com outros tons de rosa \\
& 1 vermelho vivo +3 novelos com mais tons de vermelho \\
& 1 amarelo +1 castanho +1 cinza \\
& 1 bege +1 violeta claro +1 azul claro \\
\hline ITEM 3 (temperatura) & -3 tubos de ensaios contendo: \\
& - água quente \\
& - água morna \\
\hline ITEM 4 & água gelada \\
(sensibilidade plantar) & - estilete \\
& - borracha \\
& - ponta de caneta \\
\hline ITEM 5 & - algodão \\
(destreza manual) & -1 conta-gotas \\
& -1 recipiente com água \\
\hline
\end{tabular}

Cabe destacar que o quadro optométrico de pontos utilizado na subescala I para verificar a competência física quanto à acuidade visual foi substituído pelo cartão de Jaeger. Primeiramente, por não constar o modelo do quadro no guia. Após consulta a autora, a mesma indicou o uso de outro método, sem especificar qual, sugerindo manter a atribuição do escore neste item. Em seguida, realizamos a consulta a três optometristas que indicaram o cartão de Jaeger como a melhor opção para a avaliação da acuidade visual para perto (JARVIS, 2002).

Os dados da subescala II (capacidades cognitivas) e da subescala III (capacidades motivacionais e emocionais) da "ECDAC" foram obtidos por meio da técnica da entrevista dirigida e registrados manualmente pela pesquisadora no instrumento.

A segunda etapa da coleta de dados foi realizada no mês de junho de 2009 (T2), após o término do Programa de Educação em Diabetes. Nessa etapa, foram aplicadas novamente as três subescalas da ECDAC (ANEXO A). Para a obtenção dos dados da subescala I (competência 
física), foi preparada novamente a bancada, em uma sala reservada, com os materiais necessários para a coleta dos cinco itens distribuídos em cinco estações (Tabela 2). Para a obtenção dos dados da subescala II (capacidades cognitivas) e III (capacidades motivacionais e emocionais), os dados foram obtidos novamente por meio da técnica da entrevista dirigida e registrados manualmente pela pesquisadora no instrumento.

Os dados relacionados aos valores da pressão arterial, glicemia capilar pós-prandial, circunferência abdominal, peso e Índice de Massa Corporal das pessoas com DM foram obtidos através de consultas às planilhas, em ambas as etapas.

\subsection{Organização e análise dos dados}

Para a organização dos dados, foi criado, primeiramente, um banco de dados no Programa Microsoft Excel, versão XP (Microsoft CO, USA), com dupla digitação dos dados os quais foram, posteriormente, importados para o Programa SPSS "Statistical Package for the Social Science" (versão 11.5 for Windows). Este software possibilitou o processo de análise estatística dos dados.

Os dados relacionados às variáveis sociodemográficas, clínicas e relacionadas ao tratamento qualitativas nominais e ordinais foram dispostos por meio de tabelas e descritos através de proporções numéricas e percentuais. Tais variáveis, quando quantitativas discretas, além da disposição dos dados por meio de tabelas e da descrição através de proporções numéricas e percentuais, também foram realizados os cálculos das médias, desvio padrão, valores mínimos, máximos e medianas.

Os dados relacionados às variáveis quantitativas contínuas foram apresentados em gráficos mediante a comparação das médias, desvio padrão, diferença das médias nos Tempos 1 e 2 . Também foram 
calculados e apresentados nos gráficos o $\mathrm{p}$ valor e o Intervalo de Confiança.

Os dados relacionados às comparações das competências de pessoas com diabetes mellitus para o autocuidado foram dispostos por meio de tabelas e descritos através das médias, desvio padrão, Coeficiente de Variação, valores mínimos e máximos. Para a diferença entre as médias, $\mathrm{p}$ valor e Intervalo de Confiança, foi proposto o modelo de efeitos mistos.

Os modelos lineares de efeitos mistos (efeitos aleatórios e fixos) são utilizados na análise de dados onde as respostas de um mesmo indivíduo estão agrupadas e a suposição de independência entre observações num mesmo grupo não é adequada. Esses modelos têm como pressuposto que seus resíduos tenham distribuição normal com média 0 e variância $\sigma^{2}$ (SCHALL, 1991).

O nível de significância estatística adotado foi de $5 \%(p<0,05)$.

\subsection{Aspectos éticos}

A coleta de dados foi realizada após o consentimento da pessoa entrevistada em participar do estudo e a assinatura do Termo de Consentimento Livre e Esclarecido (APÊNDICE B).

O projeto foi encaminhado para apreciação ao Comitê de Ética em Pesquisa da Escola de Enfermagem de Ribeirão Preto da Universidade de São Paulo (CEP-EERP/USP), atendendo a resolução 196 de 10 de outubro de 1996 do Conselho Nacional de Saúde (CNS), obedecendo às exigências éticas e científicas fundamentais da pesquisa envolvendo seres humanos, com aprovação em 26 de maio de 2009, protocolo 0907/2008 (ANEXO C). 


\section{Resultadas}

"Vai dizer, que nassas preces nãa alcançaram a céu..."

Fernanda Anitelli 


\section{Resultados}

Os resultados estão apresentados em conformidade com os objetivos propostos no presente estudo, sendo contempladas todas as variáveis anteriormente mencionadas e definidas.

\subsection{Caracterização da população do estudo segundo as variáveis sociodemográficas}

Das $43(100 \%)$ pessoas entrevistadas, $29(67.4 \%)$ eram do sexo feminino e $14(32.6 \%)$ masculino. A população era em quase sua totalidade procedente da cidade de Ribeirão Preto, 37 (86.0\%), enquanto que 06 (14.0\%) eram de outras cidades do estado de São Paulo. Em relação à cor/raça, observou-se que $36(83.7 \%)$ pessoas consideraram-se brancas, $06(14.0 \%)$ pretas e $01(2.3 \%)$ parda/mulato. Também foi constatado que a maioria era casada (65.2\%), 05 (11.6\%) eram solteiras, $04(9.3 \%)$ viúvas, 05 (11.6\%) separada/divorciada e 01 (2.3\%) em união consensual.

Quanto às ocupações mais prevalentes, 20 (46.5\%) eram pessoas aposentadas e $13(30.2 \%)$ do lar. Encontrou-se ainda, em relação à religião, que $26(60.5 \%)$ pessoas eram católicas, 08 (18.6\%) eram evangélicas, $01(2.3 \%)$ espírita e $08(18.6 \%)$ referiram não ter religião.

A Tabela 3 mostra as variáveis sociodemográficas qualitativas nominais: sexo, procedência, cor/raça, estado civil, ocupação e religião. 
Tabela 3 - Distribuição numérica (n) e percentual (\%) das variáveis sociodemográficas qualitativas nominais da população do estudo $(n=43)$. Ribeirão Preto, 2009

\begin{tabular}{llc|c}
\hline VARIÁVEIS & CATEGORIAS & $\mathbf{n}$ & \multicolumn{1}{c}{$\%$} \\
\hline Sexo & feminino & 29 & 67.4 \\
& masculino & 14 & 32.6 \\
\hline Procedência & Ribeirão Preto - SP & 37 & 86.0 \\
& outras cidades - estado de SP & 06 & 14.0 \\
\hline Cor/Raça & branca & 36 & 83.7 \\
& preta & 06 & 14.0 \\
& parda/mulato & 01 & 2.3 \\
\hline Estado civil & Solteiro & 05 & 11.6 \\
& casado & 28 & 65.2 \\
& viúvo & 04 & 9.3 \\
& separado/divorciado & 05 & 11.6 \\
& união consensual & 01 & 2.3 \\
\hline Ocupação & funcionário público & 01 & 2.3 \\
& trabalha com carteira assinada & 02 & 4.7 \\
& autônomo & 06 & 14.0 \\
& do lar & 13 & 30.2 \\
& aposentado & 20 & 46.5 \\
\hline Religião & desempregado & 01 & 2.3 \\
\hline & católica & 26 & 60.5 \\
& evangélica & 08 & 18.6 \\
& espírita & 01 & 2.3 \\
& sem religião & 08 & 18.6 \\
\hline
\end{tabular}

Quanto ao número de pessoas que moram no domicílio junto com a pessoa entrevistada, e, encontrou-se que 18 (41.9\%) viviam com até 2 pessoas e 17 (39.5\%) viviam com 3 a 5 pessoas. Em relação ao nível de escolaridade, os resultados mais prevalentes foram: 11 (25.6\%) pessoas tinham até o primeiro grau incompleto, 07 (16.3\%) o primeiro grau completo, $08(18.6 \%)$ o segundo grau incompleto e $08(18.6 \%)$ o segundo grau completo.

No que se refere à renda familiar em número total de salários mínimos, 19 (44.1\%) pessoas possuíam de 3 a 4 salários mínimos, 11 (25.6\%) 1 a 2, $09(21.0 \%) 5$ a 6, $03(7.0 \%)$ até 1 salário mínimo e 01 (2.3\%) 7 a 8 salários mínimos.

As variáveis sociodemográficas qualitativas ordinais: número de pessoas no domicílio, nível de escolaridade e renda familiar, são apresentadas logo a seguir na Tabela 4. 
Tabela 4 - Distribuição numérica (n) e percentual (\%) das variáveis sociodemográficas qualitativas ordinais da população do estudo $(n=43)$. Ribeirão Preto, 2009

\begin{tabular}{|c|c|c|c|}
\hline VARIÁVEIS & CATEGORIAS & $\mathbf{n}$ & $\%$ \\
\hline $\begin{array}{l}\text { Número de pessoas } \\
\text { no domicílio }\end{array}$ & $\begin{array}{l}\leq 2 \text { pessoas } \\
3 \text { a } 5 \text { pessoas } \\
6 \text { a } 8 \text { pessoas } \\
\geq 9 \text { pessoas }\end{array}$ & $\begin{array}{l}18 \\
17 \\
05 \\
03 \\
\end{array}$ & $\begin{array}{r}41.9 \\
39.5 \\
11.6 \\
7.0 \\
\end{array}$ \\
\hline Nível de escolaridade & $\begin{array}{l}\text { pós-graduação } \\
\text { terceiro grau completo } \\
\text { terceiro grau incompleto } \\
\text { segundo grau completo } \\
\text { segundo grau incompleto } \\
\text { primeiro grau completo } \\
\text { primeiro grau incompleto } \\
\text { sem escolarid (alfabetizada) } \\
\text { sem escolarid (analfabetizada) }\end{array}$ & $\begin{array}{l}01 \\
01 \\
03 \\
08 \\
08 \\
07 \\
11 \\
03 \\
01\end{array}$ & $\begin{array}{r}2.3 \\
2.3 \\
7.0 \\
18.6 \\
18.6 \\
16.3 \\
25.6 \\
7.0 \\
2.3 \\
\end{array}$ \\
\hline Renda familiar* & $\begin{array}{l}\text { < } 1 \text { salário mínimo } \\
1 \text { a } 2 \text { salários mínimos } \\
3 \text { a } 4 \text { salários mínimos } \\
5 \text { a } 6 \text { salários mínimos } \\
7 \text { a } 8 \text { salários mínimos }\end{array}$ & $\begin{array}{l}03 \\
11 \\
19 \\
09 \\
01\end{array}$ & $\begin{array}{r}7.0 \\
25.6 \\
44.1 \\
21.0 \\
2.3 \\
\end{array}$ \\
\hline
\end{tabular}

*valores calculados com base no salário mínimo vigente - $R \$ 465,00$, segundo Lei $n^{\circ} 11.944$, de 28 de maio de 2009, que dispõe sobre o salário mínimo a partir de $1^{\circ}$ de fevereiro de 2009 (BRASIL, 2009).

Quanto à idade das $43(100 \%)$ pessoas entrevistadas, a menor foi de 36 anos e a maior 79 (60.9 \pm 11.8$)$, com mediana de 63 anos. Predominou-se 14 (32.6\%) pessoas na faixa etária entre 60 a 69 anos, seguido de $12(27.8 \%)$ de 70 a 79 anos e $10(23.3 \%)$ de 50 a 59 anos.

A idade, classificada nesse estudo como uma variável sociodemográfica quantitativa discreta, está apresentada na Tabela 5.

Tabela 5 - Distribuição numérica $(n)$, percentual (\%), média $\pm d p *$, valores mínimo, máximo e mediana da idade da população do estudo $(n=43)$. Ribeirão Preto, 2009

\begin{tabular}{|c|c|c|c|c|c|c|}
\hline VARIÁVEL & CATEGORIAS & $\mathbf{n}$ & $\%$ & Média $\pm d p *$ & Mín - Máx & Mediana \\
\hline Idade & $\begin{array}{l}30 \text { a } 39 \text { anos } \\
40 \text { a } 49 \text { anos } \\
50 \text { a } 59 \text { anos } \\
60 \text { a } 69 \text { anos } \\
70 \text { a } 79 \text { anos }\end{array}$ & $\begin{array}{l}02 \\
05 \\
10 \\
14 \\
12 \\
\end{array}$ & \begin{tabular}{|c|}
4.7 \\
11.6 \\
23.3 \\
32.6 \\
27.8 \\
\end{tabular} & $60.9 \pm 11.8$ & $36-79$ & 63 anos \\
\hline
\end{tabular}




\subsection{Caracterização da população do estudo segundo as variáveis clínicas e relacionadas ao tratamento do diabetes mellitus}

Das $43(100 \%)$ pessoas entrevistadas, 42 (97.7\%) tinham diabetes mellitus tipo 2 (DM2) e 01 (2.3\%) diabetes mellitus tipo 1 (DM1).

Em relação ao hábito de fumar, 34 (79.0\%) pessoas referiram que não fumam e 09 (21.0\%) pararam de fumar. O tempo de abandono do tabagismo e o número de cigarros ao dia foram em média de 14.3 anos e 5.5 cigarros/dia, respectivamente. Cabe destacar que, das pessoas entrevistadas, ninguém referiu que fuma atualmente. Quanto à ingestão de bebida alcoólica, 38 (88.3\%) pessoas declararam que não ingerem, e $05(11.7 \%)$ o fazem, com uma frequência média de 3,8 dias por semana.

Quanto ao acompanhamento médico, a totalidade das pessoas o realiza, sendo 31 (72\%) na rede pública de saúde, $03(7.0 \%)$ e 09 $(21.0 \%)$ em instituições particulares e conveniadas, respectivamente. No que se refere ao seguimento do plano alimentar, 22 (51.2\%) pessoas referiram que não o seguem e, 21 (48.8\%) o seguem. Quanto à realização de atividade física, 31 (72.0\%) referiram que não realizam e apenas $12(28.0 \%)$ a realiza regularmente.

Dos 43 sujeitos, $38(88.3 \%)$ pessoas fazem uso de tratamento medicamentoso para o DM, sendo que 33 (76.7\%) utilizam somente antidiabético oral, 17 (39.5\%) biguanidas + sulfoniluréias, 14 (32.6\%) apenas biguanidas; 4 (9.3\%) associação de antidiabético oral + insulina; e $1(2.3 \%)$ somente insulina.

Quanto às co-morbidades e às complicações crônicas relacionadas ao DM, obteve-se que as mais prevalentes foram: hipertensão arterial (76.8\%) e dislipidemia (32.6\%); retinopatia (23.3\%) e neuropatia $(11.7 \%)$, respectivamente.

As variáveis clínicas e relacionadas ao tratamento do diabetes mellitus qualitativas nominais, tais como tipo de DM, hábito de fumar, ingestão de bebida alcoólica, acompanhamento médico, plano alimentar 
atividade física, tratamento medicamentoso, complicações crônicas e comorbidades estão apresentadas na Tabela 6.

Tabela 6 - Distribuição numérica (n) e percentual (\%) das variáveis clínicas e relacionadas ao tratamento do diabetes mellitus qualitativas nominais da população do estudo $(n=43)$. Ribeirão Preto, 2009

\begin{tabular}{|c|c|c|c|}
\hline VARIÁVEL & CATEGORIAS & $\mathbf{n}$ & $\%$ \\
\hline Tipo de DM & $\begin{array}{l}\text { diabetes mellitus tipo } 1 \text { (DM1) } \\
\text { diabetes mellitus tipo } 2 \text { (DM2) }\end{array}$ & $\begin{array}{l}01 \\
42\end{array}$ & $\begin{array}{l}2.3 \\
97.7 \\
\end{array}$ \\
\hline Hábito de fumar & $\begin{array}{l}\text { não } \\
\text { parou de fumar }\end{array}$ & $\begin{array}{l}34 \\
09 \\
\end{array}$ & $\begin{array}{l}79.0 \\
21.0\end{array}$ \\
\hline Bebida alcoólica & $\begin{array}{l}\text { não } \\
\text { sim }\end{array}$ & $\begin{array}{l}38 \\
05\end{array}$ & $\begin{array}{l}88.3 \\
11.7 \\
\end{array}$ \\
\hline $\begin{array}{l}\text { Acompanhamento } \\
\text { médico }\end{array}$ & $\begin{array}{l}\text { rede pública } \\
\text { particular } \\
\text { conveniada }\end{array}$ & $\begin{array}{l}31 \\
03 \\
09\end{array}$ & \begin{tabular}{|l|}
72.0 \\
7.0 \\
21.0 \\
\end{tabular} \\
\hline Dieta & $\begin{array}{l}\text { não } \\
\text { sim }\end{array}$ & $\begin{array}{l}22 \\
21\end{array}$ & $\begin{array}{l}51.2 \\
48.8 \\
\end{array}$ \\
\hline Atividade física & $\begin{array}{l}\text { não } \\
\text { sim, regularmente }\end{array}$ & $\begin{array}{l}31 \\
12 \\
\end{array}$ & $\begin{array}{ll}72.0 \\
28.0\end{array}$ \\
\hline $\begin{array}{l}\text { Tratamento } \\
\text { medicamentoso (DM) }\end{array}$ & $\begin{array}{l}\text { não utiliza } \\
\text { biguanidas+sulfoniluréias } \\
\text { biguanidas } \\
\text { biguanidas+insulina(NPH) } \\
\text { sulfoniluréias } \\
\text { insulina(NPH) } \\
\text { biguanidas+insulina(NPH+R) } \\
\text { biguanidas+sulfoniluréias+acarbose }\end{array}$ & $\begin{array}{l}05 \\
17 \\
14 \\
03 \\
01 \\
01 \\
01 \\
01\end{array}$ & $\begin{array}{l}11.7 \\
39.5 \\
32.6 \\
7.0 \\
2.3 \\
2.3 \\
2.3 \\
2.3 \\
\end{array}$ \\
\hline $\begin{array}{l}\text { Complicações } \\
\text { crônicas* }\end{array}$ & $\begin{array}{l}\text { retinopatia } \\
\text { neuropatia } \\
\text { nefropatia } \\
\text { problemas relacionados aos pés } \\
\text { cardiopatia }\end{array}$ & $\begin{array}{l}10 \\
05 \\
04 \\
03 \\
01\end{array}$ & $\begin{array}{r}23.3 \\
11.7 \\
9.3 \\
7.0 \\
2.3 \\
\end{array}$ \\
\hline Co-morbidades* & $\begin{array}{l}\text { hipertensão arterial } \\
\text { dislipidemia } \\
\text { obesidade } \\
\text { cardiovasculares } \\
\text { doença renal } \\
\text { outras doenças }\end{array}$ & $\begin{array}{l}33 \\
14 \\
11 \\
12 \\
04 \\
09\end{array}$ & $\begin{array}{c}76.8 \\
32.6 \\
25.3 \\
27.8 \\
9.3 \\
21.0\end{array}$ \\
\hline
\end{tabular}

*variáveis não mutuamente exclusivas

Quanto ao tempo de diagnóstico de DM das 43 (100\%) pessoas entrevistadas, o tempo variou de 1 ano a 32 anos, com média e desvio padrão de $8.4 \pm 6.9$, com mediana de 6 anos. Houve predomínio de 20 (46.5\%) pessoas com tempo de diagnóstico $\leq 5$ anos, seguido de 13 $(30.2 \%)$ de 11 a 20 anos. 
O tempo de diagnóstico de DM, classificado nesse estudo como uma variável quantitativa discreta, está apresentado na Tabela 7.

Tabela 7 - Distribuição numérica $(n)$, percentual (\%), média $\pm d p *$, valores mínimo, máximo e mediana da população do estudo segundo o tempo de diagnóstico do diabetes mellitus $(n=43)$. Ribeirão Preto, 2009

\begin{tabular}{lllc|cccc}
\hline VARIÁVEL & CATEGORIAS & $\mathbf{n}$ & $\%$ & Média \pm dp* & Mín - Máx & Mediana \\
\hline Tempo de & $\leq 5$ anos & 20 & 46.5 & $8.4 \pm 6.9$ & $1-32$ & 6 anos \\
diagnóstico & 6 a 10 anos & 08 & 18.6 & & & \\
(anos) DM & 11 a 20 anos & 13 & 30.2 & & & \\
& $\geq 30$ anos & 02 & 4.7 & & & \\
\hline
\end{tabular}

*desvio padrão

4.3 Comparação dos valores obtidos em relação às variáveis pressão arterial, glicemia capilar pós-prandial, circunferência abdominal, peso e IMC antes e após o oferecimento das atividades educativas

Os resultados das variáveis quantitativas contínuas relacionadas à Pressão Arterial Sistólica (PAS), Pressão Arterial Diastólica (PAD), glicemia capilar pós-prandial, Circunferência Abdominal (CA), peso e Índice de Massa Corporal (IMC) são apresentados mediante a comparação da média \pm desvio padrão, diferença, valor $p$ e Intervalo de Confiança (IC) da população do estudo nos Tempos 1 e 2.

Em relação à PAS e PAD, encontraram-se média \pm desvio padrão de $130 \mathrm{mmHg} \pm 13.58$ e $81 \mathrm{mmHg} \pm 10.47$ no $\mathrm{T} 1, \mathrm{e}, 123 \mathrm{mmHg} \pm 14.26$ e $76 \pm 8.90$ no $\mathrm{T} 2$, respectivamente.

Destaca-se que, além da representação das médias menores da PAS e da PAD da população do estudo no T2 em comparação ao T1, com diferenças de -6.62 e -5.27, respectivamente. Também observou-se diferenças estatisticamente significantes $(p<0.05)$, na PAS com $p=0.03$ e IC (0.65-12.60) e na PAD com $p=0.01$ e IC $(1.10-9.44)$. 
Dessa forma, como o valor da PAS considerado normal foi $<130$ $\mathrm{mmHg}$ e alterado $\geq 130 \mathrm{mmHg}$ e o da PAD normal foi $<80 \mathrm{mmHg}$ e alterado $\geq 80 \mathrm{mmHg}$, a média \pm desvio padrão dos valores pressóricos no T2 para a PAS foi de $123 \mathrm{mmHg} \pm 14.26$ e $76 \mathrm{mmHg} \pm$ 8.90, respectivamente conforme Figura 2.

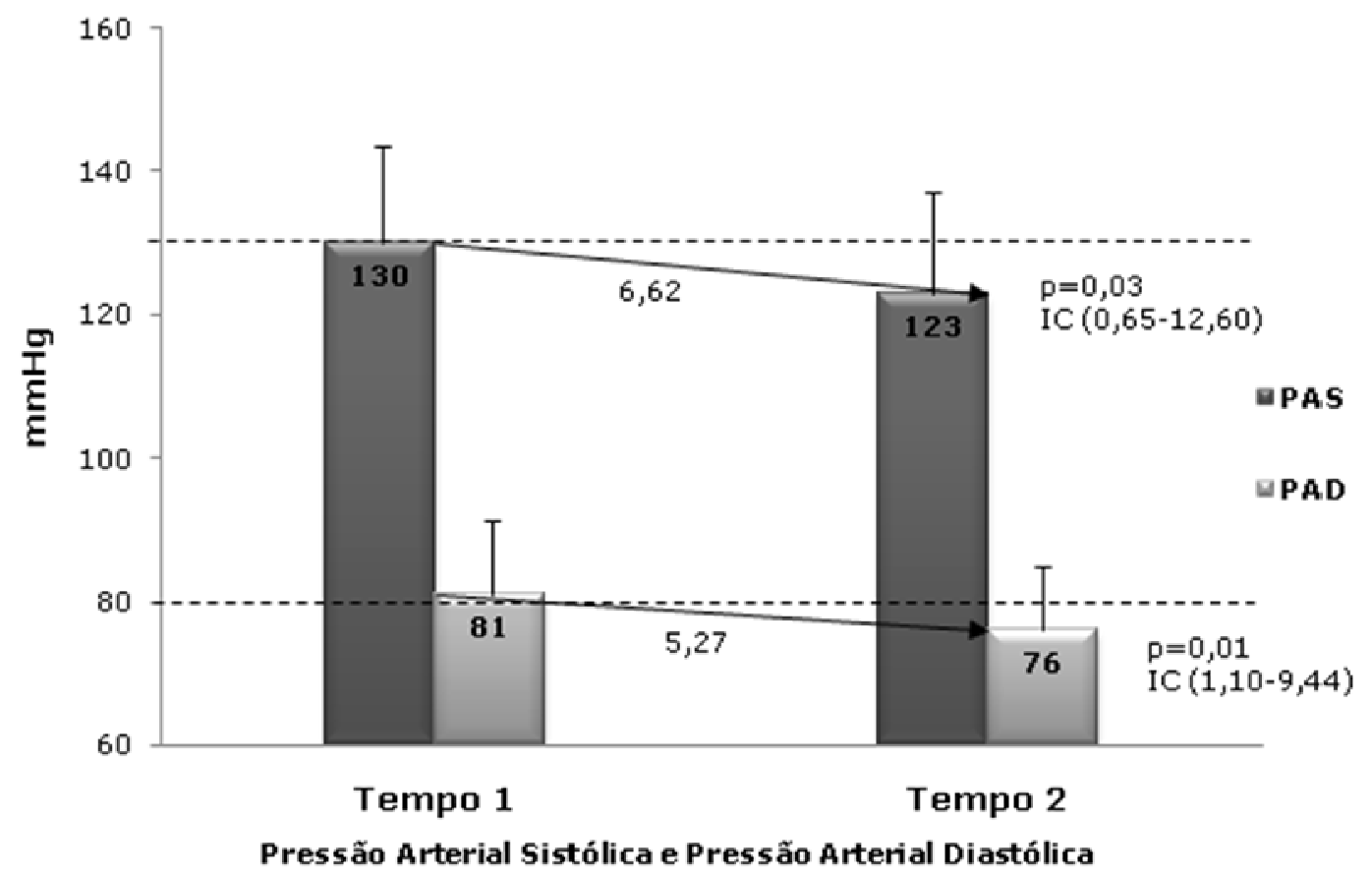

Figura 2 - Média \pm desvio padrão, valor $p$, IC e diferença entre a comparação das médias no T1 e no T2 da PAS e PAD da população do estudo $(n=43)$. Ribeirão Preto, 2009

Quanto à glicemia capilar pós-prandial, encontrou-se $181 \mathrm{mg} / \mathrm{dL} \pm$ 81.74 no $\mathrm{T} 1$ e $157 \mathrm{mg} / \mathrm{dL} \pm 64.54$ no $\mathrm{T} 2$. Apesar dos resultados não terem revelado diferenças estatisticamente significantes, quando o $\mathrm{p}=1.27$ e IC [(-7.12)-56.09], encontrou-se menor média no T2 em comparação ao T1, com diferença de -24.48 . Porém, ao utilizar-se como parâmetro normal para a glicemia capilar pós-prandial valores < 140 $\mathrm{mg} \backslash \mathrm{dL}$, a média dos valores glicêmicos no T2 foi de $157 \mathrm{mg} / \mathrm{Dl}$, com desvio padrão de 64.54 conforme Figura 3. 


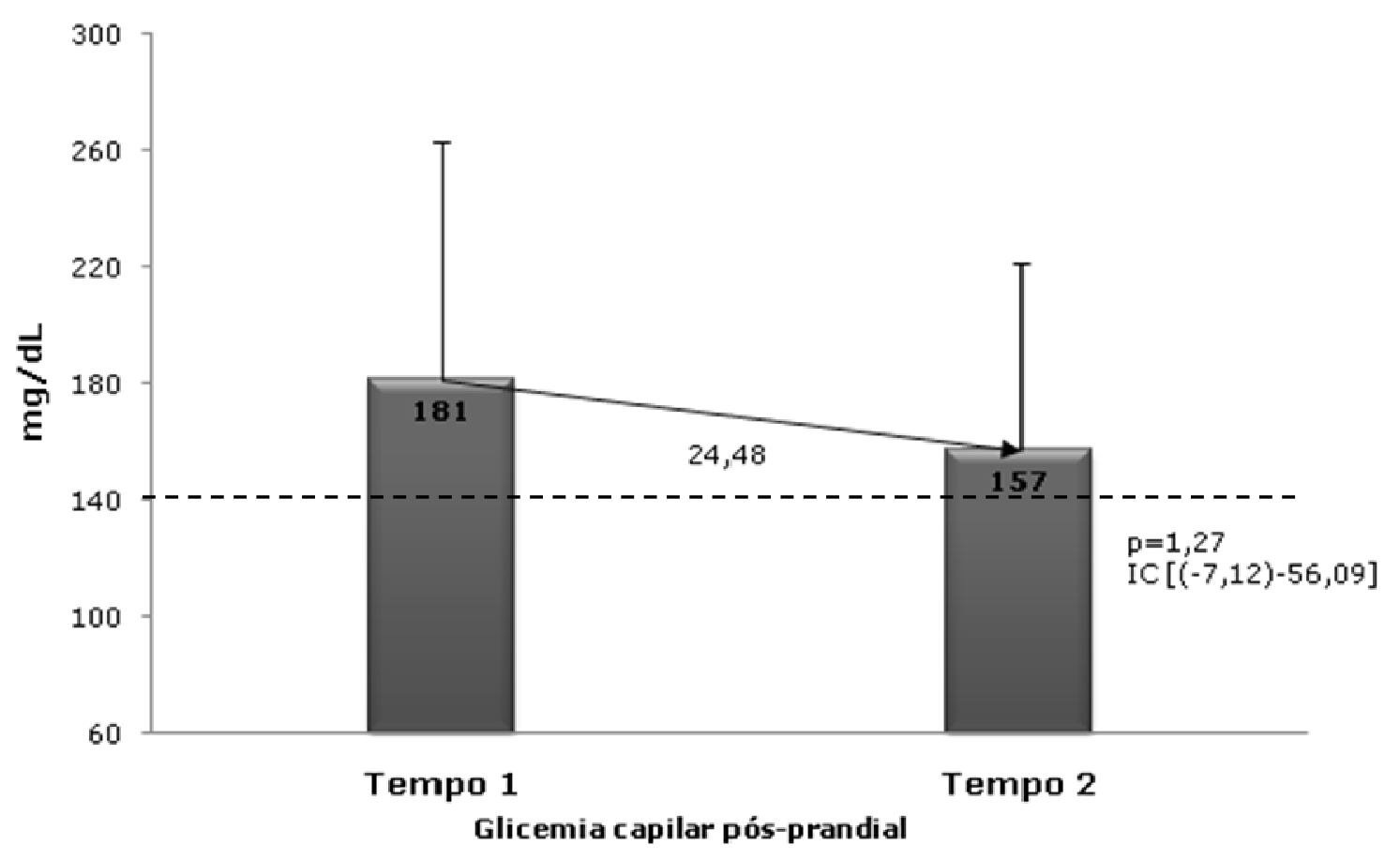

Figura 3 - Média \pm desvio padrão, valor $p$, IC e diferença entre a comparação das médias no $\mathrm{T} 1$ e no $\mathrm{T} 2$ da glicemia capilar pós-prandial da população do estudo ( $n=43)$. Ribeirão Preto, 2009

Para a Circunferência Abdominal, encontrou-se média e desvio padrão de $102.1 \mathrm{~m} \pm 10.88$ no $\mathrm{T} 1 \mathrm{e} 100.5 \mathrm{~m} \pm 64.54$ no $\mathrm{T} 2$. Os resultados também não mostraram diferenças estatisticamente significantes, quando o $\mathrm{p}=0.51$ e IC [(-3.24)-6.39], e uma média de fraca magnitude no $\mathrm{T} 2$ em comparação ao $\mathrm{T} 1$, com diferença de -1.57 . Ao utilizar-se como ponto de corte para a CA em adultos de $94 \mathrm{~cm}$ para homens e $80 \mathrm{~cm}$ para mulheres, a média dos valores da CA no T2 foi de $100.5 \mathrm{~cm}$, com desvio padrão de 11.59 como mostra a Figura 4 . 


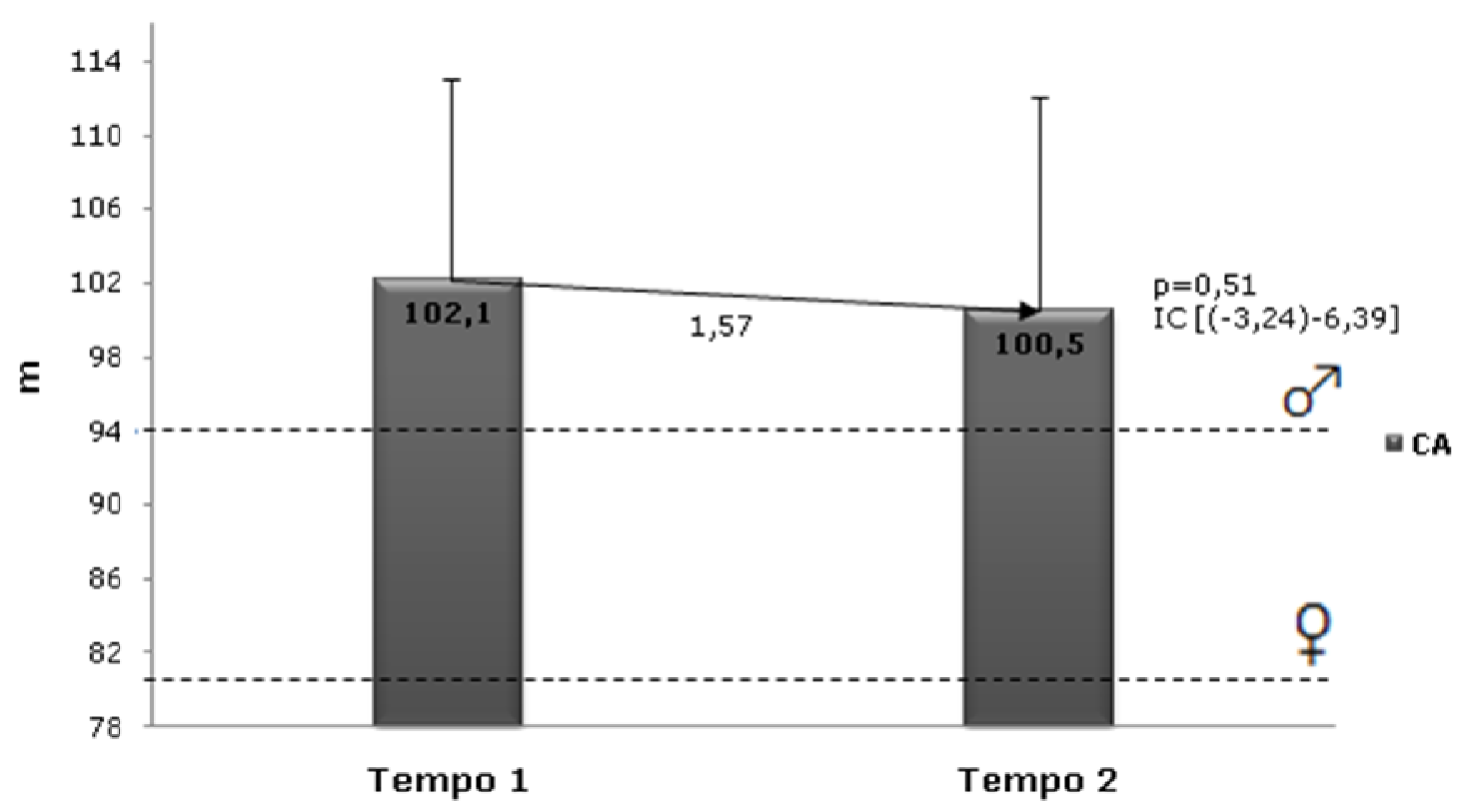

Circunferência Abdominal

Figura 4 - Média \pm desvio padrão, valor $p$, IC e diferença entre a comparação das médias no T1 e no T2 da CA da população do estudo $(n=43)$. Ribeirão Preto, 2009

No que se refere ao peso e IMC, encontraram-se média \pm desvio padrão de $77.7 \mathrm{~kg} \pm 16.70$ e $30.2 \mathrm{~kg} / \mathrm{m}^{2} \pm 5.57$ no $\mathrm{T} 1, \mathrm{e}, 76.1 \mathrm{~kg} \pm$ 17.29 e $29.4 \mathrm{~kg} / \mathrm{m}^{2} \pm 5.66$ no T2. Também foram encontradas médias menores da população do estudo no T2 em comparação ao T1, com diferenças de -1.57 e -0.72 , respectivamente. Observou-se que os resultados também não foram estatisticamente significantes, no peso com $\mathrm{p}=0.66$ e IC (-5.71)-8.86 e no IMC com $\mathrm{p}=0.55$ e IC $(-1.68)-3.129$.

Ao considerar-se sobrepeso quando o valor do IMC apresentou-se entre 25 e $30 \mathrm{~kg} / \mathrm{m}^{2}$, e, obesidade quando o valor do IMC apresentou-se maior que $30 \mathrm{~kg} / \mathrm{m}^{2}$, a média \pm desvio padrão dos valores do IMC no T2 foi de $29.4 \mathrm{~kg} / \mathrm{m}^{2} \pm 5.66$ (sobrepeso), em comparação no T1 com $30.2 \pm$ 5.57 (obesidade) conforme as Figuras 5 e 6. 


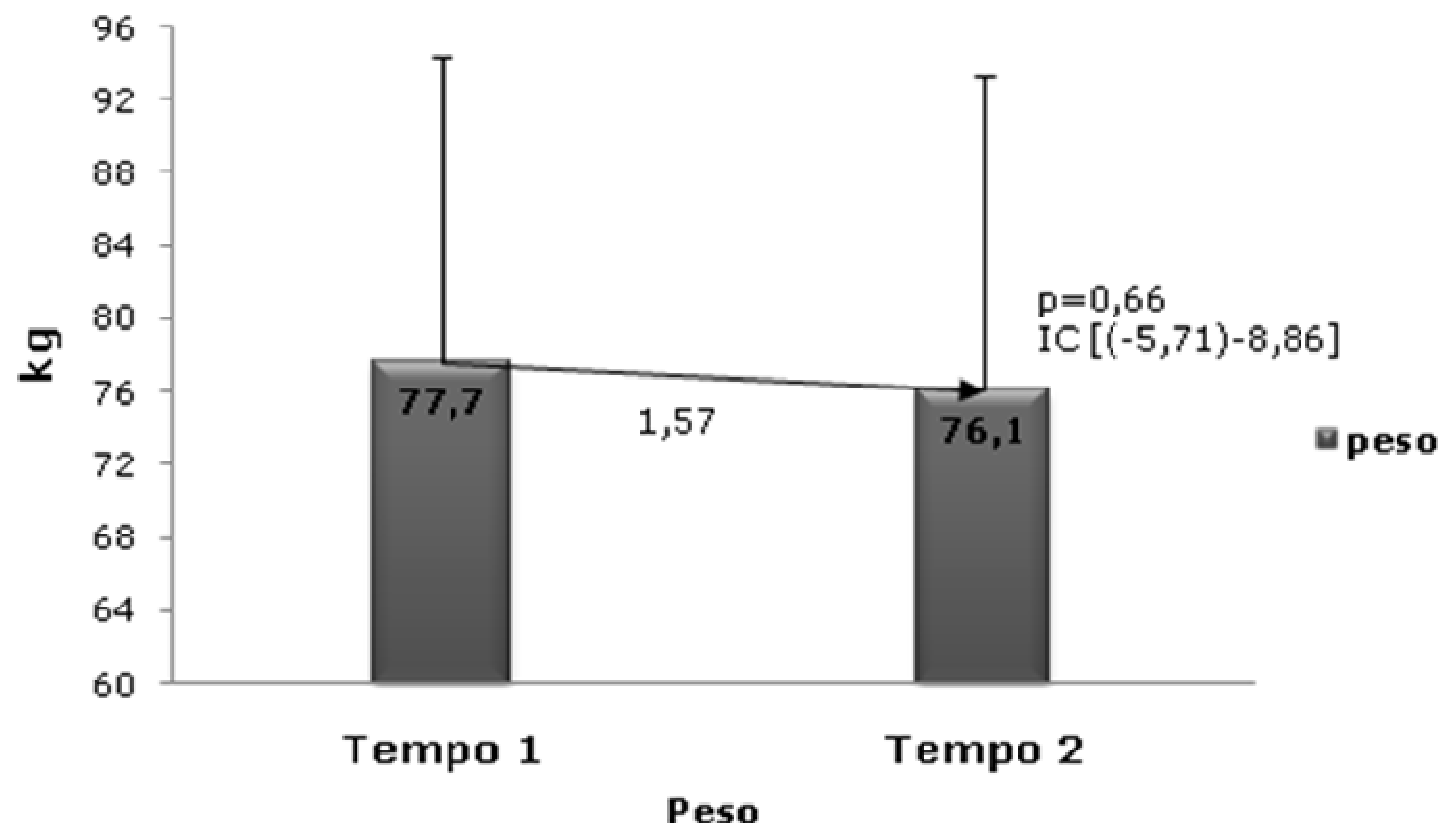

Figura 5 - Média \pm desvio padrão, valor $p$, IC e diferença entre a comparação das médias no T1 e no T2 do peso da população do estudo $(n=43)$. Ribeirão Preto, 2009

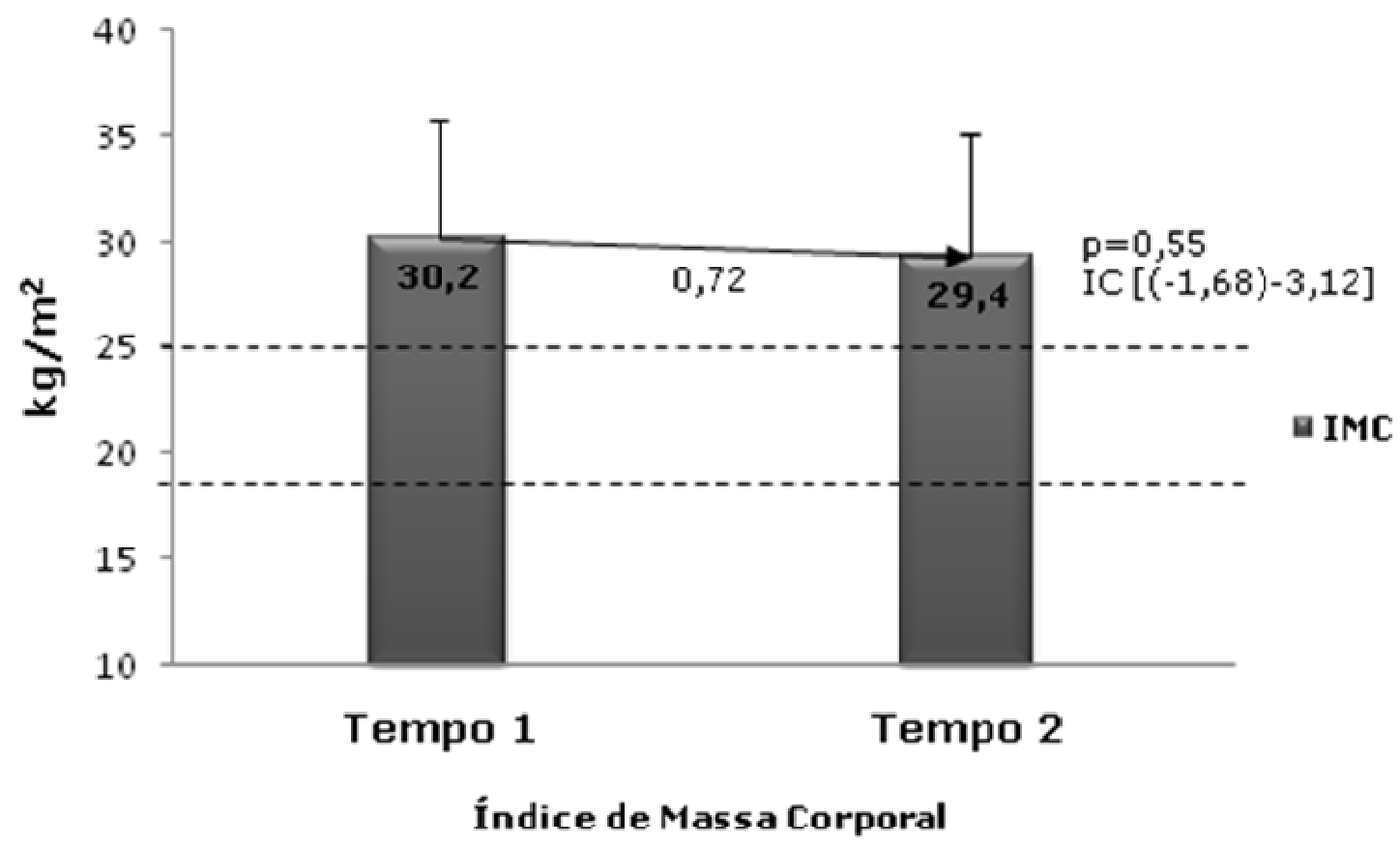

Figura 6 - Média \pm desvio padrão, valor $p$, IC e diferença entre a comparação das médias no T1 e no T2 do IMC da população do estudo $(n=43)$. Ribeirão Preto, 2009 


\subsection{Comparação da competência de pessoas com diabetes mellitus para o autocuidado antes e após o oferecimento das atividades educativas}

As variáveis relacionadas à competência da pessoa com diabetes mellitus para o autocuidado da população do estudo foram avaliadas mediante a aplicação das subescalas I, II e III (ECDAC) (ANEXO A), antes (T1) e após (T2) as atividades educativas. A seguir apresentam-se os resultados das competências física, cognitiva, emocional e motivacional para o autocuidado.

\subsubsection{Competência física da população do estudo antes e após a participação no Programa de Educação em Diabetes do referido Centro}

Cabe ressaltar que a amplitude da somatória total dos escores possíveis para a subescala I (cinco itens) referente à competência física varia entre 5 (mínimo) a 20 (máximo).

A somatória total dos escores que determinam a competência física para o autocuidado diagnosticada pela subescala I variou no T1 de 13.5 (mínimo) a 20 (máximo), com média \pm desvio padrão de $17.80 \pm 1.54$ e coeficiente de variação (CV) $8.65 \%$. No T2, a somatória total dos escores variou entre 14 (mínimo) a 20 (máximo), com média \pm desvio padrão de $18.10 \pm 1.43$ e CV $7.90 \%$ conforme Tabela 8. 
Tabela 8 - Média \pm desvio padrão, Coeficiente de Variação (CV), valores mínimo e máximo dos escores obtidos da competência física no T1 e no T2 da população do estudo $(n=43)$. Ribeirão Preto, 2009

\begin{tabular}{cccccc}
\hline Tempo & $\mathbf{n}$ & Média $\pm \mathbf{d p}$ & $\mathbf{C V}$ & Mínimo & Máximo \\
\hline 1 & 43 & $17.80 \pm 1.54$ & $8.65 \%$ & 13.5 & 20 \\
\hdashline 2 & 43 & $18.10 \pm 1.43$ & $7.90 \%$ & 14 & 20 \\
\hline
\end{tabular}

Com relação à comparação dos itens da subescala I entre o T1 e o T2, a diferença encontrada das médias foi -0.302 , o valor $p=0.349$ e o Intervalo de Confiança (IC) $95 \%-0.941$ e 0.337. Dessa forma, não houve diferença estatisticamente significante como apresentado na Tabela 9.

Tabela 9 - Diferença entre as médias, valor p e Intervalo de Confiança (IC) $95 \%$ da comparação entre o T1 e o T2 dos itens da subescala I. Ribeirão Preto, 2009

\begin{tabular}{ccccc}
\hline Comparação & Diferença & p & \multicolumn{2}{c}{ IC 95\% } \\
\hline $1-2$ & -0.302 & $\mathrm{p}=0.349$ & -0.941 & 0.337 \\
\hline
\end{tabular}

Os resultados dos escores de cada um dos cinco itens da subescala I foram analisados mediante a comparação das médias do T1 e do T2. Em relação à acuidade visual (item 1), a diferença da média do escore obtido no T1 em comparação ao T2 foi -0.302 . Para os demais itens, percepção das cores (item 2), temperatura (item 3), sensibilidade plantar dos pés (item 4) e destreza manual (item 5), a diferença entre as médias dos escores obtidos no T2 em comparação ao T1 foi de 0 , ou seja, não houve diferença, conforme Tabela 10.

Tabela 10 - Média \pm desvio padrão (dp) dos escores obtidos no T1 e no T2 da população do estudo $(n=43)$ dos cinco itens da subescala I. Ribeirão Preto, 2009

\begin{tabular}{lc|c}
\multicolumn{1}{c}{ ITEM } & TEMPO 1 & TEMPO 2 \\
\cline { 2 - 3 } & Média (escores) \pm dp \\
\hline 1. Acuidade visual & $2.73 \pm 1.04$ & $3.03 \pm 0.93$ \\
2. Percepção das cores & $4 \pm 0$ & $4 \pm 0$ \\
\hline 3. Temperatura & $4 \pm 0$ & $4 \pm 0$ \\
4. Sensibilidade plantar dos pés & $3.32 \pm 0.78$ & $3.32 \pm 0.78$ \\
\hline 5. Destreza manual & $3.74 \pm 0.58$ & $3.74 \pm 0.58$ \\
\hline
\end{tabular}




\subsubsection{Competência cognitiva da população do estudo antes e após a participação no Programa de Educação em Diabetes do referido}

\section{Centro}

Cabe lembrar que a amplitude da somatória total dos escores possíveis para a subescala II (onze itens) referente à competência cognitiva varia entre 11 (mínimo) a 44 (máximo).

A somatória total dos escores que determinam a competência cognitiva para o autocuidado diagnosticada pela subescala II variou no T1 de 14 (mínimo) a 32 (máximo), com média \pm desvio padrão de $21.35 \pm$ 4.28 e Coeficiente de Variação (CV) $20.05 \%$. No T2, a somatória total dos escores variou entre 25 (mínimo) a 43 (máximo), com média \pm desvio padrão de $33.26 \pm 3.68$ e CV $11.06 \%$, como mostra a Tabela 11.

Tabela 11 - Média \pm desvio padrão, Coeficiente de Variação (CV), valores mínimo e máximo dos escores obtidos da competência cognitiva no T1 e no T2 da população do estudo $(n=43)$. Ribeirão Preto, 2009

\begin{tabular}{cccccc}
\hline Tempo & $\mathbf{n}$ & Média $\pm \mathbf{d p}$ & CV & Mínimo & Máximo \\
\hline 1 & 43 & $21.35 \pm 4.28$ & $20.05 \%$ & 14 & 32 \\
\hdashline 2 & 43 & $33.26 \pm 3.68$ & $11.06 \%$ & 25 & 43 \\
\hline
\end{tabular}

Com relação à comparação dos itens da subescala II entre o T1 e o T2, a diferença entre as médias foi -11.91 , o valor $\mathrm{p}<0.01$ e o Intervalo de Confiança (IC) 95\% -13.62 e -10.19 , mostrando diferença estatisticamente significante, apresentado na Tabela 12.

Tabela 12 - Diferença entre as médias, valor p e Intervalo de Confiança (IC) $95 \%$ da comparação entre o T1 e o T2 dos itens da subescala II. Ribeirão Preto, 2009

\begin{tabular}{ccccc}
\hline Comparação & Diferença & P & \multicolumn{2}{c}{ IC 95\% } \\
\hline $1-2$ & -11.91 & $<0.01$ & -13.62 & -10.19 \\
\hline
\end{tabular}


Das $43(100 \%)$ pessoas entrevistadas, apenas $03(7,0 \%)$ apresentaram escores no intervalo entre 40 a 44 no T2. Ao passo que, no T1, não se encontrou frequência da população do estudo para esse intervalo de escores. Escores situados nesse intervalo são considerados altamente positivos em relação à competência cognitiva para o autocuidado.

Observa-se que $01(2.3 \%)$ e $31(72.0 \%)$ pessoas desse estudo, no T1 e no T2, respectivamente, situaram-se em escores médios, ou seja, escores que situaram no intervalo entre 31 a 39.

Destaca-se ainda que, no T1, $42(97.7 \%)$ pessoas apresentaram escores que variaram de 11 a 30. Em contrapartida, no T2, apenas 09 (21.0\%) pessoas situaram-se em escores para esse intervalo. Escores situados nesse intervalo diagnosticam déficits de competência cognitiva para o autocuidado.

A distribuição numérica e percentual dos escores obtidos inseridos nos quatro intervalos da subescala II da população do estudo no T1 e no T2 pode ser visualizada na Tabela 13.

Tabela 13 - Distribuição numérica $(n)$ e percentual (\%) dos escores obtidos no T1 e no T2 da população do estudo $(n=43)$ dos itens da subescala II. Ribeirão Preto, 2009

\begin{tabular}{ccc|cc}
\hline ESCORES & \multicolumn{2}{c|}{ TEMPO 1 } & \multicolumn{2}{c}{ TEMPO 2 } \\
\cline { 2 - 5 } & $\mathbf{n}$ & $\mathbf{\%}$ & $\mathbf{n}$ & $\mathbf{\%}$ \\
\hline 40 a 44 & 00 & 0.0 & 03 & 7.0 \\
\hline 31 a 39 & 01 & 2.3 & 31 & 72.0 \\
\hline 21 a 30 & 22 & 51.2 & 09 & 0.0 \\
\hline 11 a 20 & 20 & 46.5 & 00 & 100.0 \\
\hline TOTAL & 43 & 100.0 & 43 &
\end{tabular}

Em relação aos resultados dos escores obtidos da subescala II, a competência cognitiva da população do estudo também foi analisada mediante a comparação entre as médias \pm desvio padrão dos escores.

Em relação à capacidade de ler (item 6 ), a diferença entre a média do escore obtido no T1 em comparação ao T2 foi -0.25 . Para as questões 
relacionadas ao conhecimento da doença (item 7), aos métodos de exame (item 8) e aos métodos de tratamento (item 9), a diferença entre as médias dos escores obtidos no T1 em comparação ao T2 foram -1.53, 1.07 e -1.26 , respectivamente.

Para as questões relacionadas à hipoglicemia (itens 10, 11 e 12), encontraram-se as seguintes diferenças entre as médias dos escores obtidos no T2 em comparação ao T1: $-1.44,-1.28$ e -1.44 . Ao analisar os escores obtidos em relação à hipoglicemia (itens 13, 14 e 15), as diferenças encontradas entre as médias dos escores obtidos no T1 em comparação ao T2 foram de $-1.21,-1.38$ e -1.14.

Por fim, com relação à capacidade de atenção e memória (item 16), a diferença entre a média do escore obtido no T1 em comparação ao T2 foi -0.16 .

Destaca-se que em todos os onze itens da subescala II encontraram-se maiores médias dos escores obtidos no T2, em comparação ao T1, conforme Tabela 14. 
Tabela 14 - Média \pm desvio padrão dos escores obtidos no T1 e no T2 da população do estudo $(n=43)$ dos itens da subescala II. Ribeirão Preto, 2009

\begin{tabular}{|c|c|c|}
\hline \multirow[t]{2}{*}{ ITEM } & TEMPO 1 & TEMPO 2 \\
\hline & \multicolumn{2}{|c|}{ Média (escores) $\pm \mathrm{dp}$} \\
\hline 6. Em relação à capacidade de ler & $3.09 \pm 1.06$ & $3.34 \pm 0.97$ \\
\hline $\begin{array}{l}\text { 7. Em relação ao conhecimento do } \\
\text { diabetes }\end{array}$ & $2.02 \pm 0.74$ & $3.55 \pm 0.54$ \\
\hline $\begin{array}{l}\text { 8. Em relação aos métodos de exame } \\
\text { que conhece para identificar e } \\
\text { controlar o diabetes }\end{array}$ & $2.02 \pm 0.64$ & $3.09 \pm 0.52$ \\
\hline $\begin{array}{l}\text { 9. Em relação aos métodos de } \\
\text { tratamento que conhece para } \\
\text { controlar o diabetes }\end{array}$ & $2.39 \pm 0.62$ & $3.65 \pm 0.65$ \\
\hline $\begin{array}{l}\text { 10. Em relação aos sinais que o } \\
\text { diabético pode apresentar se tiver } \\
\text { muito pouco açúcar no corpo }\end{array}$ & $1.72 \pm 0.79$ & $3.16 \pm 0.65$ \\
\hline $\begin{array}{l}\text { 11. Em relação as principais situações } \\
\text { que podem levar o diabético a ter } \\
\text { uma diminuição de açúcar no corpo }\end{array}$ & $1.30 \pm 0.51$ & $2.58 \pm 0.82$ \\
\hline $\begin{array}{l}\text { 12. Em relação aquilo que o diabético } \\
\text { deve fazer quando tiver sinais de } \\
\text { hipoglicemia }\end{array}$ & $1.69 \pm 0.45$ & $3.13 \pm 0.55$ \\
\hline $\begin{array}{l}\text { 13. Em relação as principais situações } \\
\text { que podem levar o diabético a ter } \\
\text { um aumento de açúcar no corpo }\end{array}$ & $1.34 \pm 0.57$ & $2.55 \pm 0.93$ \\
\hline $\begin{array}{l}\text { 14. Em relação aos sinais que o } \\
\text { diabético pode apresentar se tiver } \\
\text { muito açúcar no corpo }\end{array}$ & $1.48 \pm 0.59$ & $2.86 \pm 0.67$ \\
\hline $\begin{array}{l}\text { 15. Em relação aquilo que o diabético } \\
\text { deve fazer quando apresentar sinais } \\
\text { de hiperglicemia }\end{array}$ & $1.32 \pm 0.61$ & $2.46 \pm 0.76$ \\
\hline $\begin{array}{l}\text { 16. Em relação à capacidade de atenção } \\
\text { e memória }\end{array}$ & $2.93 \pm 0.83$ & $3.09 \pm 0.75$ \\
\hline
\end{tabular}

\subsubsection{Competência emocional e motivacional da população do estudo antes e após a participação no Programa de Educação em Diabetes do referido Centro}

Vale lembrar que a amplitude da somatória total dos escores possíveis para a subescala III varia entre 11 (mínimo) a 44 (máximo).

A somatória total dos escores que determinam a competência emocional e motivacional para o autocuidado diagnosticada pela subescala 
III variou nesse estudo no T1 entre 19 (mínimo) a 42 (máximo), com média \pm desvio padrão de $34.51 \pm 4.50$ e Coeficiente de Variação (CV) 13.04\%. No T2, a somatória total dos escores variou entre 29 (mínimo) a 43 (máximo), com média \pm desvio padrão de $37.98 \pm 3.80$ e CV $10.00 \%$ (Tabela 15).

Tabela 15 - Média \pm desvio padrão (dp), Coeficiente de Variação (CV), valores mínimo e máximo dos escores obtidos no T1 e no T2 da população do estudo $(n=43)$ da competência emocional e motivacional. Ribeirão Preto, 2009

\begin{tabular}{cccccc}
\hline Tempo & $\mathbf{n}$ & Média $\pm \mathbf{d p}$ & CV & Mínimo & Máximo \\
\hline 1 & 43 & $34.51 \pm 4.50$ & $13.04 \%$ & 19 & 42 \\
\hdashline 2 & 43 & $37.98 \pm 3.80$ & $10.00 \%$ & 29 & 43 \\
\hline
\end{tabular}

Em relação à comparação dos itens da subescala III entre o T1 e o T2, a diferença encontrada entre as médias foi -3.47 , o valor $p<0.01$ e o intervalo de confiança (IC) $95 \%-5.25$ e -1.68 , havendo diferença estatisticamente significante, como mostra a Tabela 16.

Tabela 16 - Diferença entre as médias, valor p e Intervalo de Confiança (IC) $95 \%$ da comparação entre o T1 e o T2 dos itens da subescala III. Ribeirão Preto, 2009

\begin{tabular}{ccccc}
\hline Comparação & Diferença & $\mathbf{p}$ & \multicolumn{2}{c}{ IC 95\% } \\
\hline $1-2$ & -3.47 & $\mathrm{p}<0.01$ & -5.25 & -1.68 \\
\hline
\end{tabular}

Das $43(100 \%)$ pessoas entrevistadas, $04(9.3 \%)$ e $18(41.9 \%)$ apresentaram escores entre 40 a 44 no $T 1$ no $T 2$, respectivamente. Escores situados nesse intervalo são considerados altamente positivos em relação à competência emocional e motivacional para o autocuidado.

Entretanto, observa-se que as maiores frequências desse estudo situaram-se em escores médios, ou seja, escores que situaram no intervalo entre 31 a 39: 33 (76.8\%) no T1 e 25 (58.1\%) no T2.

Destaca-se ainda que, no T1, apenas 06 (13.9\%) pessoas apresentaram escores que variaram entre 11 a 30 . Tais escores 
diagnosticam déficits de competência emocional e motivacional para o autocuidado. Ao passo que, não foi encontrado frequência para esse intervalo de escores no T2. A distribuição numérica e percentual dos escores obtidos inseridos em quatro intervalos da subescala III da população do estudo no T1 e no T2 pode ser visualizada na Tabela 17.

Tabela 17 - Distribuição numérica $(n)$ e percentual (\%) dos escores obtidos no T1 e no T2 da população do estudo $(n=43)$ dos itens da subescala III. Ribeirão Preto, SP, Brasil, 2009

\begin{tabular}{ccc|cc}
\hline ESCORES & \multicolumn{2}{c|}{ TEMPO 1 } & \multicolumn{2}{c}{ TEMPO 2 } \\
\cline { 2 - 5 } & $\mathbf{n}$ & $\mathbf{\%}$ & $\mathbf{n}$ & $\mathbf{\%}$ \\
\hline 40 a 44 & 04 & 9.3 & 18 & 41.9 \\
\hline 31 a 39 & 33 & 76.8 & 00 & 0.1 \\
\hline 21 a 30 & 05 & 11.6 & 00 & 0.0 \\
\hline 11 a 20 & 01 & 2.3 & 43 & 100.0 \\
\hline TOTAL & 43 & 100.0 & &
\end{tabular}

Quanto aos resultados dos escores obtidos da subescala III, a competência emocional e motivacional da população do estudo também foi analisada mediante a comparação entre as médias \pm desvio padrão dos escores.

Com relação à auto-estima (itens 17, 18 e 19), as diferenças entre as médias dos escores obtidos no T1 em comparação ao T2 foram -0.28, 0.35 e -0.21. Para a auto-valorização (itens 18, 19 e 20), as diferenças entre as médias dos escores obtidos no T1 em comparação ao T2 foram de $-0.35,-0.21$ e -0.45 . Para o controle emocional para fazer julgamentos e controlar o autocuidado (itens $21,22,23,24$ e 25), as diferenças entre as médias dos escores obtidos no T1 em comparação ao T2 foram -0.42, $0.30,-1.14,-0.33$ e -0.32 . Por fim, para a aceitação da situação de ser uma pessoa com diabetes (itens 24, 25, 26 e 27), as diferenças entre as médias dos escores obtidos no T1 em comparação ao T2 foram de -0.33, $0.32,-0.14$ e -0.53 .

Destaca-se que em todos os onze itens da subescala III encontraram-se maiores médias dos escores obtidos no T2, em comparação ao T1, conforme Tabela 18. 
Tabela 18 - Média \pm desvio padrão $(\mathrm{dp})$ dos escores obtidos no T1 e no T2 da população do estudo $(n=43)$ no Programa de Educação em Diabetes dos itens da subescala III. Ribeirão Preto, SP, Brasil, 2009

\begin{tabular}{|c|c|c|}
\hline \multirow[t]{2}{*}{ ITEM } & TEMPO 1 & TEMPO 2 \\
\hline & \multicolumn{2}{|c|}{ Média (escores) $\pm \mathrm{dp}$} \\
\hline \multicolumn{3}{|l|}{ AUTO-ESTIMA } \\
\hline 17. Eu gosto de mim & $3.32 \pm 0.81$ & $3.60 \pm 0.58$ \\
\hline 18. Eu penso primeiro em mim & $2.44 \pm 0.83$ & $2.79 \pm 0.96$ \\
\hline 19. Eu me considero um peso & $3.44 \pm 0.70$ & $3.65 \pm 0.61$ \\
\hline \multicolumn{3}{|l|}{ AUTO-VALORIZAÇÃO } \\
\hline 18. Eu penso primeiro em $\mathrm{mim}$ & $2.44 \pm 0.83$ & $2.79 \pm 0.96$ \\
\hline 19. Eu me considero um peso & $3.44 \pm 0.70$ & $3.65 \pm 0.61$ \\
\hline $\begin{array}{l}\text { 20. Eu me considero incapaz de ajudar } \\
\text { outras pessoas na realização de } \\
\text { alguma coisa }\end{array}$ & $3.13 \pm 0.97$ & $3.58 \pm 0.73$ \\
\hline \multicolumn{3}{|l|}{$\begin{array}{c}\text { CONTROLE EMOCIONAL PARA } \\
\text { FAZER JULGAMENTOS E EXECUTAR } \\
\text { O AUTOCUIDADO }\end{array}$} \\
\hline $\begin{array}{l}\text { 21. Eu faço as coisas que são } \\
\text { necessárias para me manter } \\
\text { saudável }\end{array}$ & $3.06 \pm 0.83$ & $3.48 \pm 0.79$ \\
\hline $\begin{array}{l}\text { 22. Eu tenho vontade de fazer as coisas } \\
\text { que ajudam a controlar o diabetes }\end{array}$ & $3.32 \pm 0.81$ & $3.62 \pm 0.57$ \\
\hline $\begin{array}{l}\text { 23. Eu me interesso em aprender sobre } \\
\text { meu diabetes }\end{array}$ & $3.72 \pm 0.55$ & $3.86 \pm 0.35$ \\
\hline $\begin{array}{l}\text { 24. Eu me preocupo em comer apenas } \\
\text { os alimentos que me mantém } \\
\text { saudável }\end{array}$ & $2.90 \pm 0.93$ & $3.23 \pm 0.81$ \\
\hline $\begin{array}{l}\text { 25. Eu preciso da ajuda de outros para } \\
\text { fazer a minha insulina e/ou } \\
\text { controlar a minha dieta }\end{array}$ & $2.93 \pm 1.21$ & $3.25 \pm 1.00$ \\
\hline \multicolumn{3}{|l|}{$\begin{array}{l}\text { ACEITAÇÃO DA SITUAÇÃO DE SER } \\
\text { UMA PESSOA COM DIABETES }\end{array}$} \\
\hline $\begin{array}{l}\text { 24. Eu me preocupo em comer apenas } \\
\text { os alimentos que me mantém } \\
\text { saudável }\end{array}$ & $290 \pm 0.93$ & $3.23 \pm 0.81$ \\
\hline $\begin{array}{l}\text { 25. Eu preciso da ajuda de outros para } \\
\text { fazer a minha insulina e/ou } \\
\text { controlar a minha dieta }\end{array}$ & $2.93 \pm 1.21$ & $3.25 \pm 1.00$ \\
\hline $\begin{array}{l}\text { 26. Eu considero as recomendações que } \\
\text { me são dadas para conviver com } \\
\text { meu diabetes }\end{array}$ & $3.60 \pm 0.58$ & $3.74 \pm 0.53$ \\
\hline $\begin{array}{l}\text { 27. Eu aceito minha situação de } \\
\text { diabético }\end{array}$ & $2.60 \pm 1.26$ & $3.13 \pm 1.03$ \\
\hline
\end{tabular}




\section{Discussãa}

"Palaura, tenha que escalher a mais banita Para pader dizer caisas da caraçãa Da letra e de quem lê Tada palawra escrita, raliscada" 


\section{DISCUSSÃO}

A discussão dos resultados obedeceu a mesma sequência da apresentação dos resultados, com o propósito de subsidiar a análise realizada mediante as variáveis utilizadas e os objetivos propostos.

\subsection{Caracterização da população do estudo segundo as variáveis sociodemográficas}

As variáveis sociodemográficas qualitativas nominais foram: sexo, procedência, cor/raça, estado civil, ocupação e religião.

Em relação ao sexo, obteve-se que, das 43 (100\%) pessoas entrevistadas, 29 (67.4\%) foram do sexo feminino. Destaca-se que, em vários estudos realizados com pessoas com DM, também foi encontrado em sua caracterização sociodemográfica, uma maior frequência de pessoas do sexo feminino, merecendo um estudo do gênero para comparação (CIECHANOWSKI et al., 2001; DAMASCENO, 2005; FARIA, 2008; GOMES-VILLAS BOAS, 2009; HEISLER et al., 2004; SCHECTMAN; NADKARNI; VOSS, 2002; SILVA, 2009; XAVIER; BITTAR; ATAÍDE, 2009; ZANETTI et al., 2007).

Um estudo randomizado realizado por Duff et al. (2006) em pessoas adultas com diabetes mellitus quanto à avaliação das práticas de autocuidado para o bom controle metabólico do DM, atendidas em uma clínica especialista em diabetes de um hospital universitário da Índia Ocidental, na Jamaica, mostrou o predomínio do sexo feminino em $73.6 \%$ das pessoas investigadas.

Estudo quase-experimental, prospectivo, realizado por Zanetti et al. (2007), no qual se avaliou o impacto de um programa educativo no controle metabólico de pessoas com diabetes mellitus na cidade de 
Ribeirão Preto, São Paulo, obteve, na sua maioria (74.1\%), população feminina.

Esse resultado pode indicar, de maneira geral, que as mulheres buscam mais os serviços de saúde do que os homens e possuem um maior comportamento de busca para o autocuidado. Dessa forma, as mulheres comparecem mais aos serviços de saúde e são mais assíduas aos programas de educação (TRAVASSOS et al., 2002; PÉRES; FRANCO; SANTOS, 2006, 2008).

Tais resultados podem refletir um viés de demanda, uma vez que no estudo de prevalência de diabetes mellitus no Brasil realizado por Malerbi e Franco (1992) mostrou, em seus resultados, a mesma grandeza entre homens e mulheres. Assim como estudos regionais também têm apontado que não há diferença significativa da prevalência de DM em relação ao sexo (TORQUATO et al., 2003).

Ribas et al. (2009) ao investigar as expectativas das mulheres com DM em relação à participação em programa educativo, encontrou cinco categorias de análise: aprendizagem sobre o manejo do diabetes; apoio, ânimo e esperança; superação do temor em relação ao uso da insulina; qualidade de vida; e, compartilhamento e troca de experiências. Essas categorias devem ser valorizadas pelos profissionais de saúde, uma vez que podem constituir um componente que poderá favorecer a adesão às atividades de educação em diabetes.

No que se refere à procedência, a população do estudo foi em quase sua totalidade procedente da cidade de Ribeirão Preto (86.0\%). É válido destacar a relevância que o Centro representa como um importante alvo para o desenvolvimento de pesquisas em diabetes mellitus, com alta predominância da população procedente da cidade de Ribeirão Preto (BECKER; TEIXEIRA; ZANETTI, 2008; FARIA, 2008; OTERO, 2005; RIBAS, 2009; SANTOS et al., 2008; SANTOS, 2009).

Quanto à cor/raça, observou-se que 36 pessoas com diabetes mellitus do estudo declararam-se brancas, o que corresponde a uma frequência de $83.7 \%$. Um estudo multicêntrico do DM e intolerância 
alterada à glicose (ITG) realizado na população urbana brasileira, na faixa etária de 30 à 39 anos, realizado no período de novembro de 1986 à julho de 1988 , encontrou-se que o DM está presente em $7.6 \%$ desta população e $7.8 \%$ apresentavam ITG. As prevalências de DM e ITG em relação à cor da pele foram de $7.5 \%$ e $7.8 \%$, respectivamente, nas pessoas brancas (64\%) e de $7.1 \%$ e $7.6 \%$ em pessoas de outros grupos raciais, denominadas não brancas (MARLEBI; FRANCO, 1992).

Em contrapartida, estudos internacionais mostraram que a prevalência de DM2 e ITG é maior entre pessoas negras do que em pessoas de cor branca (KING; REWERS, 1993; LIPTON et al., 1993; OSEI; SCHUSTER, 1995; RESNICK et al., 1998; WINKLEBY et al., 1998).

Da mesma forma, um estudo realizado por Brito, Lopes e Araújo (2001) analisou 480 mulheres de um ambulatório de obesidade de um hospital universitário da cidade de Salvador/BA, objetivando avaliar a alta prevalência da cor da pele negra em mulheres com DM2 e ITG, e foi encontrado que as mulheres obesas com pele escura tiveram maior associação com DM2 (13.3\%) e ITG (18.8\%), quando comparadas com as de pele clara associadas com DM2 (7.2\%) e ITG (12.7\%). O estudo também concluiu que ainda não estão bem estabelecidas as razões dessas diferenças raciais.

Tratando de estado civil, constatou-se que a maioria (65.2\%) da população do estudo era casada. Esse resultado está em concordância com a literatura, segundo a qual a prevalência de pessoas com DM casadas foi de $57 \%$ e $68 \%$, em estudo realizado por Grant et al. (2003) e Ciechanowski et al. (2001), respectivamente.

A importância do estado civil revelou-se no estudo realizado por Dever $^{1}$ (1988 apud GUIMARÃES; TAKAYANAGUI, 2002), o qual verificou que o coeficiente de morbidade e mortalidade foi mais elevado entre os viúvos, os divorciados e os solteiros e mais baixo entre os casados.

\footnotetext{
${ }^{1}$ DEVER, D. E. A. Epidemiologia: enfocando a prevenção. In: serviços de saúde. São Paulo: Pioneira, 1988. cap. 1.
} A epidemiologia na administração dos 
Armour et al. (2005) destacam que um ambiente familiar desfavorável pode interferir na adesão da pessoa ao tratamento. È importante destacar que famílias organizadas e estruturadas fornecem um ambiente mais apropriado como apoio ao cuidado da pessoa com DM, influenciando o comportamento desta diante da sua colaboração para a obtenção de um bom controle metabólico (ZANETTI et al., 2008).

Com relação à ocupação, predominaram-se $46,5 \%$ de pessoas aposentadas e $30.2 \%$ do lar, ou seja, $76.7 \%$ da população do estudo não exercem atividades remuneradas. Esse resultado deve ser levado em consideração, uma vez que a pessoa que se mantém ativa remuneradamente poderá obter maior satisfação pessoal, interação social, favorecimento na saúde física e mental, o que pode contribuir para a redução do estresse e depressão (KINDER et al., 2002).

Um estudo que buscou determinar os diferenciais de saúde dos idosos, segundo sua inserção no mercado de trabalho, após considerar a influência dos fatores sociodemográficos, mostrou que $25 \%$ dos idosos eram ativos no trabalho em relação aos aposentados. Aqueles que trabalhavam, sentiam-se mais dispostos, tinham maior escolaridade e maior renda domiciliar. Estes relataram menor prevalência de doenças crônicas (GIATTI; BARRETO, 2003).

No que se refere à religião da população do estudo, encontrou-se que $26(60.5 \%)$ pessoas eram católicas, 08 (18.6\%) eram evangélicas, 01 (2.3\%) espírita e 08 (18.6\%) não tinham religião. Em uma pesquisa qualitativa, com o objetivo de descrever as manifestações de religiosidade e espiritualidade de quatro famílias de pessoas com doenças crônicas revelou que a religião e a espiritualidade são recursos importantes para os familiares no enfrentamento da doença crônica. O estudo ainda destacou a importância de compreender a religião e a espiritualidade da família no processo de adoecimento (PAULA; NASCIMENTO; ROCHA, 2009).

As variáveis sociodemográficas qualitativas ordinais foram: número de pessoas no domicílio, nível de escolaridade e renda familiar. 
Quanto ao número de pessoas que moram no domicílio junto com a pessoa entrevistada, encontrou-se que 18 (41.9\%) viviam com até 2 pessoas e 17 (39.5\%) viviam com 3 a 5 pessoas. No estudo realizado por Zanetti et al. (2008) revelou que a ampliação do aprendizado pode favorecer a aquisição de hábitos saudáveis entre os membros da família. Dessa forma, compreende-se que o processo de educação em diabetes deve estar centrado nos profissionais da equipe multiprofissional, no sistema familiar, na própria pessoa e nos equipamentos sociais. Quando há essa rede de apoio, a pessoa alcança uma maior efetividade no processo educativo.

O mesmo estudo destacou que o DM provoca mudanças nos hábitos de vida das pessoas e dos seus familiares, exercendo influência na motivação e na capacidade da pessoa lidar com a doença. Portanto, atividades em grupo de apoio educativo têm o papel fundamental de esclarecer e educar a pessoa, podendo-se pensar também na necessidade de intervenções que estendam esse apoio à família, capacitando-os a funcionarem como aliados ao tratamento (ZANETTI et al., 2008).

Com relação ao nível de escolaridade, 42 (97.7\%) das pessoas entrevistadas são alfabetizadas, onde $11(25.6 \%)$ pessoas tinham até o primeiro grau incompleto, $08(18,6 \%)$ o segundo grau incompleto e 08 (18.6\%) o segundo grau completo. Os dados revelam que o estudo foi realizado com uma população diferenciada quanto à escolaridade ao comparar com outros estudos (GUEDES, 2007; ROSSI, 2005).

O desenvolvimento do diabetes mellitus independe do nível de escolaridade, podendo acometer pessoas de todos os níveis socioeconômicos, porém a baixa escolaridade poderá levar a pessoa a não incorporação dos comportamentos de autocuidado devido à falta de acesso às informações para o bom controle metabólico. Reconhece-se, portanto, que a escolaridade é um fator que deve ser considerado na proposição de programas educativos. Estudos mostram que a baixa escolaridade pode dificultar o acesso às informações e, dessa forma, prejudicar o desempenho do autocuidado de forma segura (ALVES, 2005; 
DELAMATER, 2006; PAIVA; BERSUSA; ESCUDER, 2006). Outros estudos confirmaram que pessoas com maior nível educacional aderem mais ao tratamento e apresentam melhor controle metabólico (DELAMATER, 2006; PEYROT et al., 2005).

Quanto a renda familiar, $19(44.1 \%)$ pessoas possuíam entre 3 a 4 salários mínimos e 11 (25.6\%) entre 1 a 2 . Um estudo de caracterização do perfil de 204 pessoas com hipertensão arterial cadastradas no Grupo de Hipertensão do Ambulatório do Hospital de Base de São José do Rio Preto, objetivando implantar um programa de educação a essa população, encontrou que $82.8 \%$ das pessoas entrevistadas apresentaram renda familiar inferior a 4 salários mínimos, representando um baixo nível sócio-econômico (CESARINO et al., 2004).

Os resultados de um estudo realizado com uma população idosa da cidade de Fortaleza/CE demonstraram que os idosos que viviam em piores condições materiais apresentaram maiores prevalências de doenças crônicas, maiores dependências, piores condições mentais e dificuldade de acesso aos serviços de saúde, do que aqueles em melhores níveis socioeconômicos, que apresentaram maiores necessidades sociais e maior morbidade física e mental (COELHO FILHO; RAMOS, 1999).

A idade foi classificada nesse estudo como uma variável sociodemográfica quantitativa discreta, onde a menor das idades foi 36 anos e a maior 79, predominando $14(32.6 \%)$ pessoas na faixa etária entre 60 a 69 anos. Segundo um estudo multicêntrico de prevalência do diabetes mellitus no Brasil realizado por Malerbi e Franco (1992), constatou-se que a frequência do DM aumenta gradativamente após 50 anos. Estudos mencionam que a frequência de pessoas com DM torna-se cada vez maior na faixa etária de 60 a 69 anos (HERAS; MACIAS, 1996; ZARATE, 1995). Rico e Arriaga (1995) apontam que a prevalência de diabetes mellitus aumenta progressivamente com a idade, sendo o diagnóstico, na maioria das vezes, estabelecido após os 60 anos.

A média de idade encontrada nesse estudo, $60.9 \pm 11.8$, com mediana de 63 anos, deve-se ao processo de transição epidemiológica que 
está atravessando no Brasil. De 1900 a 2025, a população brasileira terá sido multiplicada por 5 e pessoas com mais de 60 anos de idade terá o seu número multiplicado por 15 , onde, um em cada sete brasileiros fará parte do contingente idoso da população, com uma expectativa de vida ao nascer de aproximadamente 73 anos (RAMOS et al., 1987). Essa impressionante e rápida mudança no perfil populacional, por outro lado, coloca as pessoas a uma maior exposição aos fatores de risco que contribuem para o aumento no desenvolvimento de doenças crônicas, dentre elas o diabetes mellitus (RAMOS et al., 1987; ROMEROBAQUEDANO, 2008; ZAGO, 2004).

É importante destacar que, a alta expectativa de vida da população brasileira leva ao aumento da população de pessoas idosas, que incorporam em seu cotidiano, crenças, costumes e valores que podem dificultar bom o controle metabólico em pessoas com DM. No entanto, a adoção de mudanças no estilo de vida torna-se uma tarefa difícil. Dessa forma, observa-se o quanto é válido manter a pessoa com diabetes mellitus atento à importância da adesão ao tratamento e do autocuidado, pois são considerados aspectos essenciais da educação em saúde e merecem ser refletidos profundamente (ATAÍDE, 2004; XAVIER; BITTAR; ATAÍDE, 2009).

Dessa forma, acredita-se que a necessidade de conhecer a caracterização sociodemográfica de pessoas com diabetes mellitus no início do Programa de Educação é um dos elementos essenciais em atividades educativas em grupo (OTERO, 2008). Logo, permite a equipe mutiprofissional traçar as adequadas estratégias de ensino para 0 autocuidado. 


\subsection{Caracterização da população do estudo segundo as variáveis clínicas e relacionadas ao tratamento do diabetes mellitus}

As variáveis clínicas e relacionadas ao tratamento do diabetes mellitus qualitativas nominais foram: tipo de DM, hábito de fumar, ingestão de bebida alcoólica, acompanhamento médico, dieta, atividade física, tratamento medicamentoso (DM), complicações crônicas (DM) e comorbidades.

Em relação ao tipo de DM, $42(97.7 \%)$ têm diabetes mellitus tipo 2 (DM2), sendo apenas 01 (2.3\%) com diabetes mellitus tipo 1 (DM1). Esses dados estão de acordo com a Sociedade Brasileira de Diabetes (2009), que aponta que o DM1 está presente em 5 a 10\% dos casos e o DM2, em 90 a 95\%. Também condizem com o estudo realizado por Ciechanowski et al. (2001), no qual se obteve uma prevalência de DM1 e DM2 de 3,8\% e $96,2 \%$, respectivamente.

Com relação ao hábito de fumar, 34 (79.0\%) pessoas declararam que não fumam e 09 (21.0\%) pararam de fumar, declarando o tempo (anos) que parou de fumar e a quantidade de cigarros/dia que fumava, com médias de 14.3 anos e 5.5 cigarros/dia. É válido ressaltar que não houve pessoas que declararam atualmente que fumam. Quanto à ingestão de bebida alcoólica, $38(88.3 \%)$ pessoas declararam que não ingerem. Dessa forma, as $05(11.7 \%)$ pessoas que declararam que ingerem bebida alcoólica informaram a frequência da ingestão (dias/semana), com média de 3,8.

O tabagismo e o alcoolismo são hábitos de rotina diária que podem afetar a saúde (DEAN, 1989). Dessa forma, os padrões de autocuidado são estabelecidos a partir de condutas repetidas em diversas circunstâncias que a pessoa enfrenta no dia a dia e são influenciados pelo próprio sistema de valores, de outras pessoas e pelos eventos sociais, políticos e econômicos que caracterizam o estilo de vida. 
O hábito de fumar é promotor da progressão da nefropatia diabética, seja em pessoas com DM1 ou com DM2 (BIESENBACH et al., 1997). A cessação do tabagismo é fundamental em pessoas com DM, quando o tabagismo reduz a sensibilidade à insulina e piora a albuminúria (VAN DAM et al., 2002).

Em estudo recente realizado no Kaiser Permanente Northern Califórnia analisando a adesão ao autocuidado em pessoas com diabetes, o consumo de álcool foi relatado por $50,8 \%$ dos adultos. Esse estudo concluiu que o consumo de álcool é um marcador de baixa adesão ao autocuidado em diabetes (AHMED; KARTER; LIU, 2006). Os autores apontam que ao se utilizar o auto-relato do consumo de álcool podem-se obter dados subnotificados.

Contudo, apesar dos dados mostrarem que a maioria não ingere bebida alcoólica, percebe-se que durante o programa educativo, as pessoas com DM relatam maior ingestão de álcool do que no início do Programa. Em geral, acredita-se que conforme o vínculo e maior relacionamento com a equipe multiprofissional, as pessoas relatam informações diferentes daquelas obtidas no início do Programa.

Dessa forma, o hábito de fumar e a ingestão de bebida alcoólica podem ser influenciados por programas de educação em saúde, manifestados pela aquisição de um comportamento positivo em pessoas com DM para mudanças essenciais nesses fatores modificáveis (GAMBA et al., 2004).

Em relação à realização de acompanhamento médico, encontrou-se no estudo que 31 (72\%) pessoas realizam na rede pública, enquanto que $03(7.0 \%)$ e 09 (21.0\%) pessoas realizam acompanhamento médico de forma particular e em plano de saúde, respectivamente. Estudo descritivo e transversal realizado em um programa educativo de um Centro de Pesquisa e Extensão Universitária do interior paulista com 46 pessoas com DM1 e DM2 encontrou que mais de $50 \%$ da população do estudo realizava acompanhamento médico na rede pública (FARIA, 2008). 
No Brasil, apesar das várias experiências municipais bem sucedidas de acompanhamento dos casos de pessoas com DM, observa-se, em grande parte do país, a falta de vínculos entre as pessoas e as unidades de saúde. Em regra geral, o atendimento às pessoas ocorre nos serviços de emergência, não propiciando a identificação de lesões em órgãos-alvo do DM, como também o não estabelecimento de um programa de tratamento e acompanhamento adequado (BARBOSA; BARCELÓ; MACHADO, 2001).

No que se refere ao seguimento de uma dieta alimentar e na realização de atividade física, $22(51.2 \%)$ pessoas informaram que não seguem dieta e $31(72.0 \%)$ declararam que não realizam atividade física regularmente.

Os resultados obtidos com relação à predominância do não seguimento da dieta e da não realização de atividade física regular condizem com o estudo realizado por Gomes-Villas Boas (2009), onde a média total da variável relacionada à adesão ao autocuidado em pessoas com DM foi de 4.34, mostrando baixa adesão às recomendações de dieta e atividade física, em uma escala pontuada de 0 a 8 , onde os escores maiores ou iguais a 5 indicam adesão. Um estudo realizado por Torres (2004), objetivando avaliar o efeito de um programa educativo na adesão ao autocuidado (dieta e atividade física) em 129 pessoas adultas brasileiras com DM2, encontrou uma média de 4.42 para o grupo experimental e 4.32 para o grupo controle, indicando baixa adesão a esses aspectos do tratamento.

O seguimento da dieta está relacionado ao grau de satisfação e motivação da pessoa com diabetes mellitus. Assim, é necessária a utilização da educação em saúde por meio de metodologias ativas que possibilitam a participação e envolvimento da pessoa com DM. O seguimento da dieta deve levar a pessoa com DM a uma melhor condição clínica (PADILLA; ARÁUZ; ROSELLÓ, 1997).

É preciso também considerar as dificuldades das pessoas para a adesão regular à prática de atividade física, considerando a idade, a 
presença de outras co-morbidades, outros problemas de saúde e a falta de tempo merecem ser investigados, pois esses fatores constituem alguns dos motivos referidos por pessoas com DM para a não adesão regular da atividade física (MARTINEZ; MORENO, 2006; ZANETTI et al., 2007).

Os resultados do presente estudo estão em discordância com as recomendações da Sociedade Brasileira de Diabetes (2009), quando recomendam o seguimento da dieta e a prática regular da atividade física associados a mudanças no estilo de vida para a obtenção de um controle glicêmico e metabólico adequado. Essas recomendações têm como objetivo melhorar a sensibilidade à insulina, diminuir os níveis plasmáticos de glicose, reduzir a circunferência abdominal e a gordura visceral, o que melhora o perfil lipídico, reduzir risco cardiovascular e, por fim, melhorar a auto-estima da pessoa com DM.

Das $38(88.3 \%)$ pessoas entrevistadas no presente estudo que fazem uso de tratamento medicamentoso para o DM, 33 (76.7\%) utilizam somente antidiabético oral, sendo 17 (39.5\%) biguanidas + sulfoniluréias e 14 (32.6\%) apenas biguanidas; 4 (9.3\%) pessoas utilizam a associação de antidiabético oral + insulina; e apenas 1 (2.3\%) pessoa utiliza somente insulina.

O estudo de Ciechanowski et al. (2001) mostrou que 52,6\% das pessoas com DM realizavam o tratamento somente com antidiabético oral, $19,1 \%$ somente com insulina, seguido por $11,7 \%$ com antidiabético oral associado à insulina. Já no estudo de Guedes (2007), a porcentagem de pessoas com diabetes mellitus que faziam uso somente de antidiabético oral e antidiabético oral associado à insulina foi de $30,9 \%$ e $11,8 \%$, respectivamente. Faria (2008) encontrou em seu estudo que $26,1 \%$ realizam o tratamento somente com antidiabético oral, $17,4 \% \mathrm{com}$ antidiabético oral associado à insulina e apenas $8,7 \%$ somente com insulina. Esses dados assemelham-se aos obtidos no presente estudo em relação à utilização somente de antidiabéticos orais ou também associados à insulina. 
Quanto às co-morbidades mais prevalentes encontradas na população investigada, obteve-se que as mais prevalentes foram: hipertensão arterial (76.8\%) e dislipidemia (32.6\%). Tal resultado apresentou concordância com os estudos realizados por Faria (2008), Gomes-Villas Boas (2009), Grant et al. (2003) e Otero (2005).

A hipertensão arterial e o diabetes mellitus são condições clínicas frequentemente associadas. No DM1, verifica-se a relação entre hipertensão arterial e desenvolvimento de nefropatia diabética, onde a pressão arterial começa a se elevar cerca de três anos após o início da microalbuminúria. No DM2, cerca de $40 \%$ das pessoas já se encontram hipertensos na ocasião do diagnóstico (SBD, 2009).

A associação entre o DM e a hipertensão arterial é de $50 \%$. Tal associação está relacionada à resistência insulínica, resistência vascular aumentada e disfunção endotelial. Os fatores de risco para o desenvolvimento das doenças, a cronicidade, a necessidade de acompanhamento por uma equipe multidisciplinar e de modificações no estilo de vida e a dificuldade de adesão ao tratamento são aspectos comuns ao diabetes mellitus e à hipertensão arterial (BRASIL, 2002).

Destaca-se que $75 \%$ das mortes em pessoas com DM2 são causadas por problemas cardiovasculares, relacionados a uma série de fatores, dos quais a dislipidemia é o mais importante. O perfil lipídico nessas pessoas consiste em hipertrigliceridemia e baixo HDL (SBD, 2009).

Outros fatores que predispõem a hipertensão arterial, a dislipidemia, o desenvolvimento do DM e, consequentemente, problemas cardiovasculares são a obesidade e o sobrepeso. Estima-se que $80 \%$ das pessoas com DM2 apresentam obesidade ou excesso de peso (SBD, 2009). Portanto, o controle adequado do peso corporal, da hipertensão arterial e da dislipidemia em associação ao controle glicêmico e metabólico é de suma importância para a pessoa com diabetes mellitus.

No presente estudo, com relação às complicações crônicas, $23.3 \%$ da população do estudo tinham retinopatia diabética, seguida de $11.7 \%$ com neuropatia. Estudo realizado por Ciechanowiski et al. (2001) 
obteve uma prevalência de $50,7 \%$ em pessoas com pelo menos uma complicação decorrente do DM. A presença de retinopatia diabética associada ao DM também foi encontrada como a complicação crônica mais prevalente nas pessoas investigadas nos estudo de Faria (2008), 17.4\%, e Guedes (2007), 21.1\%.

O Ministério da Saúde assegura a presença da retinopatia diabética como um marcador precoce do início das complicações microvasculares e do risco de comprometimento renal do DM; e a neuropatia é como a complicação mais comum, compreendendo um conjunto de síndromes clínicas que afetam o sistema nervoso (BRASIL, 2006).

Segundo o estudo UKPDS (1998), a obtenção de um bom controle glicêmico está relacionada a menores taxas de morbidade e mortalidade referentes ao DM e à redução do aparecimento de algumas complicações crônicas microvasculares: retinopatia, neuropatia e nefropatia diabética.

Cabe ressaltar que tanto as co-morbidades como as complicações decorrentes do DM foram referidas pela população do estudo, sem confirmação no prontuário da pessoa entrevistada, o que poderá constituir um dado sub ou super estimado.

Frente ao exposto, reconhece-se que a educação em saúde para o autocuidado no controle do DM é fundamental para a melhora do nível glicêmico, uma vez que os resultados mostram que as pessoas do presente estudo já apresentam co-morbidades associadas, tais como a hipertensão arterial e dislipidemia. Assim, a abordagem da equipe multiprofissional de saúde em um programa de educação em diabetes deve contemplar conteúdos que englobam não só o diabetes mellitus, como também a associação de outras morbidades.

O tempo de diagnóstico de DM foi classificado nesse estudo como uma variável clínica e relacionada ao tratamento do diabetes mellitus quantitativa discreta. Encontrou-se que o menor tempo foi de 1 ano e o maior $32(8.4 \pm 6.9)$, com mediana de 6 anos, predominaram-se $46.5 \%$ com tempo de diagnóstico $\leq 5$ anos, seguido de $30.2 \%$ com tempo de diagnóstico entre 11 a 20 anos. 
Estudos têm demonstrado que, no momento do diagnóstico de DM2, as pessoas já apresentam algum tipo de complicação (MALERBI, 1991; TORQUATO et al., 2003). Ao considerar a predominância da população desse estudo com DM2 (97.7\%), é importante ressaltar a dificuldade em se determinar, com exatidão, a duração do tempo do DM2 pelo período assintomático anterior ao diagnóstico. Tal fato justifica-se pela concentração glicêmica não ser suficientemente elevada para o aparecimento dos sintomas clássicos, aumentando o risco para o desenvolvimento de complicações agudas e crônicas (ADA, 2004; NAZIMEK-SIEWNIAK; MOCZULSKI; GRZESZCZAK, 2000).

É possível que as pessoas com diabetes mellitus, durante os anos do longo período da doença, tenham recebido algum tipo de informação positiva relacionada à patogenia. No entanto, fatores responsáveis pelo processo de aquisição dessas informações podem ter limitado/impedido sua incorporação. Nesse sentido, fatores socioeconômicos e culturais constituem elementos que facilitam ou dificultam para a aquisição de atividades de autocuidado, aos quais estão associados também aos aspectos pessoais e o acesso aos serviços de saúde (PACE et al., 2006).

\subsection{Comparação dos valores obtidos em relação às variáveis} pressão arterial, glicemia capilar pós-prandial, circunferência abdominal, peso e IMC antes e após o oferecimento das atividades educativas

As variáveis quantitativas contínuas consideradas nesse estudo foram: Pressão Arterial Sistólica (PAS), Pressão Arterial Diastólica (PAD), glicemia capilar pós-prandial, Circunferência Abdominal (CA), peso e Índice de Massa Corporal (IMC).

Em relação à PAS e PAD, encontraram-se representações de menores médias da população do estudo no T2 em comparação ao T1, 
com diferenças de -6.62 e -5.27 , respectivamente. Além disso, observaram-se resultados estatisticamente significantes $(p<0.05)$ na PAS com $p=0.03$ e na PAD com $p=0.01$.

A Sociedade Brasileira de Diabetes (2009) considera o valor da PAS normal $<130 \mathrm{mmHg}$ e alterado $\geq 130 \mathrm{mmHg}$ e o da PAD normal $<80$ $\mathrm{mmHg}$ e alterado $\geq 80 \mathrm{mmHg}$.

Estudo aleatório mostrou que um incremento de $10 \mathrm{mmHg}$ na PAS em pessoas com DM2 pode elevar o risco de apresentar uma enfermidade coronariana em até $2 \%$ (SBD, 2009). É importante destacar que a hipertensão arterial é uma co-morbidade da síndrome metabólica e pode aparecer antes do diagnóstico do DM. A coexistência dessas duas condições crônicas multiplica de forma exponencial o risco de morbimortalidade por problemas relacionados com a macroangiopatia e a microangiopatia (WHO, 2002).

Estudos demonstraram que os benefícios da redução de fatores de risco para doenças cardiovasculares são significativos também em pessoas com diabetes mellitus. Ensaios clínicos controlados demonstraram a efetividade do controle intensivo da hipertensão arterial na redução de complicações em pessoas com DM e hipertensão arterial (UKPDS, 1998; ESTACIO et al., 2000; SCHRIER et al., 2002). Estudo prospectivo demonstrou que o nível ótimo de controle da pressão arterial em pessoas com DM com hipertensão arterial é menor do que em pessoas com hipertensão sem diabetes mellitus (HANSSON et al., 1998).

Programas educativos eficazes de prevenção e controle do diabetes mellitus relacionados às mudanças no estilo de vida, incluindo modificações na dieta e combate ao sedentarismo, têm sido apontados como importantíssimos na prevenção e controle do DM e da hipertensão arterial (TOSCANO, 2004).

Quanto à glicemia capilar pós-prandial, apesar dos resultados não terem revelado diferenças estatisticamente significantes, quando o $p=1.27$, encontrou-se menor média no $T 2$ em comparação ao $T 1$, com diferença de -24.48 . 
Utilizou-se como parâmetro glicêmico de normalidade para a glicemia capilar pós-prandial (duas horas após o consumo do último alimento): valores < $140 \mathrm{mg} \backslash \mathrm{dL}$ (SBD, 2009).

Um adequado controle da glicemia capilar (jejum e pós-prandial) reduz a mortalidade por enfermidade cardiovascular e vascular periférica em 54\%. UKPDS (1998) demonstrou de forma inequívoca que a redução da glicemia a valores próximos a normalidade reduz em $16 \%$ o infarto do miocárdio e $12 \%$ as complicações relacionadas ao DM.

Apesar dos resultados da população do presente estudo não terem alcançado os parâmetros glicêmicos de normalidade. Observa-se que no T2 houve diminuição da média, devendo-se ser clinicamente valorizado.

Destaca-se a falta da avaliação dos parâmetros da hemoglobina glicosilada na população do estudo, pois, atualmente, a fração de hemoglobina glicosilada é considerada o padrão ouro para o controle do glicêmico e metabólico do DM, conforme apresentado por dois estudos de impacto para o DM: o Diabetes Control and Complications Trial (DCCT), 1993 e o UK Prospective Diabetes Study (UKPDS), 1998.

Esse fato causou-nos preocupação, pois, segundo a Sociedade Brasileira de Diabetes (2009), a hemoglobina glicosilada reflete a glicemia média de uma pessoa durante os dois a três meses anteriores à data de realização do exame. Assim, é de grande utilidade na avaliação do nível de controle glicêmico e da eficácia do tratamento vigente. Portanto, deve ser solicitada rotineiramente, duas vezes ao ano para todas as pessoas com DM e quatro vezes para aquelas que se submeteram a alterações no esquema terapêutico ou encontra-se em mau controle glicêmico.

Para a CA, encontrou-se que os resultados também não revelaram diferenças estatisticamente significantes, quando o $p=0.51$, e uma média de fraca magnitude no $\mathrm{T} 2$ em comparação ao $\mathrm{T} 1$, com diferença de -1.57 .

IDF (2006) utiliza como ponto de corte para a CA em adultos de 94 $\mathrm{cm}$ para homens e $80 \mathrm{~cm}$ para mulheres, a média dos valores da CA no T2 foi de $100.5 \mathrm{~cm}$, com desvio padrão de 11.59 . 
Observou-se que a média dos valores $100.5 \mathrm{~cm}$ encontrada no T2 está muito distante do ponto de corte normal e não foi realizada a análise por sexo.

Em relação ao peso e ao IMC, observou-se que os resultados também não foram estatisticamente significantes, no peso com $p=0.66 \mathrm{e}$ no IMC com $p=0.55$, apesar de médias menores da população do estudo no T2 em comparação ao T1, com diferenças de -1.57 e -0.72, respectivamente.

Ao considerar-se sobrepeso quando o valor do IMC apresenta-se entre 25 e $30 \mathrm{~kg} / \mathrm{m}^{2}$, e, obesidade quando o valor do IMC apresenta-se maior que $30 \mathrm{~kg} / \mathrm{m}^{2}$ (SBH, 2006), a média \pm desvio padrão dos valores do IMC no T2 foi de $29.4 \mathrm{~kg} / \mathrm{m}^{2} \pm 5.66$ (sobrepeso), em comparação no T1 com $30.2 \pm 5.57$ (obesidade).

Dessa forma, apesar dos valores não terem alcançado O IMC normal, destaca-se que no decorrer do Programa Educativo destaca-se o esforço da maioria das pessoas do estudo em alcançá-lo. Além disso, o curto período de tempo (quatro meses) pode ter sido um ponto importante para o não alcance de melhores padrões de normalidade.

O predomínio de gordura visceral tem relação estreita com o IMC. Geralmente, a maioria das pessoas com obesidade (IMC $\geq 30 \mathrm{~kg} / \mathrm{m}^{2}$ ), também apresenta excesso de gordura abdominal, e consequentemente obesidade abdominal (SBD, 2009).

O Comitê de Especialistas de Diagnóstico e Classificação do Diabetes Mellitus (1997) aponta que a obesidade é um fator de risco que tem gerado preocupação para as instituições de saúde, profissionais, famílias e pessoas com DM2, pois $85 \%$ têm algum grau de sobrepeso ou obesidade. Essa preocupação está respaldada em evidências científicas que indicam que a perda de 5 a $7 \%$ de peso corporal contribuem para redução dos valores da glicemia plasmática. 


\subsection{Comparação da competência de pessoas com diabetes mellitus para o autocuidado antes e após o oferecimento das atividades educativas}

Segue-se a discussão das competências física, cognitiva, emocional e motivacional para o autocuidado, nos Tempos 1 (T1) e 2 (T2).

\subsubsection{Competência física da população do estudo antes e após a participação no Programa de Educação em Diabetes do referido Centro}

A diferença encontrada entre as médias do T2 em comparação ao T1 foi -0.302 , com $p$ valor 0.349 .

Destaca-se que não houve diferença estatisticamente significante no resultado da comparação do presente estudo, porém a importância da competência física da pessoa com diabetes mellitus para o autocuidado não deve ser despercebida, devendo-se fornecer subsídios relevantes para o desenho de futuros estudos.

Estudo exploratório com objetivo de examinar a competência para o autocuidado em pessoas com diabetes mellitus em relação ao sexo, utilizando a ECDAC, evidenciou-se a porcentagem de $96,87 \%$ para competência física no sexo feminino e $96.30 \%$ no sexo masculino (PETERS et al., 2004).

No presente estudo, a somatória total dos escores que determinam a competência física para o autocuidado diagnosticados pela subescala I variaram nesse estudo no T1 entre 13.5 (mínimo) a 20 (máximo), com média \pm desvio padrão de $17.80 \pm 1.54$. No T2, a somatória total dos escores variaram entre 14 (mínimo) a 20 (máximo), com média \pm desvio padrão de $18.10 \pm 1.43$. 
Os resultados do presente estudo estão em conformidade com Nunes (1982), que desenvolveu um estudo metodológico para identificar a competência física de 81 pessoas estudadas, encontrando média \pm desvio padrão de $17.85 \pm 2.48$ dos escores obtidos, com variação da amplitude dos escores de 10 a 20.

O diagnóstico da doença crônica usualmente constitui uma situação de estresse para a própria pessoa. Sabe-se que essas exigências para o tratamento do diabetes mellitus como doença crônica são percebidas inicialmente como metas impossíveis, em função da possibilidade de perdas, incluindo integridade física, da liberdade, da autonomia e da qualidade de vida (LACROIX; ASSAL, 2003; FLEURY, 2007). Destaca-se a importância de incrementar estudos acerca dos benefícios de atividades educativas em diabetes relacionados à competência física de pessoas com DM para o autocuidado.

Com relação à acuidade visual, a diferença entre a média do escore obtido no T1 em comparação ao T2 foi -0.302. Para percepção das cores, temperatura, sensibilidade plantar dos pés e destreza manual, não houve diferença entre as médias dos escores obtidos no T2 em comparação ao T1.

Ao iniciar a prática de insulinoterapia, a pessoa com DM deverá ser avaliada pelo médico, pela enfermeira ou por educadores em diabetes. Esta avaliação torna-se fundamental para assegurar a ausência de infecção nos locais de aplicação de insulina e determinar se a pessoa apresenta competência para realizar a prática de aplicação de insulina com segurança. Tal prática exige acuidade visual adequada, destreza manual e ausência de tremor (COSTA; ALMEIDA NETO, 2004; AMERICAN DIABETES ASSOCIATION (ADA), 1999).

A educação em diabetes é considerada como alicerce para a construção do autocuidado consciente, prevenção do surgimento de complicações e, principalmente, para a melhoria da qualidade de vida (SBD, 2009). 
Para a obtenção de um bom controle metabólico, educação em diabetes é um processo muito importante, sendo assim considerado o processo de promover ao indivíduo o conhecimento, a habilidade e a técnica necessária para o autocuidado, o manejo das crises e a facilidade de realizar adaptações eventualmente necessárias em seu estilo de vida visando a prevenção de complicações crônicas e, acima de tudo, à melhora na qualidade de vida (HOEY et al., 2001; SWIFT, 2007;).

A educação em saúde para pessoas com DM deve ser realizada de forma contínua, sendo a melhora do controle glicêmico e da saúde da pessoa a meta constante da prática clínica, desde o primeiro contato. Muitas pessoas irão vivenciar mudanças físicas ao longo da vida, por exemplo, diminuição da acuidade visual ou da destreza manual e da mobilidade, demandando novas adaptações e aprendizados, com reinvenção do autocuidado, sendo necessárias avaliações frequentes, contínuas e individualizadas (AMERICAN ASSOCIATION OF DIABETES EDUCATORS (AADE), 2002).

\subsubsection{Competência cognitiva da população do estudo antes e após a participação no Programa de Educação em Diabetes do referido} Centro

Os resultados sugerem que nos onze itens da competência cognitiva para o autocuidado encontraram-se maiores médias dos escores obtidos no T2, em comparação ao T1. Esses resultados estão consistentes com o estudo de Mickus e Quaile (1997) que reportou que um programa educativo sobre diabetes mellitus foi 0 fator que contribuiu para 0 aprimoramento dos conhecimentos em DM e aquisição de habilidades de autocuidado.

A diferença encontrada entre as médias foi -11.91 , com $p$ valor $<0.01$. Destaca-se que houve diferença estatisticamente significante. 
Estudo quase-experimental que analisou o conhecimento em questões relacionadas ao diabetes após 12 meses de oferecimento de um Programa de Educação em Diabetes. Observou-se que houve aumento desse conhecimento, sendo considerado estatisticamente significante $(p<0.05)$ (OTERO; ZANETTI; OGRIZIO, 2008).

Em relação aos aspectos gerais do diabetes mellitus - conceito, fisiopatologia e tratamento - estudos obtiveram maior aumento do conhecimento (CLEMENT, 1995; NORRIS; ENGELGAU; NARAYAN, 2001; RICKHEIM et al., 2002; SANTOS et al., 2005; OTERO; ZANETTI; OGRIZIO, 2008; RODRIGUES et al., 2009).

Das $43(100 \%)$ pessoas entrevistadas, apenas $03(7,0 \%)$ apresentaram escores altamente positivos em relação à competência cognitiva para o autocuidado no $T 2$. Ao passo que, no $T 1$, não foi encontrado frequência da população do estudo.

Observa-se que 31 (72.0\%) pessoas desse estudo, no T2, situaram-se em escores médios. Destaca-se ainda que, no T1, 42 (97.7\%) pessoas apresentaram escores que diagnosticam déficits de competência cognitiva para o autocuidado.

Peters et al. (2004), em seu estudo exploratório objetivando examinar a competência para o autocuidado em pessoas com diabetes mellitus em relação ao sexo, utilizando a ECDAC, evidenciou-se maior percentagem de alta competência cognitiva em pessoas do sexo masculino (59.25\%) e do sexo feminino (53.13\%).

Os programas educativos são de grande importância para o conhecimento da doença e os riscos que ela pode trazer para a saúde da pessoa com DM. Porém, é importante ressaltar que a aquisição de conhecimento não significa mudança de comportamento, portanto, a educação para o autocuidado em DM torna-se mais complexa ao educador que precisa, além de ensinar, aprender técnicas para vencer resistências e promover mudanças no estilo de vida (FUNNEL; ANDERSON, 2004).

Em contrapartida, Mulcahy et al., (2000) e Trento et al., (2002) declararam que o controle de DM é possível por meio de programas 
educativos, da mobilização das pessoas e da incorporação de conhecimentos sobre a doença. Essas estratégias favorecem a mudança de comportamentos a partir do estabelecimento de uma dieta balanceada e a adoção da prática de atividades físicas, que possibilitam reduzir as complicações agudas e crônicas e as necessidades de hospitalização.

Nesse sentido, a educação em saúde tem sido muito valorizada e é considerada parte integrante do tratamento das doenças crônicas (ALMEIDA et al., 1995). No entanto, muitos programas de educação em saúde fracassam por não levarem em consideração os aspectos psicológicos, culturais, sociais, interpessoais e as reais necessidades psicológicas da pessoa com DM (ZANETTI; MENDES, 1993).

Desta forma, as atividades educativas em diabetes devem estar direcionadas para a construção de conhecimentos que favoreçam o autocuidado e a autonomia das pessoas, na perspectiva de que possam ter uma vida mais saudável (COELHO; SILVA, 2006).

$\mathrm{Na}$ educação para o autocuidado em DM, o empowerment tem sido definido como a descoberta e o desenvolvimento de uma capacidade inerente a pessoa: a de ser responsável pela sua vida. A forma das pessoas lidarem com situações desfavoráveis denomina-se empowerment, que está diretamente relacionado à implementação de programas que promovam consciência crítica sobre a realidade vivida (FUNNEL; ANDERSON, 2003).

Enfim, é fundamental que a educação em saúde leve em consideração a realidade e a vivência das pessoas, pois, muitas vezes, as informações em saúde são fornecidas de maneira vertical, sem permitir maior participação das pessoas com DM, desconsiderando os conhecimentos prévios. Nesse enfoque, é fundamental situar a pessoa com DM em uma participação ativa na condução do seu próprio tratamento (PERES et al., 2007). 


\subsubsection{Competência emocional e motivacional da população do estudo antes e após a participação no Programa de Educação em Diabetes do referido Centro}

No presente estudo, a diferença encontrada entre as médias no T2 em comparação ao $\mathrm{T} 1$ foi -3.47 , com $\mathrm{p}$ valor $<0.01$, havendo diferença estatisticamente significante no resultado dessa comparação.

Estudos revelam que o DM está intimamente relacionado com o estado emocional. Essa relação existe antes do surgimento da doença, onde acredita-se que o DM é uma doença psicossomática, ou seja, tem entre os seus fatores desencadeantes, causas emocionais, podendo provocar sentimentos de menos-valia, inferioridade, baixa auto-estima, medo, revolta, raiva, ansiedade, regressão, negação da doença, desesperança, incapacidade de amar e se relacionar bem com as pessoas e depressão. A presença de tais sentimentos dependerá da aceitação de ser uma pessoa com diagnóstico de DM (MARCELINO; CARVALHO, 2005).

Muitas vezes, quando a pessoa não suporta o diagnóstico de uma doença crônica, a negação funciona como um pára-choque diante de notícias inesperadas e chocantes, com alto impacto sobre o cotidiano e a auto-imagem. Quando a realidade é muito áspera, muitas pessoas utilizam a negação para digerir o impacto emocional e elaborar a experiência traumática, com o objetivo de criar forças para enfrentar de forma mais adequada a doença (PÉRES; FRANCO; SANTOS, 2008).

Das pessoas entrevistadas, $9.3 \%$ no $\mathrm{T} 1$ e $41.9 \%$ n $\quad$ T2 apresentaram escores considerados altamente positivos em relação à competência emocional e motivacional para o autocuidado. Entretanto, observou-se que as maiores frequências desse estudo situaram-se em escores médios, $76.8 \%$ no T1 e $58.1 \%$ no T2.

Peters et al. (2004), em seu estudo exploratório objetivando examinar a competência para o autocuidado em pessoas com diabetes mellitus em relação ao sexo, utilizando a ECDAC, evidenciou maior 
percentagem de alta competência emocional e motivacional em pessoas do sexo masculino (77.78\%) e do sexo feminino (84.38\%).

A influência do estado emocional no controle glicêmico exige um domínio intenso para evitar complicações. Diante de toda a relação expressa entre o emocional e o DM observa-se que o acompanhamento psicológico a essas pessoas torna-se muito importante, pois proporcionará uma elaboração dos aspectos emocionais da doença e com isso minimizará os sofrimentos psíquicos (MARCELINO; CARVALHO, 2005).

O acompanhamento dos aspectos emocionais da pessoa com DM poderá realizar-se individualmente ou em grupo, ambos têm como objetivo a elaboração e aceitação da doença para obtenção de uma melhor qualidade de vida (MARCELINO; CARVALHO, 2005). Porém, atividades em grupo auxiliam no combate da alienação, da baixa autoestima e desmoralização que ocorrem quando o indivíduo sente-se a única pessoa afligida pelo DM (GRAÇA et al., 2000).

O trabalho em grupo possibilita o compartilhamento de sentimentos entre as pessoas, oportunizando a redução de fantasias a respeito da doença, contribuindo assim, para uma aceitação interna dela e consequentemente uma melhor qualidade de vida (MARCELINO; CARVALHO, 2005).

Em relação aos resultados do presente estudo referentes à autoestima, as diferenças entre as médias dos escores obtidos no T1 em comparação ao T2 foram -0.28, -0.35 e -0.21.

Rubin, Peyrot e Saudek (1989) estudaram os efeitos da educação no autocuidado, controle metabólico e bem estar emocional de pessoas com DM em um programa educativo. Ao final do programa de seis meses, os resultados mostraram melhora da auto-estima e do autocuidado, quando comparados aos níveis iniciais do programa.

A melhora da auto-estima está associada à predisposição para assumir o autocuidado direcionado ao manejo do DM. Tal predisposição propicia a redução do estresse associado à doença, maior receptividade à conduta do tratamento, confiança no cuidado da equipe multiprofissional, 
melhora da auto-estima, senso de auto-eficácia, percepção mais positiva acerca da saúde e aceitação social (STEED; COOKE; NEWMAN, 2003).

Adquirir respeito pela doença é um processo lento, sofrido, permeado por oscilações de humor e sentimentos de impotência, que podem gerar vivências de desamparo e desvalia. Dessa forma, a percepção de que se tem o controle sobre os acontecimentos significativos do próprio viver pode estar comprometida e a auto-eficácia - isto é, o sentimento de se ter competência na realização das tarefas cotidianas pode estar prejudicado, contribuindo para uma auto-estima rebaixada (PÉRES et al., 2007).

Para os resultados referentes à auto-valorização, as diferenças entre as médias dos escores obtidos no T1 em comparação ao T2 foram de $-0.35,-0.21$ e -0.45 .

Torna-se necessário compreender como a pessoa com DM percebe a si própria, vivenciando um mundo de muitas limitações, ou seja, a pessoa enquanto ser integral, dotado de compreensão, afetividade e ação, dentro da sua própria perspectiva de mundo. O choque emocional causado pelo diagnóstico do DM dificulta a auto-valorização da pessoa e, consequentemente, a adoção de hábitos saudáveis que permitam lidar com as limitações decorrentes da condição crônica (PÉRES et al., 2007).

Quanto ao controle emocional para fazer julgamentos e controlar o autocuidado, as diferenças entre as médias dos escores obtidos no T1 em comparação ao T2 foram $-0.42,-0.30,-1.14,-0.33$ e -0.32 . Para a aceitação da situação de ser uma pessoa com diabetes, as diferenças entre as médias dos escores obtidos no T1 em comparação ao T2 foram de $-0.33,-0.32,-0.14$ e -0.53 .

A melhora nos aspectos emocionais, promovendo melhor equilíbrio no estado psicológico, é fundamental para sustentar a mudança de hábitos de vida no controle do autocuidado (SANTOS et al, 2009).

Delamater et al. (2001) declara que a oportunidade de viver as dificuldades do controle glicêmico do DM em atividades educativas em grupo oferece apoio uns aos outros, podendo fornecer o apoio emocional e 
a motivação que se tornam indispensáveis para encorajar as pessoas a implementarem ações para o monitoramento do diabetes mellitus.

Contata-se que a competência cognitiva, emocional e a motivacional para o autocuidado apresentaram resultados estatisticamente significantes, visto que estão intimamente relacionadas com o vínculo com as outras pessoas do grupo, devendo-se ser trabalhando com os profissionais da equipe multiprofissional de forma efetiva, podendo levar ao alcance de grandes mudanças no comportamento para o autocuidado e a manutenção do bom controle glicêmico e metabólico do DM. 


\section{Canclusães}

"De um lada a paesia, a verlea, a saudade Da autra a luta, a farça e a caragem pra chegar na fim E a fim é leela incerta... depende de cama vacê vê $\mathcal{O}$ nava, a creda, a fé que uacê depasita em vacê e sá" 


\section{CONCLUSÕES}

As conclusões desse estudo estão apresentadas de acordo com a sequência dos objetivos propostos, dos resultados e da discussão.

\subsection{Caracterização da população do estudo segundo as variáveis sociodemográficas}

Dentre as $43(100 \%)$ pessoas entrevistadas, 29 (67.4\%) eram do sexo feminino e $14(32.6 \%)$ do sexo masculino, a menor das idades foi de 36 anos e a maior 79, predominando $14(32.6 \%)$ pessoas na faixa etária entre 60 a 69 anos, com mediana de 63 anos. A população foi em quase sua totalidade, 37 (86.0\%), procedente da cidade de Ribeirão Preto. Com relação à cor/raça, observou-se que 36 (83.7\%) pessoas consideraram-se brancas. A maioria era casada (65.2\%), 20 (46.5\%) aposentadas e 13 (30.2\%) do lar e $26(60.5 \%)$ consideraram-se católicas.

Quanto ao número de pessoas que moram no domicílio junto com a pessoa entrevistada, encontrou-se que 18 (41.9\%) viviam com até 2 pessoas. Com relação ao nível de escolaridade, 11 (25.6\%) pessoas tinham até o primeiro grau incompleto. Sobre renda familiar, 19 (44.1\%) pessoas possuíam entre 3 a 4 salários mínimos e $11(25.6 \%)$ entre 1 a 2 .

\subsection{Caracterização da população do estudo segundo as variáveis clínicas e relacionadas ao tratamento do diabetes mellitus}

Das $43(100 \%)$ pessoas entrevistadas, 42 (97.7\%) tinham diabetes mellitus tipo 2 (DM2); predominando 20 (46.5\%) pessoas com 
tempo de diagnóstico $\leq 5$ anos, com mediana de 6 anos; 34 (79.0\%) pessoas declararam que não fumam, declarando o tempo (anos) que parou de fumar e a quantidade de cigarros/dia que fumava, com médias de 14.3 anos e 5.5 cigarros/dia; 31 (72\%) pessoas realizam acompanhamento médico na rede pública; 38 (88.3\%) pessoas declararam que não ingerem bebida alcoólica; 22 (51.2\%) pessoas informaram que não seguem dieta; 31 (72.0\%) declararam que não realizam atividade física.

Das $38(88.3 \%)$ pessoas entrevistadas que fazem uso de tratamento medicamentoso para o DM: 33 (76.7\%) utilizam somente antidiabético oral, sendo 17 (39.5\%) biguanidas + sulfoniluréias e 14 (32.6\%) apenas biguanidas; 4 (9.3\%) utilizam a associação de antidiabético oral + insulina; e, apenas 1 (2.3\%) somente insulina. Quanto às co-morbidades e às complicações crônicas relacionadas ao DM, obteve-se que as mais prevalentes foram: hipertensão arterial (76.8\%) e dislipidemia (32.6\%); retinopatia (23.3\%) e neuropatia $(11.7 \%)$, respectivamente.

6.3 Comparação dos valores obtidos em relação às variáveis pressão arterial, glicemia capilar pós-prandial, circunferência abdominal, peso e IMC antes e após o oferecimento das atividades educativas

Com relação à PAS e PAD, encontraram-se média \pm desvio padrão de $130 \mathrm{mmHg} \pm 13.58$ e $81 \mathrm{mmHg} \pm 10.47 \mathrm{no} \mathrm{T} 1, \mathrm{e}, 123 \mathrm{mmHg} \pm 14.26$ e $76 \pm 8.90$ no T2, respectivamente. Dessa forma, as diferenças entre as médias do T1 em comparação ao T2 foram de -6.62 da PAS e -5.27 da $P A D$, com resultados estatisticamente significantes $(p<0,05)$, na PAS com $p=0.03$ e IC $(0.65-12.60)$ e na PAD com $p=0.01$ e IC (1.10-9.44). 
Para a glicemia capilar pós-prandial, encontrou-se $181 \mathrm{mg} / \mathrm{dL} \pm$ 81.74 no $\mathrm{T} 1$ e $157 \mathrm{mg} / \mathrm{dL} \pm 64.54$ no $\mathrm{T} 2$. E, apesar dos resultados não terem revelado diferenças estatisticamente significantes, quando 0 $p=1.27$ e IC [(-7.12)-56.09], encontrou-se menor média no T2 em comparação ao $T 1$, com diferença de -24.48 . Para a $C A$, as médias \pm desvio padrão foram $102.1 \mathrm{~m} \pm 10.88$ no $\mathrm{T} 1$ e $100.5 \mathrm{~m} \pm 64.54$ no $\mathrm{T} 2$. Também não revelaram diferenças estatisticamente significantes, quando o $p=0,51$ e IC [(-3.24)-6.39], e uma média de fraca magnitude no T2 em comparação ao $\mathrm{T} 1$, com diferença de -1.57 .

Por fim, tratando-se de peso e IMC, encontraram-se média \pm desvio padrão de $77.7 \mathrm{~kg} \pm 16.70$ e $30.2 \mathrm{~kg} / \mathrm{m}^{2} \pm 5.57$ no T1, e, $76.1 \mathrm{~kg}$ \pm 17.29 e $29.4 \mathrm{~kg} / \mathrm{m}^{2} \pm 5.66$ no T2. Dessa forma, as diferenças entre as médias do $\mathrm{T} 1$ em comparação ao $\mathrm{T} 2$ foram de $-1,57$ do peso e $-0,72$ do IMC, com resultados também não estatisticamente significantes, no peso com $p=0,66$ e IC (-5.71)-8.86 e no IMC com $p=0.55$ e IC (-1.68)-3.129.

\subsection{Comparação da competência de pessoas com diabetes mellitus para o autocuidado antes e após o oferecimento das atividades educativas}

Segue-se as conclusões da comparação das competências física, cognitiva, emocional e motivacional de pessoas com diabetes mellitus para o autocuidado, nos Tempos 1 e 2 . 


\subsubsection{Competência física da população do estudo antes e após a participação no Programa de Educação em Diabetes do referido Centro}

A somatória total dos escores que determinam a competência física para o autocuidado diagnosticada pela subescala I variou nesse estudo no T1 entre 13.5 (mínimo) a 20 (máximo), com média \pm dp de $17.80 \pm 1.54$ e CV $8.65 \%$. No T2, a somatória total dos escores variou entre 14 (mínimo) a 20 (máximo), com média \pm dp de $18.10 \pm 1.43$ e CV 7.90\%. Com relação à comparação entre o T1 e o T2, a diferença encontrada entre as médias foi -0.302 , o valor $p=0.349$ e o IC $95 \%-0.941$ e 0.337 , não apresentando diferença estatisticamente significante. Com relação à acuidade visual (item 1), a diferença entre a média do escore obtido no T1 em comparação ao T2 foi -0.302 . Para os demais itens, percepção das cores (item 2), temperatura (item 3), sensibilidade plantar dos pés (item 4) e destreza manual (item 5), a diferença entre as médias dos escores obtidos no $\mathrm{T} 2$ em comparação ao $\mathrm{T} 1$ foi de 0 , ou seja, não houve diferença.

\subsubsection{Competência cognitiva da população do estudo antes e após a participação no Programa de Educação em Diabetes do referido Centro}

A somatória total dos escores que determinam a competência cognitiva para o autocuidado diagnosticada pela subescala II variou nesse estudo no T1 entre 14 (mínimo) a 32 (máximo), com média \pm dp de $21.35 \pm 4.28$ e CV $20.05 \%$. No T2, a somatória total dos escores variou entre 25 (mínimo) a 43 (máximo), com média \pm dp de $33.26 \pm 3.68$ e CV $11.06 \%$. Com relação à comparação dos itens da subescala II entre o T1 e 
○ T2, a diferença encontrada entre as médias foi -11.91 , com o valor $\mathrm{p}$ estatisticamente significante, $\mathrm{p}<0.01$, e o IC $95 \%-13.62$ e -10.19 .

Com relação à capacidade de ler (item 6), a diferença entre a média do escore obtido no T1 em comparação ao T2 foi -0.25 . Para as questões relacionadas ao conhecimento do diabetes (item 7), aos métodos de exame (item 8) e aos métodos de tratamento (item 9), a diferença entre as médias dos escores foram -1.53, -1.07 e -1.26, respectivamente. Para as questões relacionadas à hipoglicemia (itens 10, 11 e 12), encontraram-se as seguintes diferenças entre as médias: $-1.44,-1.28$ e 1.44. Ao questionar sobre hiperglicemia (itens 13, 14 e 15), as diferenças encontradas entre as médias dos escores obtidos no T1 em comparação ao T2 foram de $-1.21,-1.38$ e -1.14. Por fim, com relação à capacidade de atenção e memória (item 16), a diferença entre a média do escore obtido no T1 em comparação ao T2 foi -0.16 .

Destaca-se que em todos os onze itens da subescala II encontraram-se maiores médias dos escores obtidos no T2, em comparação ao T1.

\subsubsection{Competência emocional e motivacional da população do estudo antes e após a participação no Programa de Educação em Diabetes do referido Centro}

A somatória total dos escores que determinam a competência emocional e motivacional para o autocuidado diagnosticada pela subescala III variou nesse estudo no T1 entre 19 (mínimo) a 42 (máximo), com média \pm dp de $34.51 \pm 4.50$ e CV $13.04 \%$. No T2, a somatória total dos escores variou entre 29 (mínimo) a 43 (máximo), com média \pm dp de $37.98 \pm 3.80$ e CV $10.00 \%$. Com relação à comparação dos itens da subescala III entre o T1 e o T2, a diferença encontrada entre as médias 
foi -3.47 , com valor $p$ estatisticamente significante, $p<0.01$, e o IC $95 \%$ 5.25 e -1.68 .

Com relação à auto-estima (itens 17, 18 e 19), as diferenças entre as médias dos escores obtidos no T1 em comparação ao T2 foram -0.28, 0.35 e -0.21. Para a auto-valorização (itens 18, 19 e 20), as diferenças entre as médias dos escores foram de $-0.35,-0.21$ e -0.45 . Para o controle emocional para fazer julgamentos e controlar o autocuidado (itens $21,22,23,24$ e 25), encontraram-se as seguintes diferenças entre as médias: $-0.42,-0.30,-1.14,-0.33$ e -0.32 . Por fim, para a aceitação da situação de ser uma pessoa com diabetes (itens 24, 25, 26 e 27), as diferenças entre as médias dos escores obtidos no T1 em comparação ao T2 foram -0.33, $-0.32,-0.14$ e -0.53 .

Destaca-se que em todos os onze itens da subescala III encontraram-se maiores médias dos escores obtidos no T2, em comparação ao T1. 


\section{Cansideraçães finais}

"Tem sarrisa que parece chara Tem chara que é pura alegria"

Fernanda Anitelli 


\section{CONSIDERAÇÕES FINAIS}

Atualmente, o número de pessoas com pelo menos uma condição crônica de saúde tem se constituído um grande desafio para os serviços de saúde, para os profissionais e para a sociedade. Em especial, o diabetes mellitus, como uma condição crônica que requer da pessoa, família e profissionais de saúde, esforços para a manutenção de um bom controle glicêmico e metabólico, possibilitando minimizar complicações a curto e longo prazo.

Por decorrência da alta prevalência e incidência mundial, bem como a associação com co-morbidades, as pessoas com DM devem adquirir comportamentos adequados de autocuidado, o que podem ser obtidos pela adoção de estilos de vida saudáveis, por meio da educação em saúde.

Desse modo, o autocuidado deve ser encorajado por todos os profissionais de saúde que atuam em diabetes mellitus. A educação como suporte para o tratamento de pessoas com diabetes mellitus é um dos objetivos primordiais a fim de aliviar os sintomas clássicos e retardar as complicações crônicas (SBD, 2009).

A educação individual quando comparada à educação em grupo tem se mostrado equivalente na melhora do controle glicêmico e metabólico. No entanto, as atividades desenvolvidas em grupo permitem maior troca de experiências entre as pessoas, melhor relação custobenefício e têm apresentado maior adesão as ações de autocuidado para o tratamento.

A utilização de metodologias de educação em grupo como intervenção em DM tem apresentado melhores resultados nas atividades de autocuidado, pois proporciona entre os participantes apoio emocional, idéias e sugestões para a modificação do estilo de vida

O presente estudo possibilitou comparar a competência de pessoas com diabetes mellitus para o autocuidado antes e após a participação em um programa educativo multiprofissional; caracterizar as pessoas com 
diabetes mellitus atendidas em um Programa de Educação em Diabetes oferecido por equipe multiprofissional, segundo variáveis sociodemográficas, clínicas e relacionadas ao tratamento; comparar os valores de pressão arterial sistólica e diastólica, glicemia capilar pósprandial, circunferência abdominal, peso, o IMC e as competências física, cognitiva, emocional e motivacional antes e após a participação de pessoas com diabetes mellitus nas atividades educativas oferecidas pela equipe multiprofissional.

Algumas limitações do presente estudo merecem ser consideradas. A primeira é em relação à carência de estudos comparativos para a análise de comportamentos de autocuidado em programas educativos. Estudos transversais, que permitem a avaliação em um único momento, não possibilitam a observação das variações dos comportamentos de autocuidado no dia a dia da pessoa com DM.

Portanto, estudos com a temática devem ser incentivados, a fim de ampliar as análises estatísticas da competência para o autocuidado de pessoas com DM e as variáveis relacionadas, bem como estudar as influências das intervenções da equipe multiprofissional no processo de educação em saúde para o reconhecimento e a percepção de novos comportamentos de estilos de vida visando o desenvolvimento de atividades para o autocuidado, seguidas do bom controle glicêmico e metabólico do DM.

Em segundo lugar, pelo número das variáveis envolvidas, a quantidade da população do estudo deveria ser ampliada para viabilizar análises estatísticas complementares que possibilitassem estudar os efeitos dessas variáveis no controle glicêmico e metabólico. Porém, convém declarar que a motivação e a assiduidade de pessoas com DM nos encontros dos programas educativos ainda é não é o bastante.

Em relação aos resultados das médias de glicemia pós-prandial encontrados nesse estudo nos Tempos 1 e 2, observou-se que houve diminuição no T2, porém sem diferença estatisticamente significante. Destaca-se a falta da avaliação dos parâmetros da hemoglobina 
glicosilada na população do estudo, pois, atualmente, a fração de hemoglobina glicosilada é considerada o padrão ouro para a avaliação do controle do glicêmico e metabólico do DM.

Outra limitação que merece ser considerada é a falta de itens na escala ECDAC que permitissem identificar com mais especificidade a competência relacionada à insulinoterapia e ao planejamento da dieta alimentar.

Recomenda-se também uma avaliação do número e do conteúdo dos itens da subescala I que diagnosticam a competência física, para que se obtenha uma maior homogeneidade com a escala ECDAC e também para que se consiga discriminar melhor a competência física das pessoas com DM para o autocuidado, pois muitas pessoas irão vivenciar mudanças físicas ao longo da vida, por exemplo, diminuição da acuidade visual ou da destreza manual e da mobilidade, demandando novas adaptações e aprendizados relacionados ao autocuidado, sendo necessárias avaliações frequentes, contínuas e individualizadas.

Considera-se ainda que quatro meses de intervenção em atividades educativas visando atingir metas adequadas para comportamentos de autocuidado em pessoas com diabetes mellitus é considerado um tempo curto. Contudo, a interação e a troca de experiências entre as pessoas nas atividades em grupos podem contribuir positivamente para o disparo de mudanças significativas, uma vez que influencia na competência motivacional, conforme resultados estatisticamente significantes encontrados no presente estudo. 


\section{Referências*}

“Ah... e a munda é perfeita!

Hum...e a munda é perfeita!

E a munda é perfeita!"

Fernanda Anitelli

* De acordo com:

ASSOCIAÇÃO BRASILEIRA DE NORMAS TÉCNICAS. NBR 6023: informação e documentação: referências: elaboração. Rio de Janeiro, 2002. 


\section{REFERÊNCIAS}

AHMED, A.T.; KARTER, J.; LIU, J. Alcohol consumption is inversely associated with adherence to diabetes self-care behaviours Journal compilation. Diabetic Medicine, Oxford, v. 23, n. 7, p.795-802, 2006.

ALLISON, S. E. A framework for nursing action in a nurse - conducted diabetic management clinic. Journal Nursing Administration, Wakefield, v. 4, n. 3, p. 53-60, 1963.

ALMEIDA, G. G. A. et al. Avaliação dos conhecimentos teóricos dos diabéticos de um programa interdisciplinar. Revista Latino-Americana de Enfermagem, Ribeirão Preto, v. 3, n. 2, p. 145-64, jul. 1995.

ALMEIDA, M. C. P.; MISHIMA, S. M. O desafio do trabalho em equipe na atenção à saúde da família: construindo "novas autonomias" no trabalho. Interface:

Comunicação, Saúde, Educação, Marília, v. 9, p. 150-3, ago. 2001.

ALVES, V. S. Um modelo de educação em saúde para o Programa Saúde da Família: pela integridade da atenção e reorientação do modelo assistencial. Interface: Comunicação, Saúde, Educação, Marília, v. 9, p. 39-52, 2005.

AMERICAN ASSOCIATION OF DIABETES EDUCATORS (AADE). Individualization of diabetes self-management education. The Diabetes Educator, Chicago, v. 28, p. 741-49, 2002.

AMERICAN DIABETES ASSOCIATION (ADA). Implications of the United Kingdom Prospective Diabetes Study. Diabetes Care, Alexandria, v. 27, p. 28-32, 2004. Supplement 1.

AMERICAN DIABETES ASSOCIATION (ADA). Recomendações para os portadores de diabetes mellitus. Diabetes Clínica, São Paulo, v. 5, n. 4, p. 258-62, 2001.

AMERICAN DIABETES ASSOCIATION (ADA). Insulin administration (position statement). Diabetes Care, Alexandria, v. 22, p. S83, 1999. Supplement 1.

ARMOUR, T. A. et al. The effectiveness of family interventions in people with diabetes mellitus: a systematic review. Diabetic Medicine, Oxford, v. 22, n. 10, p. 1464-591, 2005. 
ARMSTRONG, N. Coping with Diabetes Mellitus. A full-time job. Nursing Clinics North America, Philadelphia, v. 22, n. 3, p. 559-68, 1987.

ATAÍDE, M. B. C. Vivência grupal: estratégia de engajamento no autocuidado e diabetes. 2004. 210 f. Tese (Doutorado) - Universidade Federal do Ceará, Fortaleza, 2004.

BACKSHEIDER, J. Self-Care requirement, Self-Care habilities and the nursing system in diabetic nursing management clinic. American Journal Public Health, Washington, DC, v. 64, n. 12, p. 1138-46, 1974.

BARBOSA, R. B.; BARCELÓ, A.; MACHADO, C. A. Campanha nacional de detecção de casos suspeitos de diabetes mellitus no Brasil: relatório preliminar. Revista Panamericana de Salud Pública, Washington, DC, v. 10, n. 5, p. 324-7, nov. 2001.

BECKER, T. A. C.; TEIXEIRA, C. R. S.; ZANETTI, M. L. Diagnósticos de enfermagem em pacientes diabéticos em uso de insulina. Revista Brasileira de Enfermagem, Brasília, DF, v. 61, n. 6, p. 847-52, nov./dez. 2008.

BIESENBACH, G. et al. Influence of cigarette-smoking on the progression of clinical diabetic nephropathy in type 2 diabetic patients. Clinical Nephrology, Deisenhofen, v. 48, n. 3, p. 146-50, 1997.

BRASIL. Ministério da Saúde. Cadernos de atenção básica: diabetes mellitus. Brasília, DF: Ministério da Saúde, 2006. (Série A. Normas e Manuais Técnicos, n. 16).

BRASIL. Ministério da Saúde. Plano de reorganização da atenção à hipertensão arterial e ao diabetes mellitus: manual de hipertensão arterial e diabetes mellitus. Brasília, DF: Ministério da Saúde, 2002.

BRASIL. Ministério da Saúde. Secretaria de Vigilância em Saúde. Departamento de Análise de Situação em Saúde. Saúde Brasil 2005: uma análise da situação de saúde no Brasil. Brasília, DF, 2005a. Disponível em:

<http://portal.saude.gov.br/portal/arquivos/pdf/saude_brasil_2005.pdf>. Acesso em: 10 out. 2008 .

BRASIL. Ministério da Saúde. Departamento de Atenção Básica. Saúde da Família. Brasília, DF, 2005b. Disponível em:

<http://dtr2004.saude.gov.br/dab/conhecadab.php>. Acesso em: 28 set. 2007. 
BRASIL. Ministério da Saúde. Secretaria de Vigilância em Saúde. Sistema Nacional de Vigilância em Saúde: Relatório de situação: Pernambuco. Brasília, DF: Ministério da Saúde, 2005c.

BRASIL. Poder Judiciário Federal. Tribunal Regional do Trabalho da $4^{a}$ Região. Atualização legislativa no 1253 01.5.2009/31.5.2009. Brasília, 2009. Disponível em: <http://www.trt4.jus.br/AtualizacaoLegislativaPortlet/download/AL1253.pdf>. Acesso em: 15 out. 2009.

BRITO, I. T.; LOPES, A. A.; ARAÚJO, L. M. B. Associação da cor da pele com Diabetes Mellitus tipo 2 e intolerância à glicose em mulheres obesas de Salvador, Bahia. Arquivos Brasileiros de Endocrinologia e Metabologia, São Paulo, v. 45 , n. 5 , p. $475-80$, out. 2001.

BROWN, S. A. et al. Atingindo populações carentes e de baixo nível cultural na orientação do diabetes. Current Diabetes Reports Latin America, Cidade, n. 1, p. 397-409, 2002.

CALLEGARI-JACQUES, S. M. Bioestatística - Princípios e Aplicações. São Paulo: Artmed, 2008. 255 p.

CAMPOS, G. W. S.; DOMITTI, A. C. Apoio matricial e equipe de referência: uma metodologia para gestão do trabalho interdisciplinar em saúde. Cadernos de Saúde Pública, Rio de Janeiro, v. 23, n. 2, p. 399-407, fev. 2007.

CARMO, E. H.; BARRETO, M. L.; SILVA JUNIOR, J. B. Mudanças nos padrões de morbimortalidade da população brasileira: os desafios para um novo século.

Epidemiologia e Serviços de Saúde, Brasília, DF, v. 12, n. 2, p. 63-75, abr./jun. 2003.

CESARINO, C. B. et al. O autocuidado de clientes portadores de hipertensão arterial em um hospital universitário. Arquivos de Ciências da Saúde, São José do Rio Preto, v. 11, n. 3, p. 146-8, jul.-set. 2004.

CIECHANOWSKI, P. S. et al. The patient provider relationship: attachment theory and adherence to treatment in diabetes. American Journal of Psychiatry, Arlington, v. 158, n. 1, p. 29-35, Jan. 2001.

CLEMENT, S. Diabetes self-management education. Diabetes Care, Alexandria, v. 18 , p. $1204-14,1995$. 
COELHO FILHO, J. M.; RAMOS, L. R. Epidemiologia do envelhecimento no Nordeste do Brasil: resultados de inquérito domiciliar. Revista de Saúde Pública, São Paulo, v. 33, n. 5, p. 445-53, 1999.

COELHO, M. S.; SILVA, D. M. G. V. Grupo educação-apoio: visualizando o autocuidado com os pés de pessoas com diabetes mellitus. Ciência, Cuidado e Saúde, Maringá, v. 5, n. 1, p. 11-5, jan. 2006.

COSTA, A. A.; ALMEIDA NETO, J. S. Manual de diabetes: educação, alimentação, medicamentos e atividade física. 5 ed. São Paulo: Sarvier, 2004. 256 p.

CYRINO, A. P. P. As competências no cuidado com diabetes mellitus: contribuições à educação e comunicação em saúde. 2005. 278 f. Tese (Doutorado) - Faculdade de Medicina, Universidade de São Paulo, São Paulo, 2005.

DAMASCENO, L. A. N. Diretrizes para a atuação do fisioterapeuta na prevenção do pé diabético. 2005. 127 f. Dissertação (Mestrado) - Escola de Enfermagem de Ribeirão Preto, Universidade de São Paulo, Ribeirão Preto, 2005.

DEAN, K. Self-care components of lifestyles: the importance of gender, attitudes and the social situation. Social Science \& Medicine, Oxford, v. 29, n. 9, p. 137-52, 1989.

DELAMATER, A. M. Improving patient adherence. Clinical Diabetes, New York, v. 24, p. 71-7, 2006.

DELAMATER, A. M. et al. Psychosocial therapies in diabetes. Diabetes Care. Alexandria, v 24, p. 1286-92, 2001.

DENYES, M. J. Development of an instrument to measure self-care agency in adolescents. 1980. Thesis (Doctoral) - University of Michigan, Detroit, 1980.

DEVER, D. E. A. Epidemiologia: enfocando a prevenção. In: A epidemiologia na administração dos serviços de saúde. São Paulo: Pioneira, 1988. cap. 1.

DIABETES CONTROL AND COMPLICATIONS TRIAL (DCCT). Research Group: The effect of intensive treatment of Diabetes on the development and progression of the long-term complications in insulin-dependent diabetes mellitus. New

England Journal of Medicine, Boston, v. 329, n. 14, p. 977-86, 1993. 
DUFF, E. M. et al. Self-care, compliance and glycaemic control in Jamaican adults with Diabetes Mellitus. West Indian Medical Journal, Kingston, v. 55, n. 4, p. 232, 2006.

ESTACIO, R. O. et al. Effect of blood pressure control on diabetic microvascular complications in patients with hypertension and type 2 diabetes. Diabetes Care, Alexandria, v. 23, p. 54-64, 2000. Supplement 2.

FARIA, H. T. G. Fatores associados à adesão do paciente diabético à terapêutica medicamentosa. 2008. 146 f. Dissertação (Mestrado) - Escola de Enfermagem de Ribeirão Preto, Universidade de São Paulo, Ribeirão Preto, 2008.

FILHO, J. et al. Grupo e corpo: psicoterapia de grupo com pacientes somáticos. Porto Alegre: Artes Médicas, p. 213-32. 2000.

FOX, D. I. Fundamental of Research in nursing. 3. ed. New York: Appleton Century - Crofts, 1972. 313 p.

FREIRE, P. Pedagogia da autonomia: saberes necessários à prática educativa. 21. ed. São Paulo: Paz e Terra, 2005. 166 p.

FUNNEL, M. M.; ANDERSON, R. M. Patient empowerment: a look back, a look ahead. The Diabetes Educator, Chicago, v. 29, n. 3, p. 454-62. 2003

FUNNELL, M. M.; ANDERSON, R. M. Role of diabetes education in patient management. Therapy for diabetes mellitus and related disorders. 4 ed. American Diabetes Association (ADA). 2004.

GAMBA, M. A. et al. Amputações de extremidades inferiores por diabetes mellitus: estudo caso-controle. Revista de Saúde Pública, São Paulo, v. 38, n. 3, p. 399-404, jun. 2004.

GARY, T. L. et al. Meta-analysis of randomized educational and behavioral interventions in type 2 diabetes. The Diabetes Educator, Chicago, v. 29, p. 488-501, 2003.

GRAÇA, L. A. C.; BURD, M.; MELLO FILHO, J. Grupos com diabéticos. In: MELLO HOEY, H. et al. Good metabolic control is associated with better quality of life in 2101 adolescents with type 1 diabetes. Diabetes Care, Alexandria, v. 24, p. 1923-8, 2001. 
GIATTI, L.; BARRETO, S. M. Saúde, trabalho e envelhecimento no Brasil.

Cadernos de Saúde Pública, Rio de Janeiro, v. 19, n. 3, p. 735-44, 2003.

\section{GOMES-VILLAS BOAS, L. C. Apoio social, adesão ao tratamento e controle} metabólico de pessoas com diabetes mellitus tipo 2. 2009. $171 \mathrm{f}$.

Dissertação (Mestrado) - Escola de Enfermagem de Ribeirão Preto, Universidade de São Paulo, Ribeirão Preto, 2009.

GRANT, R. W. et al. Polypharmacy and medication adherence in patients with type 2 diabetes. Diabetes Care, Alexandria, v. 26, n. 5, p. 1408-12, May 2003.

GROSS, J. L. et al. Diabetes Mellitus: diagnosis, classification and glucose control evaluation. Arquivos Brasileiros de Endocrinologia e Metabologia, São Paulo, v. 46, n. 1, p. 16-26, 2002.

GUEDES, A. C. A associação entre o perfil clínico e psicossocial de pessoas com diabetes mellitus usuárias de uma unidade de saúde da família de Sorocaba - SP. 2007. 103 f. Dissertação (Mestrado) - Escola de Enfermagem, Universidade de São Paulo, São Paulo, 2007.

GUIMARÃES, F. P. M; TAKAYANAGUI, A. M. M. Orientações recebidas do serviço de saúde por pacientes para o tratamento do portador de diabetes mellitus tipo 2 . Revista de Nutrição, Campinas, v. 15, n. 1, p. 37-44, jan. 2002.

HAENSGEN, I. L. Impacto de programas educativos en el autocuidado de pacientes ambulatórios. Educación Autocuidado Salud, Santiago, v. 3, n. 2, p. 6-18, 1986.

HAMDI, M. E.; HUTELMEYER, C. M. A study of the effectiveness of an assessment tool in the identification of nursing care problems. Nursing Research, New York, v. 19, n. 4, p. 354-9, 1970.

HANSSON, L. et al. Effects of intensive blood-pressure lowering and low-dose aspirin in patients with hypertension: principal results of the Hypertension Optimal Treatment (HOT) randomised trial. HOT Study Group. Lancet, London, v. 351, p. 1755-62, 1998.

HARRIS, $F$ et al. Development and initiation of a diabetes self-management program for an underserved population. The Diabetes Educator, Chicago, v. 25, p. $760-7,2000$. 
HEISLER, M. et al. The health effects of restricting prescription medication use because of cost. Medical Care, Philadelphia, v. 42, n. 7, p. 626-34, Jul. 2004.

HERAS, R. M.; MACIAS, G. R. Diabetes mellitus: complicaciones crónicas y factores de riesgo. Revista Médica del IMSS, México, v. 6, n. 34, p. 449-55, 1996.

INTERNATIONAL DIABETES CENTER (IDC). Insulin BASICS: curriculum guide. Minneapolis: International Diabetes Center, 2001.

INTERNATIONAL DIABETES FEDERATION (IDF). Complicações do diabetes e educação. Diabetes Clínica, Rio de Janeiro, v. 6, n. 3, p. 217-20, 2002.

INTERNATIONAL DIABETES FEDERATION (IDF). The IDF consensus worldwide definition of the metabolic syndrome. Belgium: IDF, 2006.

IRVINE, A. et al. Validation of scale measuring environmental Barriers to diabetes-regimen adherence. Diabetes Care, Alexandria, v. 13, n. 7, p. 705-11, 1990.

JARVIS, C. Exame físico e avaliação de saúde. 3. ed. Rio de Janeiro: Guanabara Koogan, 2002. 900 p.

KEARNEY, B. Y.; FLEISCHER, B. I. Development of an instrument to measure exercise of self-care agency. Research Nursing and Health, New York, v. 2, n. 1 , p. 25-34, 1979.

KINDER, L. S. et al. Depressive symptomatology and coronary heart disease in type 1 diabetes mellitus: a study of possible mechanism. Health Psychology, Hillsdale, v. 21, n. 6, p. 542-52, Nov. 2002.

KING, H.; REWERS, M. Global estimates for prevalence of diabetes mellitus and impaired glucose tolerance in adults. Diabetes Care, Alexandria, v. 16, p. 15777, 1993.

LACROIX, A. L.; ASSAL, L. P. L'Education thérapeutique des patients:

nouvelles approches de la maladie chronique. 2 ed. Paris: Maloine, 2003. 240 p.

LESSA, I. Chronic non-communicable diseases in Brazil: a challenge for the complex task of surveillance. Ciência e Saúde Coletiva, Rio de Janeiro, v. 9, n. 4, p. 931-43, out./dez. 2004. 
LIPTON, R. B. et al. Determinants of incident non-insulin dependent diabetes mellitus among blacks and whites in a national sample: The NHANES I

Epidemiologic Follow-up Study. American Journal Epidemiology, Baltimore, v. 138, p. 826-39, 1993.

LOBIONDO-WOOD, G.; HABER, J. Pesquisa em Enfermagem: métodos, avaliação, crítica e utilização. 4. ed. Rio de Janeiro: Guanabara Koogan, 2001.

LUCE, M. et al. O preparo para o autocuidado do cliente diabético e família. Revista Brasileira de Enfermagem, Brasília, DF, v. 43, n. 1-4, p. 36-43, jan./dez. 1990.

MALERBI, D. A. Estudo da prevalência do diabetes mellitus no Brasil. São Paulo, 1991. 154 f. Tese (Doutorado) - Faculdade de Medicina da Universidade de São Paulo, São Paulo, 1991.

MALERBI, D. A.; FRANCO, L. J. Multicenter study of the prevalence of diabetes mellitus and impaired glucose tolerance in the urban Brazilian population aged 30-69 yr. Diabetes Care, Alexandria, v. 15, n. 11, p. 1509-16, Nov. 1992.

MARCELINO, D. B.; CARVALHO, M. D. B. Reflexões sobre o diabetes tipo 1 e sua relação com o emocional. Psicologia: Reflexão e Crítica, Porto Alegre, v. 18, n. 1, p. 72-7, jan/abr. 2005.

MARQUES, A. P. O.; ARRUDA, I. K. G.; ESPIRITO SANTO, A. C. G. Prevalence of obesity and associated factors in elderly women. Arquivos Brasileiros de Endocrinologia e Metabologia, São Paulo v. 49, n. 3, p. 441-8, jun. 2005.

MARTINEZ, A. O.; MORENO, M. M. G. Barreras ambientales para el apego al tratamiento en pacientes con diabetes tipo 2. Desarrollo Científico de la Enfermera, Tlalnepantla, v. 14, n. 6, p. 196-201, jul. 2006.

MASSAD, E. et al. Métodos quantitativos em medicina. 1. ed. São Paulo: Manole, 2004. 561 p.

MAZZUCA, S. A. The diabetes education study: a controlled trial of the effects of diabetes patient education. Diabetes Care, Alexandria, v. 9, n. 1, p. 1-10, 1986.

MCBRIDE, S. Validation of an instrument of measure exercise of self-care agency. Research in Nursing and Health, New York, v. 10, p. 311-6, 1987. 
MICKUS, S.; QUAILE, B. Client management and knowledge outcomes of diabetes education program. Canadian Journal of Diabetes Care, Toronto, v. 21, n. 3, p. 14-8, 1997.

MILLER, J. F. Categories of self care needs of ambulatory patients with diabetes. Journal Advanced Nursing, Oxford, v. 7, n. 1, p. 25-31, 1982.

MONTENEGRO JÚNIOR, R. M. Insulinoterapia no diabetes do tipo 2. In:

BANDEIRA, F. et al. Endocrinologia - diagnóstico \& tratamento. 2. ed. São Paulo: Medsi, 2003. p. 824-40.

MONTENEGRO JÚNIOR, R. M. et al. Assistência multidisciplinar e o manejo efetivo do Diabetes Mellitus: desafios atuais. Revista Brasileira em Promoção da Saúde, Fortaleza, v. 17, n. 4, p. 200-5, 2004.

MULCAHY, K. et al. National diabetes education outcomes system: application to practice. The Diabetes Educator, Chicago, v. 26, n. 6, p. 957-64, 2000.

NAZIMEK-SIEWNIAK, B.; MOCZULSKI, D.; GRZESZCZAK, W. Risk of macrovascular and microvascular complications in type 2 diabetes results of longitudinal study design. Journal of Diabetes Complications, Philadelphia, v. 16 , p. 271-6, 2000.

NEVES, E. P. Reflexões acerca dos conceitos autocuidado e competência/poder para o autocuidado. Revista da Escola de Enfermagem USP, São Paulo, v. 21, n. 3, p. 235-41, dez. 1987.

NORRIS, S. L. et al. Self-management education for adults with type 2 diabetes: a meta-analysis of the effect on glycemic control. Diabetes Care, Alexandria, v. 25, p. 1159-71, 2002.

NORRIS, S.L.; ENGELGAU, M.M.; NARAYAN, K.M.V. Effectiveness of selfmanagement training in type 2 diabetes: a systematic review of randomized controlled trials (Review). Diabetes Care, Alexandria, v. 24, p. 561-87, 2001.

NUNES, A. M. P. Desenvolvimento de um instrumento para a identificação da competência do diabético para o auto-cuidado. 1982. 143 f. Dissertação (Mestrado em Ciências da Enfermagem) - Universidade Federal de Santa Catarina, Florianópolis, 1982.

OLIVEIRA, J. E. P.; MILECH, A. Diabetes mellitus: clínica, diagnóstico, tratamento multidisciplinar. São Paulo: Atheneu, 2004. 362 p. 
OREM, D. E. Nursing: concepts of practice. 5th ed. St. Louis: Mosby Year Book, 1995. $478 \mathrm{p}$.

ORGANIZAÇÃO MUNDIAL DE SAÚDE (OMS). Cuidados inovadores para condições crônicas: componentes estruturais de ação: relatório mundial. Brasília, DF, 2003. 105 p.

ORGANIZAÇÃO PAN-AMERICANA DA SAÚDE (OPAS). Doenças crônicodegenerativas e obesidade: estratégia mundial sobre alimentação saudável, atividade física e saúde. Brasília, DF: OPAS, 2003. 60 p.

OSEI, K.; SCHUSTER, D. P. Metabolic characteristics of African descendants: a comparative study of African-Americans and Guanaian immigrants using minimal model analysis. Diabetologia, Berlin, v. 38, p. 1103-9, 1995.

OTERO, L. M.; ZANETTI, M. L.; OGRIZIO, M. D. Conhecimento do paciente diabético acerca de sua doença, antes e depois da implementação de um programa de educação em diabetes. Revista Latino-Americana de Enfermagem, Ribeirão Preto, v. 16, n. 2, p. 231-37, mar./abr. 2008

OTERO, L. M. Implementação e avaliação de atendimento ao paciente diabético utilizando o protocolo Staged Diabetes Management. 2005. 169 f. Tese (Doutorado) - Escola de Enfermagem de Ribeirão Preto, Universidade de São Paulo, Ribeirão Preto, 2005.

PACE, A. E. et al. O conhecimento sobre diabetes mellitus no processo de autocuidado. Revista Latino-Americana de Enfermagem, Ribeirão Preto, $v$. 14, n. 5, p. 312-9, set.-out. 2006.

PADILLA, G.; ARÁUZ, A. G.; ROSELLÓ, M. Metodología para evaluar la adherencia a la dieta en diabetes mellitus no insulino dependiente. Revista Costarricense de Ciencias Médicas, San Jose, v. 18, n. 4, p. 15-28, 1997.

PAIVA, D. C. P.; BERSUSA, A. A. S.; ESCUDER, M. M. L. Avaliação da assistência ao paciente com diabetes e/ou hipertensão pelo Programa Saúde da Família do Município de Francisco Morato. Cadernos de Saúde Pública, Rio de Janeiro, v. 22, p. 377-85, 2006.

PAIVA, M. M. S. et al. Avaliação das ações educativas em enfermagem para diabéticos, uma experiência de integração docente-assistencial no Hospital Universitário - Universidade Federal do Ceará - UFC, Fortaleza-CE. Revista Brasileira de Enfermagem, Brasília, DF, v. 39, n. 2/3, p. 55-65, abr./set. 1986. 
PAULA, E. S.; NASCIMENTO, L. C.; ROCHA, S. M. M. Religião e espiritualidade: experiência de famílias de crianças com Insuficiência Renal Crônica. Revista Brasileira de Enfermagem, Brasília, DF, v. 62, n. 1, p. 100-6, jan.-fev. 2009.

PEDUZZI, M. Equipe multiprofissional de saúde: conceito e tipologia. Revista de Saúde Pública, São Paulo, v. 35, n. 1, p. 103-9, 2001.

PEDUZZI, M. Mudanças tecnológicas e seu impacto no processo de trabalho em saúde. Trabalho, Educação e Saúde, Rio de Janeiro, v. 1, n. 1, p. 75-91, 2002.

PELCZYNSKI, L; REILLY, A. Helping your diabetic patients help themselves. A plan for impatient education. Nursing, London, v. 11, n. 5, p. 76-83, 1981.

PÉRES, D. S.; FRANCO, L. J.; SANTOS, M. A. Comportamento alimentar em mulheres portadoras de diabetes tipo 2. Revista de Saúde Pública, v. 40, n. 2, p. 310-7, 2006.

PERES, D. S. et al. Dificuldades dos pacientes diabéticos para o controle da doença: sentimentos e comportamentos. Revista. Latino-Americana de Enfermagem, Ribeirão Preto, v. 15, n. 6, dez. 2007.

PÉRES, D. S.; FRANCO, L. J.; SANTOS, M. A. Feelings of women after the diagnosis of type 2 diabetes. Revista Latino-Americana de Enfermagem, Ribeirão Preto, v. 16, n. 1, p. 101-8, 2008.

PETERS, A. et al. Competência do portador de diabetes mellitus para o autocuidado. Nursing, São Paulo, v. 72, n. 7, p. 15-24, mai. 2004.

PEYROT, M. et al. Psychosocial problems and barriers to improved diabetes management: results of the Cross-National Diabetes Attitudes, Wishes and Needs (DAWN) Study. Diabetic Medicine, Chichester, v. 22, p. 1379-85, 2005.

POLIT, D. F.; BECK, C. T. Nursing research: methods, appraisal and utilization. 6. ed. Philadelphia: Lippincott Williams \& Wilkins. 2006. 554 p.

PONTE, C. M. M. et al. Projeto Sala de Espera: uma proposta para a Educação em Diabetes. Revista Brasileira em Promoção da Saúde, Fortaleza, v. 16, n. 4, p. 197-202, 2006. 
RABELO, S. L.; PADILHA, M. I. C. S. Compreensão dos déficits de autocuidado a partir da prática assistencial. Texto e Contexto Enfermagem, Florianópolis, v. 9, n. 2, p. 312-23, maio/ago. 2000.

RAMOS, L. R. et al. Envelhecimento populacional: uma realidade brasileira.

Revista de Saúde Pública, São Paulo, v. 21, p. 211-24, 1987.

RAMPAZZO, L. Metodologia científica: para alunos dos cursos de graduação e pós-graduação. São Paulo: Edições Loyola, 2002.

RESNICK, H. E. et al. Differential effects of BMI on diabetes risk among black and white Americans. Diabetes Care, Alexandria, v. 21, p. 1828-35, 1998.

RIBAS, C. R. P. et al. Expectativas de mulheres com diabetes em relação a um programa de educação em saúde. Revista de Enfermagem UERJ, Rio de Janeiro, v. 17, n. 2, p. 203-8, abr.-jun, 2009.

RIBAS, C. R. P. Representações sociais dos alimentos para pessoas com diabetes mellitus tipo 2. 2009. 131 f. Dissertação (Mestrado) - Escola de Enfermagem de Ribeirão Preto, Universidade de São Paulo, Ribeirão Preto, 2009.

RICKHEIM, P. R. et al. Assessment of group versus individual diabetes education. Diabetes Care, Alexandria, v. 25, p. 269-74, 2002.

RICO, V. B.; ARRIAGA, M. E. Prevalencia de DM y eficacia diagnóstica del programa de detección oportuna en una unidad de medicina familiar. Revista Médica del IMSS, México, v. 33, n. 5, p. 76-81, 1995.

ROCHA, M. P. S. Assistência de Enfermagem em uma unidade de cuidados terciários ao diabético. Revista Brasileira de Enfermagem, Brasília, DF, v. 37, n. 3/4, p. 182-7, jul./dez. 1984.

RODRIGUES, F. F. L. et al. Conhecimento e atitudes: componentes para a educação em diabetes. Revista Latino-Americana de Enfermagem, Ribeirão Preto, v. 17, n. 4, ago. 2009.

ROMERO-BAQUEDANO, I. Fatores relacionados ao autocuidado de pessoas com diabetes tipo 2 no Serviço de Urgência do Hospital Regional Mérida, Yucatán, México. 2008. 139 f. Tese (Doutorado) - Escola de Enfermagem de Ribeirão Preto, Universidade de São Paulo, Ribeirão Preto, 2008. 
ROSSI, V. E. C. Suporte social familiar no cuidado de pessoas adultas com diabetes mellitus tipo 2. 2005. $132 \mathrm{f}$. Tese (Doutorado) - Escola de Enfermagem de Ribeirão Preto, Universidade de São Paulo, Ribeirão Preto, 2005.

ROTHMAN, A. Toward a theory based analysis of behavioral maintenance.

Journal of Health Psychology, London, v. 19, p. 64-9, 2000.

RUBIN, R. R.; PEYROT, M.; SAUDEK, C. D. Effect of diabetes education on selfcare, metabolic control and emotional well-being. Diabetes Care, Alexandria, v. 12, p. 673-9, 1989.

RUIZ, V. R.; LIMA, A. R.; MACHADO, A. L. Educação em saúde para portadores de doença mental: relato de experiência. Revista da Escola de Enfermagem da USP, São Paulo, v. 38, n. 2, jun. 2004.

SANTOS, E. C. B. Direitos dos usuários com Diabetes Mellitus: do conhecimento à utilização dos benefícios na saúde. 2009. 145 f. Dissertação (Mestrado) - Escola de Enfermagem de Ribeirão Preto, Universidade de São Paulo, Ribeirão Preto, 2009.

SANTOS, I. C. R. V. Atenção à saúde do portador de pé diabético: prevalência de amputações e assistência preventiva na Rede Básica de Saúde. 2008. 223 f. Tese (Doutorado em Saúde Pública) - Fundação Oswaldo Cruz, Recife, 2008.

SANTOS, M. A. et al. Programa de Educação em Saúde: expectativas e benefícios percebidos por pacientes diabéticos. Revista Enfermagem UERJ, Rio de Janeiro, v. 17, n. 1, p. 57-63, jan/mar. 2009.

SANTOS, E. C. B. et al. Os cuidados sob a ótica do paciente diabético e de seu principal cuidador. Revista Latino-Americana de Enfermagem. Ribeirão Preto, v. 13, n. 3, p. 397-406, mai./jun. 2005.

SANTOS, M.A. et al. Programa de educação em saúde: expectativas e benefícios percebidos por pacientes diabéticos. Revista Enfermagem UERJ. Rio de Janeiro, v. 17, n. 1, p. 57-63, jan./mar. 2009.

SCHALL, R. Estimation in generalized linear models with random effects.

Biometrika, London, v. 78, n. 4, p. 719-27, 1991.

SCHECTMAN, J. M.; NADKARNI, M. M.; VOSS, J. D. The association between diabetes metabolic control and drug adherence in an indigent population.

Diabetes Care, Alexandria, v. 25, n. 6, p. 1015-21, Jun. 2002. 
SCHRAMM, J. M. A.; OLIVEIRA, A. F.; LEITE, I. C. Epidemiological transition and the study of burden of disease in Brazil. Ciência \& Saúde Coletiva, Rio de Janeiro, v. 9, n. 4, p. 897-908, out./dez. 2004.

SCHRIER, R. W. et al. Effects of aggressive blood pressure control in normotensive type 2 diabetic patients on albuminuria, retinopathy and strokes.

Kidney International, New York, v. 61, p. 1086-97, 2002.

SILVA, A. S. B. Avaliação da atenção em diabetes mellitus em uma unidade básica distrital de saúde de Ribeirão Preto SP. 2009. 130 f. Tese (Doutorado em Enfermagem) - Escola de Enfermagem de Ribeirão Preto, Universidade de São Paulo, Ribeirão Preto, 2009.

SILVA, D. G. V.; SOUZA, S. S.; MEIRELLES, B. O itinerário terapêutico de pessoas com problemas respiratórios crônicos. Texto e Contexto

Enfermagem, Florianópolis, v. 13, n. 1, p. 50-6, jan./mar. 2004.

SOCIEDADE BRASILEIRA DE DIABETES (SBD). Tratamento e acompanhamento do diabetes mellitus: diretrizes da Sociedade Brasileira de Diabetes. São Paulo: SBD, 2009.

SOCIEDADE BRASILEIRA DE HIPERTENSÃO (SBH). V Diretrizes Brasileiras de Hipertensão Arterial, 2006. Disponível em: <http://www.sbh.org.br>. Acesso em: 14 jul. 2009.

STEED, L.; COOKE, D.; NEWMAN, S. A systematic review of psychosocial outcomes following education, self-management and psychological interventions in diabetes mellitus. Patient Education and Counseling, Ireland, v. 51, p. 515, 2003.

STEINER, G. ; LAWRENCE, P. A. Educando o paciente diabético. São Paulo: Andrei, 1992. 323 p.

SWIFT, P. G. F. Diabetes education. ISPAD Clinical Practice Consensus Guidelines 2006-2007. Pediatric Diabetes, Copenhagen, v. 8, p. 103-9, 2007.

TEIXEIRA, C. F. Transição epidemiológica, modelo de atenção à saúde e previdência social no Brasil: problematizando tendências e opções políticas.

Ciência e Saúde Coletiva, Rio de Janeiro, v. 9, n. 4, p. 841-50, abr. 2004.

TEIXEIRA, E. R. Representações culturais de clientes diabéticos sobre saúde, doença e autocuidado. Revista de Enfermagem UERJ, Rio de Janeiro, v. 4, n. 2, p. 163-9, 1996. 
THE EXPERT COMMITTEE ON THE DIAGNOSIS AND CLASSIFICATION OF DIABETES MELLITUS. Report of the Expert Committee on the Diagnosis and Classification of Diabetes Mellitus. Diabetes Care, Alexandria, v. 20, p. 118397, 1997.

THOOLEN, B. J. et al. Beyond good intentions: the development and evaluation of a proactive self-management course for patients recently diagnosed with type 2 diabetes. Health Education Research, v. 23, n. 1, p. 53-61, Feb. 2008.

TORQUATO, M. T. C. G. et al. Prevalence of diabetes mellitus and impaired glucose tolerance in urban population aged 30-69 years in Ribeirão Preto (São Paulo), Brazil. São Paulo Medical Journal, São Paulo, v. 121, n. 6, p. 224-30, 2003.

TORRES, H. C. Avaliação de um programa educativo para controle do diabetes mellitus tipo 2 em Belo Horizonte, MG. 2004. 126 f. Tese (Doutorado) - Escola Nacional de Saúde Pública Sérgio Arrouca, Fundação Oswaldo Cruz, Rio de Janeiro, 2004.

TORRES, H. C.; HORTALE, V. A.; SCHALL, V. A experiência de jogos em grupos operativos na educação em saúde para diabéticos. Cadernos de Saúde Pública, Rio de Janeiro, v. 19, n. 4, p. 1039-47, jul./ago. 2007.

TOSCANO, C. M. As campanhas nacionais para detecção das doenças crônicas não-transmissíveis: diabetes e hipertensão arterial. Ciência \& Saúde Coletiva, Rio de Janeiro, v. 9, n. 4, p. 885-895, dez. 2004.

TRENTO M. et al. Lifestyle intervention by group care prevents deterioration of type II diabetes: a 4-years randomized controlled clinical trial. Diabetologia, Berlim, v. 45, n. 9, p. 1231-9, 2002.

UNITED KINGDOM PROSPECTIVE DIABETES STUDY GROUP (UKPDS). Tight blood pressure control and risk of macrovascular and microvascular complications in type 2 diabetes: UKPDS 38. British Medical Journal, London, v. 317, n. 7160, p. 703-12, Sep. 1998.

VAN DAM, R. M. et al. Dietary patterns and risk for type 2 diabetes mellitus in US men. Annals of Internal Medicine, Philadelphia, v. 136, p. 201, 2002.

WINKLEBY, M. et al. Ethnic and socioeconomic differences in cardiovascular disease risk factors. JAMA, Chicago, v. 280, p. 356-62, 1998. 
WORLD HEALTH ORGANIZATION (WHO). The World Health Report, 2002: reducing risks, promoting healthy life. Geneva: WHO, 2002. (NLM Classification: WA 540.1).

XAVIER, A. T.; BITTAR, D. B.; ATAÍDE, M. B. C. Crenças no autocuidado em diabetes - implicações para a prática. Texto Contexto Enfermagem, Florianópolis, v. 18, n. 1, p. 124-30, jan.-mar. 2009.

ZAGO, M. A. A pesquisa clínica no Brasil. Ciência \& Saúde Coletiva, Rio de Janeiro, v. 9, n. 2, p. 363-74, abr.-jun. 2004.

ZANETTI, M.L.; MENDES, I.A.C. Tendência do locus de controle de pessoas diabéticas. Revista da Escola de Enfermagem da USP, São Paulo, v. 27, n. 2, p. 246-62, ago. 1993.

ZANETTI, M. L. et al. O cuidado à pessoa diabética e as repercussões na família. Revista Brasileira de Enfermagem, Brasília, DF, v. 61, n. 2, p. 186-92, mar.abr. 2008.

ZANETTI, M. L. et al. Progress of the patients with diabetes mellitus who were managed with the staged diabetes management framework. Acta Paulista de Enfermagem, São Paulo, v. 20, n. 3, p. 338-44, jul./set. 2007.

ZARATE, T. A. Algunas consideraciones históricas del diagnóstico de la diabetes mellitus. Academia Nacional de Medicina. Gaceta Médica de México, México, v. 131, n. 2, p. 191-5, mar./abr. 1995. 
"Se lembrar de celebrar muita mais..."

Fernanda Anitelli 


\section{APÊNDICE A - Questionário}

UNIVERSIDADE DE SÃO PAULO
Escola de Enfermagem de Ribeirão Preto
Departamento de Enfermagem Geral e Especializada
Programa de Pós-Graduação em Enfermagem Fundamental

Sexo [ ] 1 feminino [ ] 2 masculino

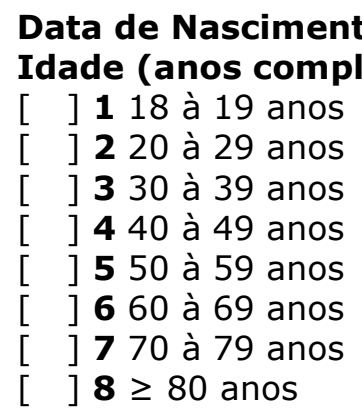

\section{Cor/Raça}

[ ] 1 branca

[ ] 2 preta

[ ] 3 amarela/oriental

[ ] 4 parda/mulato

[ ] 5 indígena

\section{Estado civil}

[ ] 1 solteiro

[ ] 2 casado

[ ] 3 viúvo

[ ] 4 separado/divorciado

[ ] 5 união consensual

\section{Procedência}

[ ] 1 Ribeirão Preto - São Paulo

[ ] 2 outras cidades do estado de São Paulo

\section{Nível de escolaridade}

[ ] 1 pós-graduação

[ ] 2 terceiro grau completo

[ ] 3 terceiro grau incompleto

[ ] 4 segundo grau completo

[ ] 5 segundo grau incompleto

[ ] 6 primeiro grau completo

[ ] 7 primeiro grau incompleto

[ ] 8 sem escolaridade - alfabetizado

[ ] 9 sem escolaridade - analfabeto

\section{Ocupação}

[ ] 1 funcionário público

[ ] 2 trabalhador com carteira assinada

[ ] 3 autônomo

[ ] 4 estudante

[ ] 5 do lar

[ ] 6 aposentado

[ ] 7 desempregado

[ ] 8 voluntário

[ ] 9 outra

\section{Renda familiar}

[ ] $\mathbf{1}<1$ salário mínimo

[ ] 21 à 2 salários mínimos

[ ] 33 à 4 salários mínimos

[ ] 45 à 6 salários mínimos

[ ] 57 à 8 salários mínimos

[ ] $6>8$ salários mínimos

\section{Religião}

[ ] 1 católica

[ ] 2 evangélica

[ ] 3 espírita

[ ] 4 outra

[ ] 5 sem religião domicílio

$\mathbf{1} \leq 2$ pessoas

a 5 pessoas

] 36 à 8 pessoas

$4 \geq 9$ pessoas 


\section{Tipo de DM}

[ ] 1 diabetes mellitus tipo 1 (DM1)

[ ] 2 diabetes mellitus tipo 2 (DM2)

\section{Tempo do diagnóstico (anos) de DM}

[ ] $\mathbf{1} \leq 5$ anos

[ ] 26 à 10 anos

[ ] 311 à 20 anos

[ ] $4 \geq 30$ anos

\section{Hábito de fumar}

[ ] 1 não

[ ] 2 sim,

[ ] 3 parou de fumar, fumava

cigarros/dia. Há quanto tempo? (anos)

\section{Ingestão de bebida alcoólica}

[ ] 1 não

[ ] 2 sim, frequência (dias/semana):

\section{Acompanhamento médico}

[ ] 1 rede pública

[ ] 2 particular

[ ] 3 plano de saúde

\section{Dieta}

[ ] 1 não

[ ] $2 \mathrm{sim}$ cigarros/dia. Quanto tempo fumou? (anos)

\section{Tratamento medicamentoso (DM)*}

* receita médica consultada

[ ] 1 não utiliza

] 2 somente antidiabético oral (biguanidas)

[ ] 3 somente antidiabético oral (sulfoniluréias)

[ ] 4 somente antidiabético oral (biguanidas + sulfoniluréias)

[ ] 5 somente antidiabético oral (biguanidas + sulfoniluréias + arcabose)

[ ] 6 antidiabético oral (biguanidas) + insulina (NPH)

[ ] 7 antidiabético oral (biguanidas) + insulina ( $\mathrm{NPH}+\mathrm{R})$

[ 8 somente insulina (NPH)

[ ] 9 somente insulina $(\mathrm{NPH}+\mathrm{R})$

[ ] 10 outro

\section{Complicações crônicas decorrentes do DM}
[ ] 1 olhos
[ ] 2 rins
[ ] 3 nervos
[ ] 4 pés
[ ] $\mathbf{5}$ coração

\section{Co-morbidades, além do DM}

$\begin{array}{llll}\text { [ ] } \mathbf{1} \text { pressão alta } & \text { [ ] } \mathbf{2} \text { obesidade } & \text { [ ] } \mathbf{3} \text { colesterol alto [ ] } 4 \text { doença renal } \\ \text { [ ] } 5 \text { cardiopatia } & \text { [ ] } \mathbf{6} \text { circulação } & \text { [ ] } \mathbf{7} \text { outras }\end{array}$




\section{APÊNDICE B - Termo de Consentimento Livre e Esclarecido}

\section{TERMO DE CONSENTIMENTO LIVRE E ESCLARECIDO}

Eu, Camila Aparecida Pinheiro Landim, enfermeira e pesquisadora, estou desenvolvendo uma pesquisa chamada: "A competência de pessoas com diabetes mellitus para o autocuidado em um programa educativo multidisciplinar", com pacientes adultos com diabetes mellitus cadastrados no Centro Educativo de Enfermagem para Adultos e Idosos, de janeiro a março de 2009, para conhecer como a pessoa com diabetes se cuida, antes e após a participação nesse Centro Educativo.

O senhor (a) está sendo convidado (a) a participar deste estudo, que será realizado uma entrevista para responder algumas perguntas. Nessa conversa, o senhor (a) estará falando sobre com se cuida, as dificuldades que tem para se cuidar e o que sabe sobre o diabetes. Isto acontecerá em dois momentos, o primeiro no início da sua participação no centro educativo, e o outro no final da sua participação. Essa entrevista será realizada às terças-feiras, das 14 às 17 horas, no dia em que é realizado o programa educativo semanal. Ao final da entrevista, será aberto um espaço para esclarecimentos de suas possíveis dúvidas.

Sua participação é voluntária, isto significará que você ou o seu representante legal estão livres a qualquer momento de recusar a participar dessa pesquisa, bem como de retirar seu consentimento em qualquer momento, e poderá continuar sendo atendido no centro sem nenhum problema. O seu nome será mantido em segredo. Não terá nenhum gasto com esta pesquisa, bem como não causará nenhum tipo de risco e dano.

Se você tiver alguma dúvida, poderá me perguntar ou entrar em contato comigo através do endereço e/ou telefone abaixo. A pesquisadora ficará com uma cópia deste termo assinada e entregará a você uma segunda via também assinada.

Declaro que, após convenientemente esclarecido (a) pela pesquisadora e ter entendido o que me foi explicado, concordo em participar do presente estudo.

Ribeirão Preto, de de 2009.

Assinatura da pessoa / representante legal

Assinatura da pesquisadora

Pesquisadora: Camila Aparecida Pinheiro Landim

Endereço: Avenida Bandeirantes, no. 3900 - Campus Universitário. Ribeirão Preto-SP. Telefones: (16) 36024796 / (16) 99647280 - E-mail: camilaapapila@usp.br 
"Lembra a que valeu a pena Fai nassa cena naa ter pressa pra passar"

Fernanda Anitelli 


\section{ANEXO A - ECDAC}

\section{ESCALA PARA IDENTIFICAÇÃO DA COMPETÊNCIA DO DIABÉTICO PARA O AUTOCUIDADO (ECDAC)}

1-Em relação a visão:

4 ( ) identifica todos os pontos dos quadros que são apresentados a uma distância de um (1) metro

3 ( ) identifica todos os pontos dos quadros com exceção do $n^{\circ} .6$ a uma distância de um (1) metro

2 ( ) identifica apenas os pontos dos quadros 1, 2, 5 e 7 a uma distância de um (1) metro

1 ( ) não identifica os pontos dos quadros a uma distância de um (1) metro

2-Em relação a percepção das cores utilizando-se a prova de Holgreen:

4 ( ) inteiramente sensível as cores

3 ( ) tem dificuldade na percepção

2 ( ) insensível ao verde e vermelho ou apenas a uma das cores

1 ( ) não consegue identificar as cores

3-Em relação a capacidade de avaliar temperatura das coisas que toca com as mãos:

4 ( ) identifica os diferentes graus de temperatura frio, morno e quente com as duas mãos

3 ( ) identifica os diferentes graus de temperatura frio, morno e quente com apenas uma mão

2 ( ) não identifica os graus de temperatura mais elevada com quaisque das mãos

1 ( ) não identifica os graus de temperatura das coisas que toca com as mãos

4-Em relação a capacidade para sentir objetos pontiagudos que tocam a planta dos pés:

4 ( ) tem sensibilidade nos pés para sentir o toque de objetos pontiagudos de vários calibres

3 ( ) tem sensibilidade para sentir o toque de objetos pontiagudos de vários calibres apenas em um pe

2 ( ) não tem sensibilidade para sentir objetos menos agudos em quaisquer dos pés

1 ( ) não tem sensibilidade para sentir o toque de objetos pontiagudos de vários calibres nos dois pés

5-Em relação a destreza manual observada através do manuseio de um conta-gotas:

4 ( ) enche o conta-gotas com água e goteja gota a gota

3 ( ) enche o conta-gotas com água e não goteja gota a gota

2 ( ) enche o conta-gotas com água e o esvazia de uma vez

1 ( ) não consegue encher o conta-gotas

6-Em relação a capacidade de ler:

4 ( ) lê o texto fluentemente

3 ( ) vacila na leitura do texto

2 ( ) lê o texto soletrando as palavras

1 ( ) não lê o texto

7-Em relação ao conhecimento do diabetes:

4 ( ) responde corretamente aos três itens da questão que the foi formulada

3 ( ) responde corretamente a dois itens da questão que Ihe foi formulada 2 ( ) responde corretamente a um item da questão que lhe foi formulada

1 ( ) não sabe sobre isto

8-Em relação aos métodos de exame que conhece para identificar anormalidades e controlar o diabetes:

4 ( ) identifica os três métodos de exame mais comuns

3 ( ) identifica apenas dois dos métodos de exame mais comuns

2 ( ) identifica apenas um dos métodos de exame mais comuns

1 ( ) não identifica nenhum método de exame

9-Em relação aos métodos de tratamento que conhece para controlar o diabetes:

4 ( ) identifica os três métodos de tratamento mais comuns

3 ( ) identifica apenas dois dos métodos de tratamento mais comuns

2 ( ) identifica apenas um dos métodos de tratamentos mais comuns

1 ( ) não sabe que métodos de tratamento controlam o diabetes

10-Em relação aos sinais que o diabético pode apresentar se tiver muito pouco açúcar no corpo:

4 ( ) identifica até três dos principais sinais

3 ( ) identifica dois dos principais sinais

2 ( ) identifica apenas um dos principias sinais

1 ( ) não identifica os principais sinais
11-Em relação as principais situações que podem levar o diabético a ter uma diminuição de açúcar no corpo:

4 ( ) cita até três das situações principais

3 ( ) cita duas das situações principais

2 ( ) cita uma das situações principais

1 ( ) não sabe a respeito

12-Em relação aquilo que o diabético deve fazer quando tiver sinais de hipoglicemia:

4 ( ) cita as três principais ações

3 ( ) cita duas das três principais ações

2 ( ) cita uma das principais ações

1 ( ) não sabe o que fazer

13-Em relação as principais situações que podem levar o diabético a ter um aumento de açúcar no corpo:

4 ( ) identifica até três das situações principais

3 ( ) identifica duas das situações principais

2 ( ) identifica até uma das situações principais

1 ( ) não sabe a respeito

14-Em relação aos sinais que o diabético pode apresentar se tiver muito açúcar no corpo:

4 ( ) identifica até três dos principais sinais

3 ( ) identifica dois dos principais sinais

2 ( ) Identifica um dos principais sinais

1 ( ) não identifica os principais sinais

15-Em relação aquilo que o diabético deve fazer quando apresentar sinais de hiperglicemia:

4 ( ) cita até três das principais ações

3 ( ) cita duas das principais ações

2 ( ) cita uma das principais ações

1 ( ) não sabe o que fazer

16-Em relação a capacidade de atenção e memória:

4 ( ) repete os números em ordem sem erro

3 ( ) repete os números em ordem com apenas um erro

2 ( ) repete os números em ordem com mais de um erro

1 ( ) não repete os números

Em relação as capacidades motivacionais e emocionais:

\begin{tabular}{|l|c|c|c|c|}
\hline & Sempre & $\begin{array}{c}\text { Muitas } \\
\text { Vezes }\end{array}$ & $\begin{array}{c}\text { Poucas } \\
\text { Vezes }\end{array}$ & Nunca \\
\hline 17-Eu gosto de mim & 4 & 3 & 2 & 1 \\
\hline 18-Eu penso primeiro em mim & 4 & 3 & 2 & 1 \\
\hline 19-Eu me considero um peso & 1 & 2 & 3 & 4 \\
\hline $\begin{array}{l}\text { 20-Eu me considero incapaz de } \\
\text { ajudar outras pessoas na } \\
\text { realização de alguma coisa }\end{array}$ & 1 & 2 & 3 & 4 \\
\hline $\begin{array}{l}\text { 21-Eu faço as coisas que são } \\
\text { necessárias para me manter } \\
\text { saudável }\end{array}$ & 4 & 3 & 2 & 1 \\
\hline $\begin{array}{l}\text { 22-Eu tenho vontade de fazer as } \\
\text { coisas que ajudam a controlar o } \\
\text { diabetes }\end{array}$ & 4 & 3 & 2 & 1 \\
\hline $\begin{array}{l}\text { 23-Eu me interesso em aprender } \\
\text { sobre meu diabetes }\end{array}$ & 4 & 3 & 2 & 1 \\
\hline $\begin{array}{l}\text { 24-Eu me preocupo em comer } \\
\text { apenas os alimentos que me } \\
\text { mantém saudável }\end{array}$ & 4 & 3 & 2 & 1 \\
\hline $\begin{array}{l}\text { 25-Eu preciso da ajuda de outros } \\
\text { para fazer minha insulina e/ou } \\
\text { controlar minha dieta }\end{array}$ & 1 & 2 & 3 & 4 \\
\hline $\begin{array}{l}\text { 26-Eu considero me as } \\
\text { recomendações que me são } \\
\text { dadas para conviver com meu } \\
\text { diabetes }\end{array}$ & 4 & 3 & 2 & 1 \\
\hline $\begin{array}{l}\text { 27-Eu aceito minha situação de } \\
\text { diabético }\end{array}$ & 4 & 3 & 2 & 1 \\
\hline
\end{tabular}




\section{ANEXO B - Guia para Administração da ECDAC}

As capacidades físicas a serem avaliadas incluem visão, tato, destreza e habilidade manual; para avaliar estas capacidades foram formulados uma série de itens cuja operacionalização para posterior avaliação, relataremos a seguir:

1 - Coloque a uma distância de um (1) metro do cliente o quadro optométrico. Peça para o cliente relatar a quantidade de pontos existentes em cada quadro. Assinale no item correspondente a competência do cliente.

2 - Utilizaremos a prova de Holgreen para este item. A prova de Holgreen consiste em apresentar um grande sortimento de meadas de lã coloridas agrupadas para que se avalie a percepção do indivíduo para cores. Os grupos de cores consistem de:

a) cores de prova (verde claro, rosa leve e vermelho vivo);

b) cores assemelháveis (tonalidade mais claras e escuras das cores de prova);

c) cores de confusão (amarelas, castanhas, cinzentas, bege, violeta claro e azul claro).

Dá-se ao cliente, num local bem iluminado (luz diurna), uma amostra de verde claro e pede-se que ele procure cores assemelháveis. Se escolher corretamente, é normal e inteiramente sensível às cores.

Se escolher além das cores assemelháveis também cores de confusão, tem dificuldades na percepção.

Se para o feixe rosa juntar além das cores semelhantes também o azul e o violeta, será cego para o vermelho, se escolher castanho e verde, será cego para o verde.

Se não tiver condições para juntar nenhuma das cores, será cego para cores.

Assinale no item correspondente a competência do cliente.

3 - Dê na mão do cliente três tubos de ensaio contendo água geladas, morna e quente. Peça para ele avaliar o grau de temperatura dizendo se está quente, morna ou gelada, segundo a sua percepção. Deve ser observado intervalo de 30 segundos entre cada avaliação. Faça primeiro com uma mão depois com a outra dando os tubos em ordem diferente.

4 - Toque os dois pés descalços do cliente com objetos pontiagudos de diversos calibres (estilete; um lápis borracha; uma ponta de caneta). Procure fazer com que o cliente não veja o que você está fazendo, pedindo para que ele feche os olhos, ou colocando-se em posição que dificulte a visualização do cliente.

Indague do cliente sobre sua sensibilidade durante o teste. Assinale no item correspondente a competência do cliente.

5 - Dê ao cliente um conta-gotas, um recipiente com água e outro recipiente vazio. Demonstre ao cliente o que deve fazer, isto é, encher uma vez o conta- 
gotas e gotejar no recipiente vazio. Observe seu desempenho. Assinale no item correspondente a competência do cliente.

As capacidades mentais a serem avaliadas incluem leitura, atenção, memória, discriminação e classificação de acontecimentos dentro de certas situações; julgamento de certas situações e conceptualização de um sistema de ações para atuar em certas situações.

Para avaliar estas capacidades, siga as instruções que seguem referentes a cada item.

6 - Dê ao cliente um trecho para leitura em voz alta. Assinale no item correspondente a competência do cliente.

7 - Dê ao cliente: (a) o que é diabete? (b) porque acontece? (c) que complicações podem ocorrer por causa da diabetes?

As respostas devem abranger: (a) é excesso de açúcar no sangue; (b) por causa de uma deficiência na produção de insulina; (c) pode acontecer coma por muito pouco açúcar, perda de tato, visão e aparecimento de ferida nos pés.

Faça uma pergunta de cada vez e espere a resposta do cliente.

Assinale em seguida no item correspondente a resposta do cliente.

8 - Pergunte ao cliente: Quais os métodos de exame que você conhece para identificar e controlar a diabete?

A resposta deve abranger: (a) exame de sangue; (b) teste de urina para açúcar; (c) teste de urina para acetona.

Assinale no item correspondente a resposta do cliente.

9 - Pergunte ao cliente: Quais os tratamentos que você conhece para controlar a diabete?

A resposta deve abranger: (a) diabete ou regulação de alimentos; (b) insulina; (c) comprimidos para diabéticos.

Assinale no item correspondente a resposta do cliente.

10 - Pergunte ao cliente: Quais os principais sinais que o diabético apresenta se tem muito pouco açúcar no corpo?

A resposta deve abranger o seguinte: (a) nervosismo; (b) fraqueza; (c) transpiração; (d) fome; (e) visão turva.

Assinale no item correspondente a resposta do cliente.

11 - O que pode levar o diabético a ter uma grande diminuição de açúcar no corpo?

A resposta deve abranger o seguinte: (a) erro para mais na dose de insulina e hipoglicemiantes; (b) não ingestão de alimentos; (c) presença de vômitos e diarréia que impedem a absorção da dieta; (d) prática de exercícios pesados.

Assinale no item correspondente a resposta do cliente. 
12 - Pergunte ao cliente: O que o diabético deve fazer quando apresentar fraqueza, transpiração e visão turva?

A resposta deve abranger o seguinte: (a) beber água açucarada ou suco de laranja ou comer doce; (b) permanecer em repouso; (c) suspender a próxima dose de insulina ou hipoglicemiante.

Assinale no item correspondente a resposta do cliente.

13 - Pergunte ao cliente: Quais as situações que podem levar o diabético a ter um aumento de açúcar no corpo?

A resposta deve abranger: (a) erro para menos na administração de insulina e hipoglicemiantes; (b) situações de stress; (c) presença de infecção; (d) não seguimento da dieta.

Assinale no item correspondente a resposta do cliente.

14 - Pergunta ao cliente: Quais os principais sinais que o diabético apresenta se tem muito açúcar no corpo?

A resposta deve abranger: (a) sede e secura na boca; (b) vômitos; (c) pele quente e seca (d) hálito com odor adocicado tipo "maçã passada"; (e) sonolência; (f) câimbras musculares.

Assinale no item correspondente a competência do cliente.

15 - Pergunte ao cliente: O quê o diabético deve fazer imediatamente quando apresentar sonolência, hálito adocicado, secura na boca, câimbras, pele seca e quente?

A resposta deve abranger: (a) testar urina para açúcar e cetona; (b) aplicar insulina conforme resultado do teste de urina; (c) ingerir líquidos sem açúcar; (d) procurar orientação médica.

Assinale no item correspondente a competência do cliente.

16 - Pede-se ao cliente para prestar atenção. Explique ao cliente que vai dizer 7 números e em seguida ele deve repetí-los. Lê-se em voz alta os números $0,3,6$, $9,12,15$ e 18. Solicite que o cliente repita os números na ordem e que foram ditos.

Assinale no item correspondente a competência do cliente.

Para avaliar as capacidades motivacionais e emocionais (itens 17 a 27), siga as instruções que seguem abaixo:

(a) Dê ao cliente quatro cartões, cada um escrito com uma das opções de resposta.

(b) Explique que vai ler uma frase de cada vez e que vai pedir a ele/ela por favor escolha um dos cartões que corresponde a sua resposta e mostre a você, dizendo de voz alta a resposta.

(c) Assinale na opção corretamente a resposta do cliente. 


\section{ANEXO C - Aprovação do Comitê de Ética em Pesquisa}
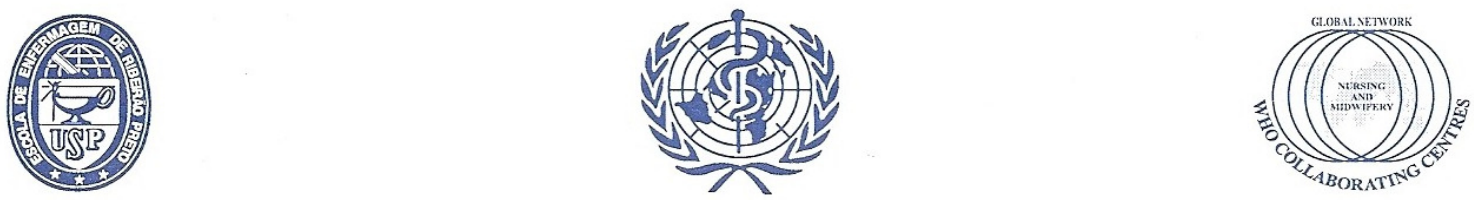

Escola de Enfermagem de Ribeirão Preto - Universidade de São Paulo

Centro Colaborador da Organização Mundial da Saúde para

o Desenvolvimento da Pesquisa em Enfermagem

Avenida Bandcirantes, 3900 - Campus Universitário - Ribeirão Preto - CEP 14040-902 - São Paulo - Brasil

FAX: (55) - 16-3633-3271/ TELEFONE: (55) - 16-3602-3382

\section{COMITÊ DE ÉTICA EM PESQUISA DA EERPIUSP}

Of.CEP-EERP/USP - 136/2008

Ribeirão Preto, 26 de maio de 2008

Prezada Senhora,

Comunicamos que o projeto de pesquisa, abaixo especificado, foi analisado e considerado APROVADO AD REFERENDUM pelo Comitê de Ética em Pesquisa da Escola de Enfermagem de Ribeirão Preto da Universidade de São Paulo, em 26 de maio de 2008.

Protocolo: $\quad n^{0} 0907 / 2008$

Projeto: $\quad$ A COMPETÊNCIA DO DIABÉTICO PARA O AUTOCUIDADO EM UM PROCESSO EDUCATIVO INTERDISCIPLINAR.

Pesquisadores: Carla Regina de Souza Teixeira

Camila Aparecida Pinheiro Landim

Em atendimento à Resolução 196/96, deverá ser encaminhado ao CEP o relatório final da pesquisa e a publicação de seus resultados, para acompanhamento, bem como comunicada qualquer intercorrência ou a sua interrupção.

$$
\begin{gathered}
\text { Atenciosamente, } \\
\text { Prica } \\
\text { Profa Dra Lucila Castanheira Nascimento } \\
\text { Coordenadora do CEP-EERP/USP }
\end{gathered}
$$

IIma. Sra.

Prof ${ }^{a}$ Dra $^{a}$ Carla Regina de Souza Teixeira

Departamento de Enfermagem Geral e Especializada

Escola de Enfermagem de Ribeirão Preto - USP 


\section{Universidade de São Paulo \\ Escola de Enfermagem de Ribeirão Preto \\ Comitê de Ética em Pesquisa}

Protocolo no: $0907 / 2008$

Entrada: 28/03/2008

Pesquisadores: Carla Regina de Souza Teixeira e Camila Aparecida Pinheiro Landim

\section{Parecer}

Título do Projeto: A COMPETÊNCIA DO DIABÉTICO PARA O AUTOCUIDADO EM UM PROCESSO EDUCATIVO INTERDISCIPLINAR

Apreciação Geral: Este parecer trata-se da apreciação da documentação constante às folhas 040 a 048 do processo.

Folha de Rosto: sem alteração e deverá ser assinada pela diretora da Escola de Enfermagem de Ribeirão Preto/USP.

Introdução: sem alteração

Metodologia: apresenta novamente a metodologia com alterações no item coleta de dados, mudando o período, sendo a primeira em março de 2009 e a segunda em junho de 2009.

Aspectos Éticos: Segue a Resolução CNS 196/96

Termo de Consentimento Livre e Esclarecido: O Termo de Consentimento em linguagem acessível comtemplando a Resolução 196/96.

Outros Comentários: Apresenta novo cronograma para desenvolvimento do estudo, coerente com a proposta.

Esclarecimentos Necessários: não se aplica.

Recomendação:

$\bigotimes$ Aprovação

$\square$ Aprovação com recomendação

Aprovação e encaminhamento para apreciação pela CONEP/MS

Conșiderar em PENDÊNCIA até esclarecimentos dos pontos levantados.

Não aprovação

$\square$ Retirado

Aprovado ad reverendum do Comitê de Ética Pesquisa da EERP/USP em $26,05,2008$

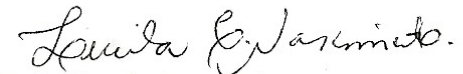

Profa. Dra. Lucila Castanheira Nescimemo Cortienator: Comitê de Etica em Pesquisa ERrp USP 